Supporting Information

\title{
Employing Water as the Hydride Source in Synthesis: A Case Study of Diboron Mediated Alkyne Hydroarylation
}

Santhosh Rao, M. Nibin Joy and Kandikere Ramaiah Prabhu*

Department of Organic Chemistry,

Indian Institute of Science,

Bangalore 560 012,

Karnataka, India

*To whom correspondence should be addressed. E-mail: prabhu@iiisc.ac.in 


\section{Contents:}

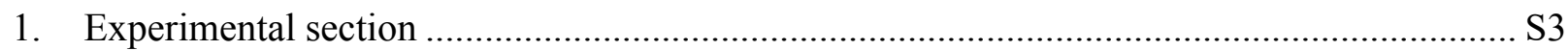

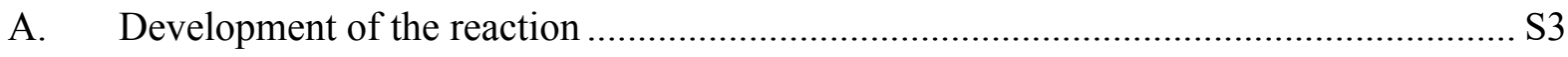

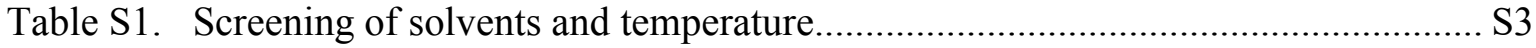

Table S2. Screening of stoichiometric equivalence of water ................................................ 3

Table S3. Screening of stoichiometric equivalence of Boronic acid and $\mathrm{B}_{2} \mathrm{Pin}_{2} \ldots \ldots \ldots \ldots \ldots . . . \mathrm{S} 4$

Table S4. Screening of time and stoichiometric equivalence of catalyst/ligand .................. S4

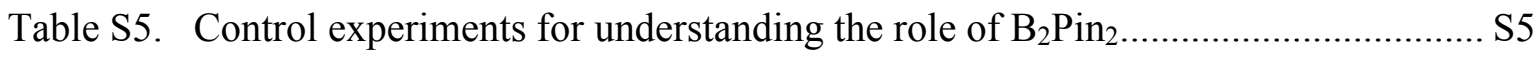

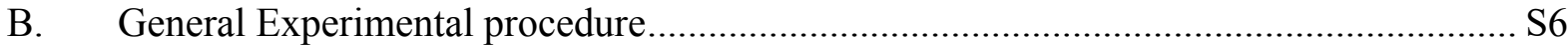

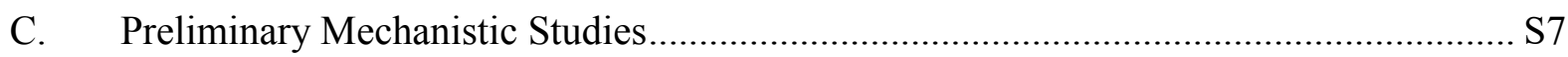

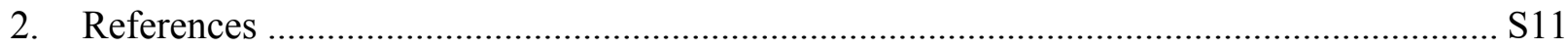

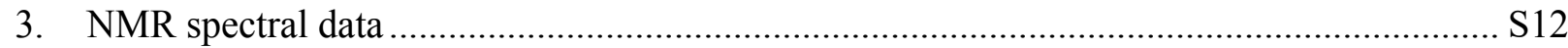


Santhosh, Nibin and Prabhu/Organic Chemistry/IISc_Org Chem

\section{Experimental section}

\section{A. Development of the reaction}

Table S1. $\quad$ Screening of solvents and temperature

\begin{tabular}{|c|c|c|c|c|c|}
\hline $\begin{array}{c}\mathrm{Ph} \\
\| \\
\mathrm{Ph} \\
1 \mathrm{a} \\
0.5 \mathrm{mmol}\end{array}$ & $\begin{array}{r}\mathrm{B}_{2} \mathrm{Pin}_{2}+1 \\
0.55 \mathrm{mmol} \\
0.55 \\
2\end{array}$ & $\begin{array}{c}\mathrm{Pd}(\mathrm{OA} \\
\mathrm{PCy} \\
\mathrm{H}_{2} \mathrm{O} \\
\text { solver }\end{array}$ & $\begin{array}{l}2(5 \mathrm{~mol} \%) \\
\frac{10 \mathrm{~mol} \%)}{\longrightarrow .5 \mathrm{mmol})} \\
\text { temp, } 16 \mathrm{~h}\end{array}$ & 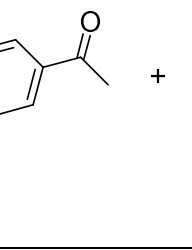 & 4a \\
\hline \multirow{2}{*}{ entry } & \multirow{2}{*}{ solvent $(2 \mathrm{~mL})$} & \multirow{2}{*}{ temp $\left({ }^{\circ} \mathrm{C}\right)$} & \multicolumn{2}{|c|}{ NMR yield (isolated yield) (\%) } & \multirow[t]{2}{*}{$1 \mathbf{a}(\%)$} \\
\hline & & & 3aw & $4 a$ & \\
\hline 1 & Toluene & 100 & $(36)$ & $(51)$ & NIL \\
\hline 2 & DME & 100 & 70 & 25 & NIL \\
\hline 3 & THF & 100 & 80 & Trace & NIL \\
\hline 4 & Dioxane & 100 & 40 & 25 & 20 \\
\hline 5 & DCE & 100 & 45 & 30 & 20 \\
\hline 6 & THF & 80 & 82 & Trace & NIL \\
\hline 7 & THF & 120 & 77 & Trace & NIL \\
\hline
\end{tabular}

NMR yield was calculated using $0.125 \mathrm{mmol}$ terephthalaldehyde as internal standard.

\section{Table S2. $\quad$ Screening of stoichiometric equivalence of water}

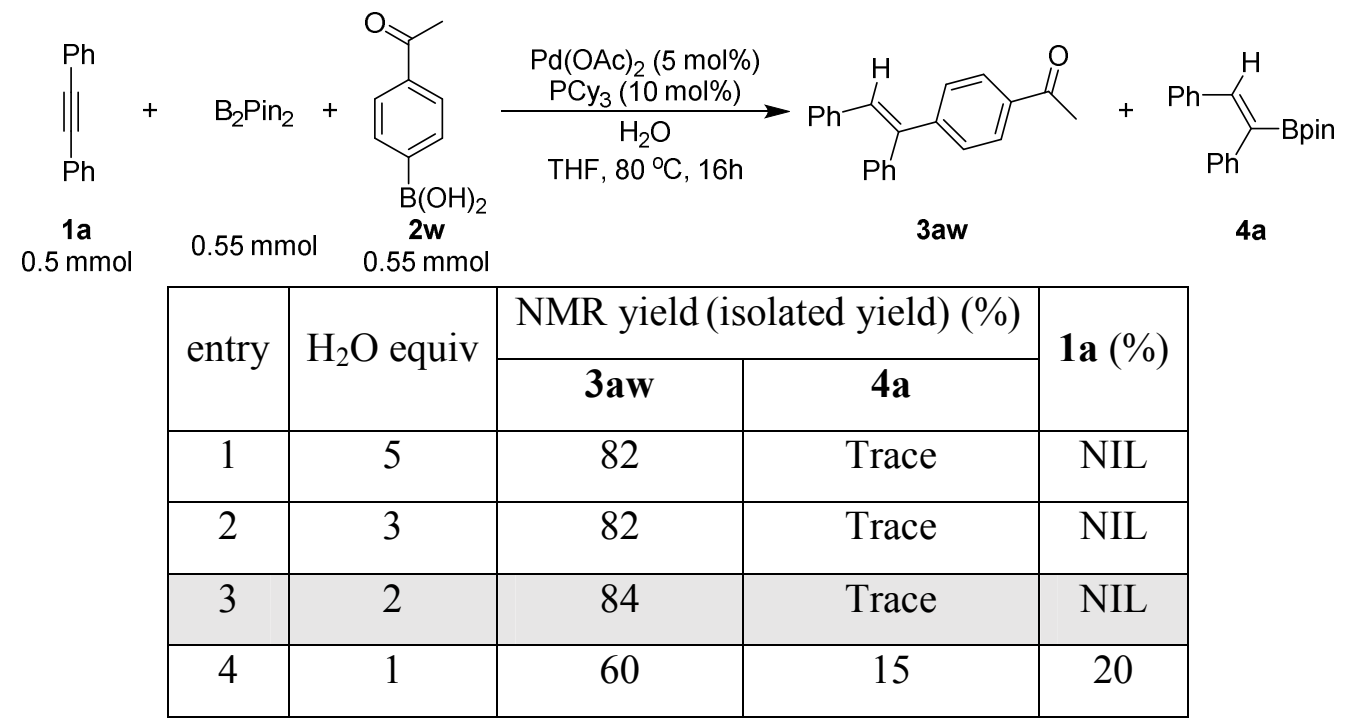

NMR yield was calculated using $0.125 \mathrm{mmol}$ terephthalaldehyde as internal standard 
Table S3. Screening of stoichiometric equivalence of Boronic acid and $B_{2} \underline{P i n}_{2}$

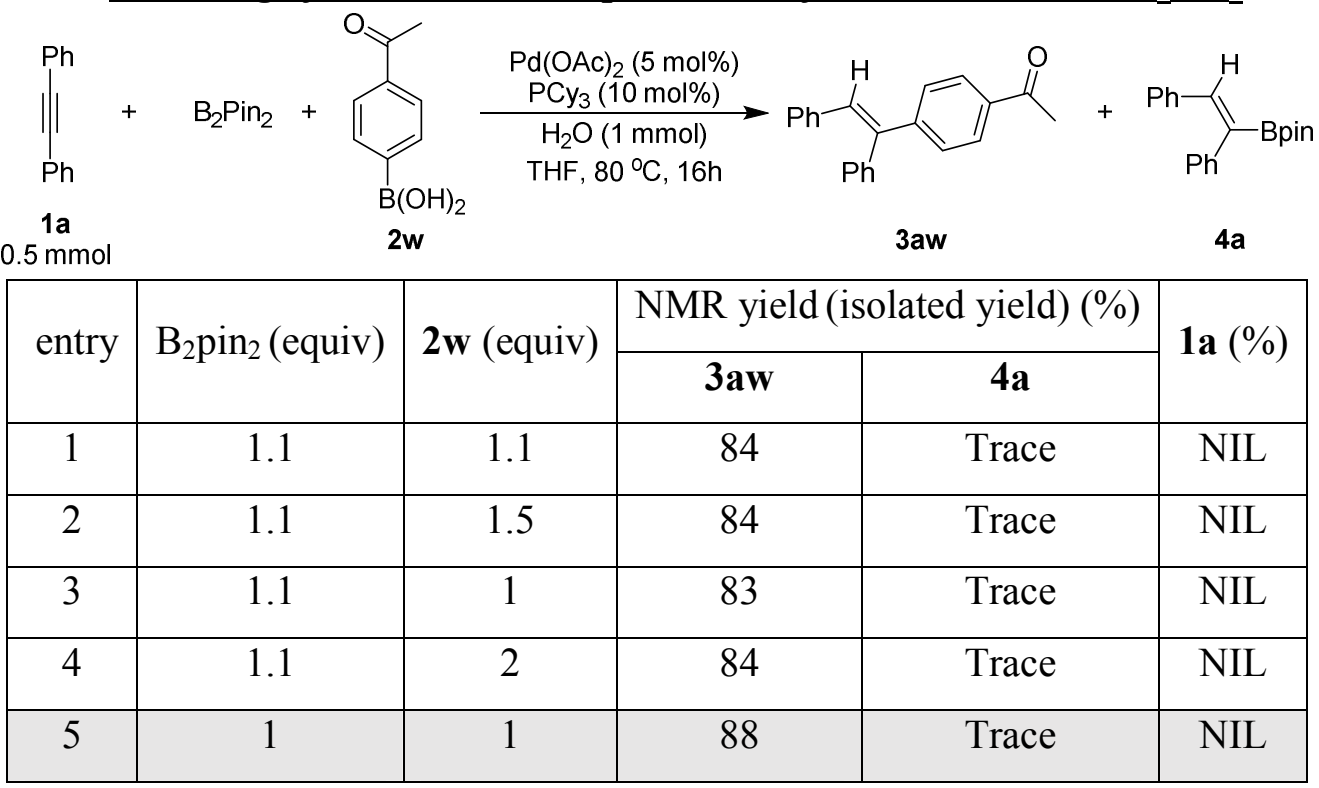

NMR yield was calculated using $0.125 \mathrm{mmol}$ terephthalaldehyde as internal standard.

Even though the yield of the reaction was found to be $88 \%$ at this stage, a trace amount $(<5 \%)$ of the starting material diphenylacetylene was being over-reduced to the corresponding alkane. Further optimization studies were focused to reduce the over reduction so as to improve the yield of the required hydroarylated product.

\section{Table S4. Screening of time and stoichiometric equivalence of catalyst/ligand}

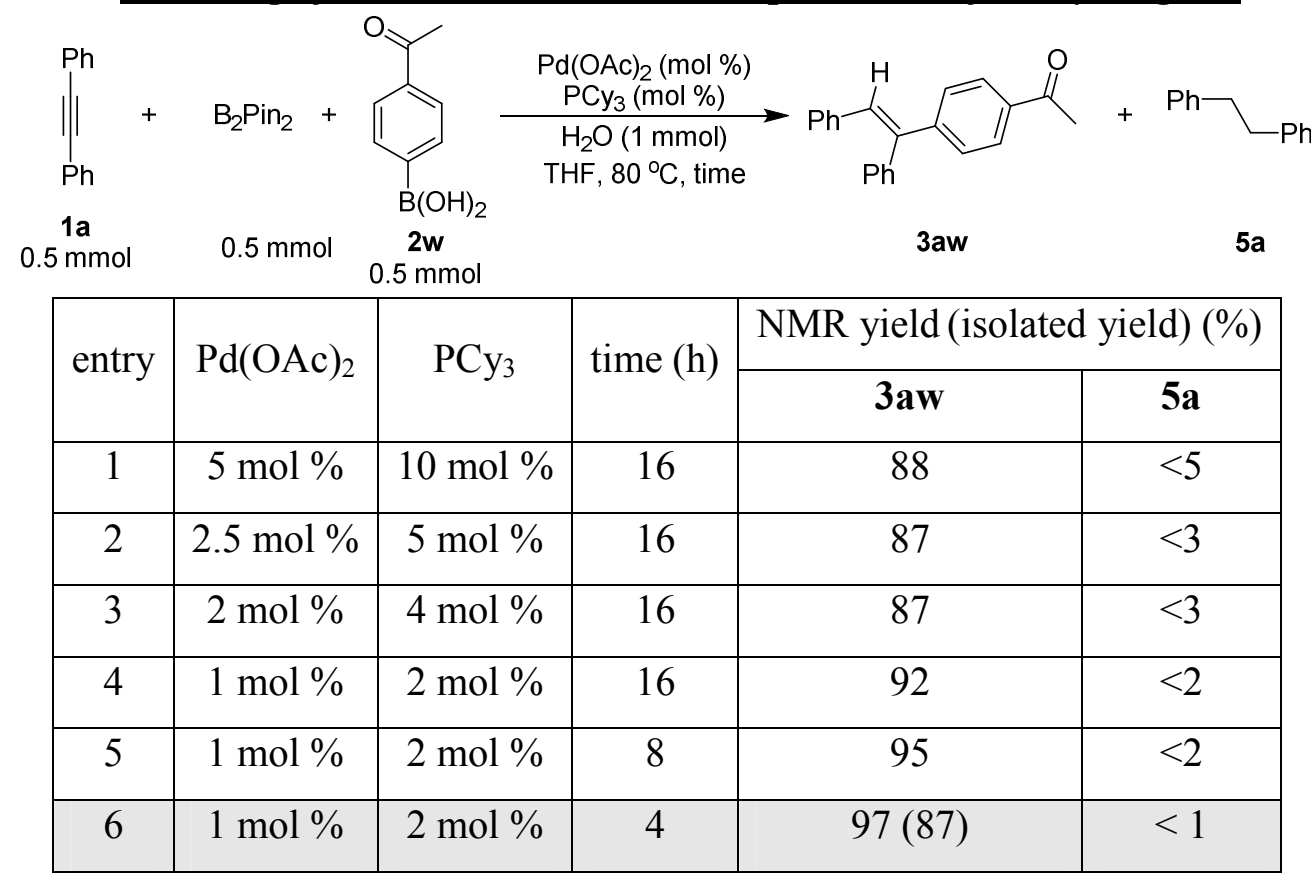

NMR yield was calculated using $0.125 \mathrm{mmol}$ terephthalaldehyde as internal standard. 
Table S5. Control experiments for understanding the role of $B_{2} \underline{P i n}_{2}$

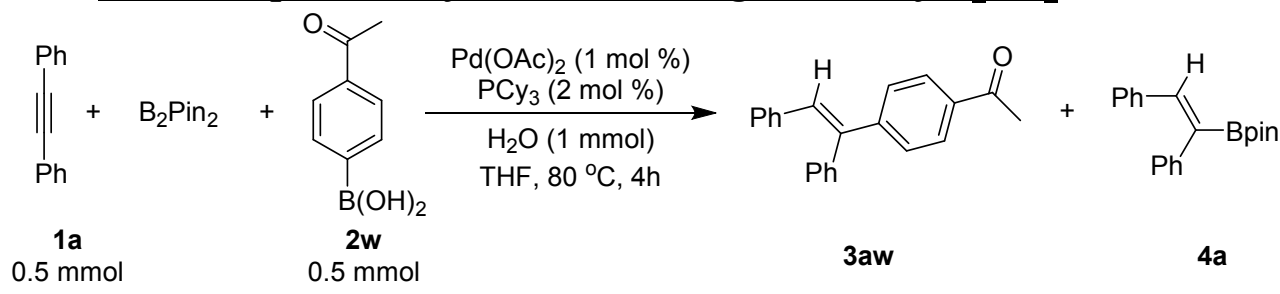

\begin{tabular}{|c|c|c|c|c|}
\hline \multirow{2}{*}{ entry } & \multirow{2}{*}{$\mathrm{B}_{2} \operatorname{Pin}_{2}$ (equiv) } & \multicolumn{3}{|c|}{ NMR yield (Isolated yield) (\%) } \\
\cline { 3 - 5 } & & $\mathbf{3 a w}$ & $\mathbf{4 a}$ & 1a recovered \\
\hline 1 & ---- & $(80)$ & Nil & $(11)$ \\
\hline 2 & 0.1 & $(77)$ & 2 & $(15)$ \\
\hline 3 & 0.2 & $(44)$ & 3 & $(44)$ \\
\hline 4 & 0.5 & $(64)$ & 4 & $(27)$ \\
\hline 5 & 1 & $(87)$ & $<5$ & nil \\
\hline 6 & 2.1 & $(82)$ & $<5$ & nil \\
\hline
\end{tabular}

NMR yield was calculated using $0.125 \mathrm{mmol}$ terephthalaldehyde as internal standard.

Table S6. Control experiments with different equivalents of $\underline{B}_{2} \underline{\text { Pin }}_{2} \underline{\text { with }}_{\text {phenylacetylene and }}$ phenylboronic acid

We also performed a similar set of reactions with a completely different set of substrates i.e. using phenylacetylene and phenylboronic acid. A similar trend was observed (see Table 1, manuscript) even in this case and results are presented below:

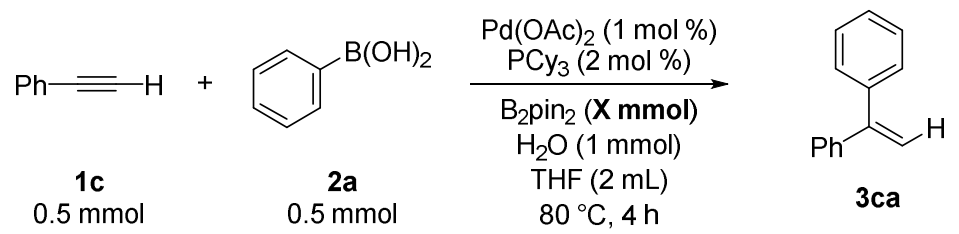

\begin{tabular}{|c|c|}
\hline B $_{2}$ pin $_{2}$ (equiv) & 3ca (NMR yield) \\
\hline 0 & $61 \%$ \\
\hline 0.1 & $61 \%$ \\
\hline 0.2 & $64 \%$ \\
\hline 0.5 & $52 \%$ \\
\hline 0.9 & $57 \%$ \\
\hline 1 & $75 \%$ \\
\hline
\end{tabular}




\section{Controls to understand the role of water in the system}

Arylboronic acids do comprise water. Hence, a control excluding water also resulted in the product formation, wherein the hydrogen was derived from the boronic acid functionality. Hence, even arylboronic acid can act as water donor in the system. Employing pinacolato group containing boron functionality did not result in the product formation. However, when 2 equiv of water was included in the system, $66 \%$ of the product was observed.

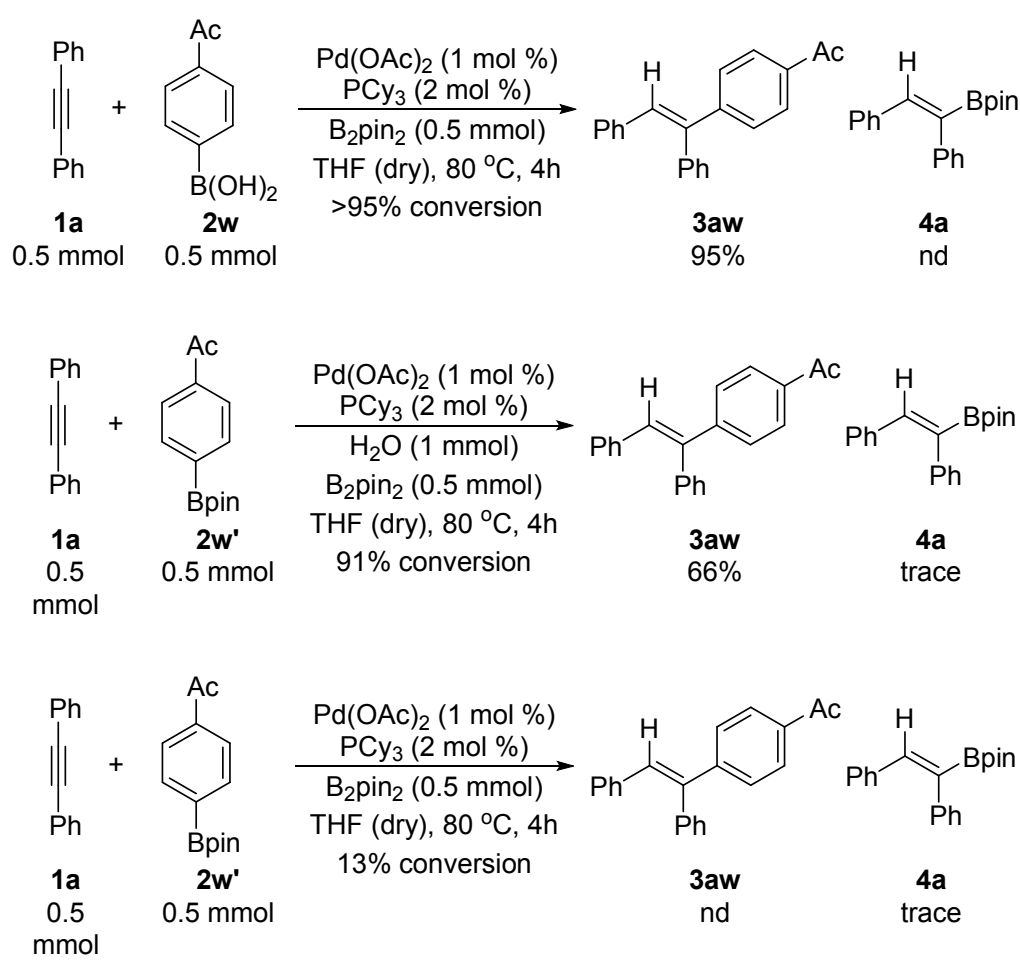

\section{B. General Experimental procedure}

\section{Synthetic method example}

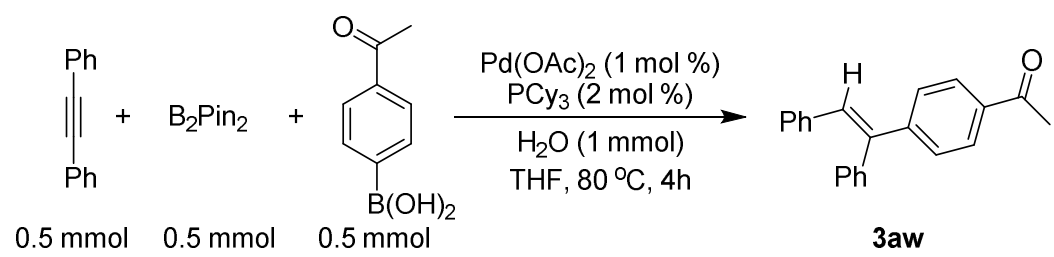

To a pre-dried $10 \mathrm{~mL}$ screw cap equipped reaction vial, water (1 mmol, $18 \mathrm{mg}$ ), diphenylacetylene (1a, $0.5 \mathrm{mmol}, 89.1 \mathrm{mg}), \mathrm{B}_{2} \operatorname{Pin}_{2}(0.5 \mathrm{mmol}, 127 \mathrm{mg})$, 4-acetylphenylboronic acid (2w, $0.5 \mathrm{mmol}, 82 \mathrm{mg}), \mathrm{PCy}_{3}(2 \mathrm{~mol} \%, 2.8 \mathrm{mg})$ and $\mathrm{Pd}(\mathrm{OAc})_{2}(1 \mathrm{~mol} \%, 1.1 \mathrm{mg})$ were added, dissolved in dry THF $(2 \mathrm{~mL})$ and the reaction mixture was heated in a pre-heated metal block for $4 \mathrm{~h}$ with continuous stirring. After the completion of the reaction, the reaction mixture 
was filtered using a short column using diethyl ether. The filtrate was distilled under reduced pressure and the crude mixture was dissolved in sufficient amount of $\mathrm{CDCl}_{3}$. To this, 0.125 mmol terephthalaldehyde as internal standard was added, dissolved and submitted for NMR analysis. The crude mixture was then purified by column chromatography to afford the title compound in $87 \%$ isolated yield.

\section{Preliminary Mechanistic Studies}

\section{Determining the intermediate}

\section{A) Two-step process}
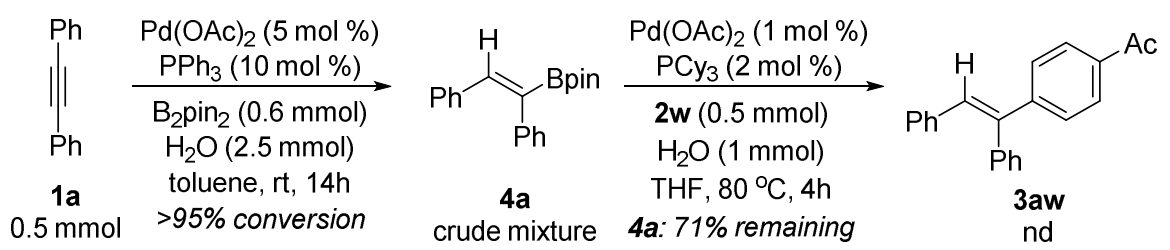

An oven dried, screw cap equipped reaction vial with a magnetic stir bar was charged with diphenylacetylene $(0.5 \mathrm{mmol}, 89.1 \mathrm{mg}), \mathrm{B}_{2} \mathrm{pin}_{2}(0.5 \mathrm{mmol}, 1$ equiv, $127.0 \mathrm{mg}), \mathrm{PPh}_{3}(10 \mathrm{~mol} \%$, $13.1 \mathrm{mg}), \mathrm{H}_{2} \mathrm{O}(2.5 \mathrm{mmol}, 5$ equiv, $45.0 \mathrm{mg})$ and $\mathrm{Pd}(\mathrm{OAc})_{2}(5 \mathrm{~mol} \%, 5.6 \mathrm{mg})$. The reaction mixture was then dissolved in toluene solvent $(1.5 \mathrm{~mL})$ and stirred at $\mathrm{rt}$ for $14 \mathrm{~h}$. Crude mixture was then filtered through a short column with 230-400 mesh silica bed using $\mathrm{Et}_{2} \mathrm{O}$, concentrated and transferred to another oven dried, screw cap equipped reaction vial containing a magnetic stir bar. To this $\mathrm{H}_{2} \mathrm{O}$ ( $1 \mathrm{mmol}, 2$ equiv, $\left.18 \mathrm{mg}\right)$, 4-acetylphenylboronic acid (2w, $0.5 \mathrm{mmol}, 1$ equiv, $82 \mathrm{mg}), \mathrm{PCy}_{3}(2 \mathrm{~mol} \%, 2.8 \mathrm{mg})$, and $\mathrm{Pd}(\mathrm{OAc})_{2}(1 \mathrm{~mol} \%, 1.1 \mathrm{mg})$ were added. The reaction mixture was then dissolved in dry THF solvent $(2 \mathrm{~mL})$ and stirred at $80{ }^{\circ} \mathrm{C}$ for $4 \mathrm{~h}$. Crude mixture was then filtered through a short column with 230-400 mesh silica bed using $\mathrm{Et}_{2} \mathrm{O}$, concentrated and analyzed.

\section{B) Probing the Possible Hydroborylated Intermediate}
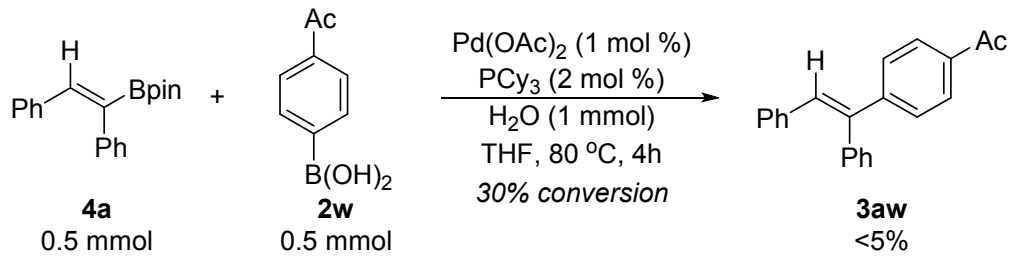

To a pre-dried $10 \mathrm{~mL}$ screw cap equipped reaction vial, water $(1 \mathrm{mmol}, 18 \mathrm{mg}), \mathbf{4 a}(0.5 \mathrm{mmol}$, $153.1 \mathrm{mg})$, 4-acetylphenylboronic acid (2w, $0.5 \mathrm{mmol}, 82 \mathrm{mg}), \mathrm{PCy}_{3}(2 \mathrm{~mol} \%, 2.8 \mathrm{mg})$ and 
$\mathrm{Pd}(\mathrm{OAc})_{2}(1 \mathrm{~mol} \%, 1.1 \mathrm{mg})$ were added, dissolved in dry THF $(2 \mathrm{~mL})$ and the reaction mixture was heated in a pre-heated metal block for $4 \mathrm{~h}$ with continuous stirring. After the completion of the reaction, the reaction mixture was filtered using a short column using diethyl ether. The filtrate was distilled under reduced pressure and the crude mixture was dissolved in sufficient amount of $\mathrm{CDCl}_{3}$. To this, $0.125 \mathrm{mmol}$ terephthalaldehyde as internal standard was added, dissolved and submitted for NMR analysis.

\section{Determining the active catalyst}

\section{A) Using catalytic amount of $P d\left(P C y_{3}\right)_{2}$}

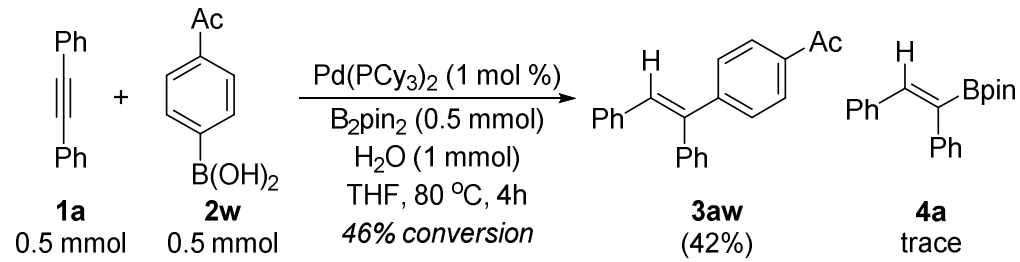

To a pre-dried $10 \mathrm{~mL}$ screw cap equipped reaction vial, water (1 mmol, $18 \mathrm{mg}$ ), diphenylacetylene (1a, $0.5 \mathrm{mmol}, 89.1 \mathrm{mg}), \mathrm{B}_{2} \mathrm{Pin}_{2}(0.5 \mathrm{mmol}, 127 \mathrm{mg})$, 4-acetylphenylboronic acid (2w, $0.5 \mathrm{mmol}, 82 \mathrm{mg})$ and $\mathrm{Pd}\left(\mathrm{PCy}_{3}\right)_{2}(1 \mathrm{~mol} \%, 3.3 \mathrm{mg})$ were added, dissolved in dry THF $(2 \mathrm{~mL})$ and the reaction mixture was heated in a pre-heated metal block for $4 \mathrm{~h}$ with continuous stirring. After the completion of the reaction, the reaction mixture was filtered using a short column using diethyl ether. The filtrate was distilled under reduced pressure and the crude mixture was dissolved in sufficient amount of $\mathrm{CDCl}_{3}$. To this, $0.125 \mathrm{mmol}$ terephthalaldehyde as internal standard was added, dissolved and submitted for NMR analysis. The crude mixture was then purified by column chromatography to afford the compound 3aw in $42 \%$ isolated yield.

\section{B) Using a catalytic amount of $\mathrm{Pd}\left(\mathrm{PC} \mathrm{y}_{3}\right)_{2}$ and $\mathrm{AcOH}$}

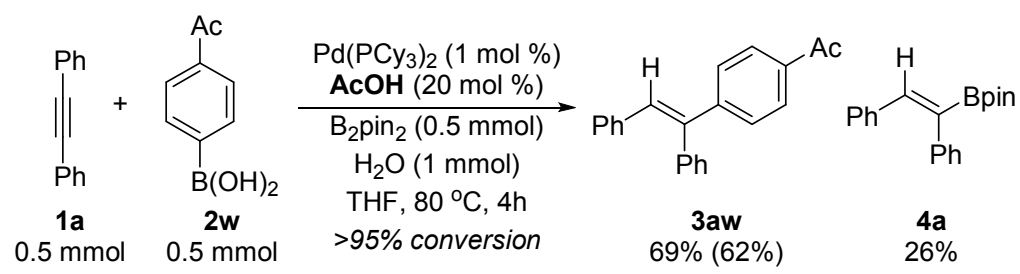

To a pre-dried $10 \mathrm{~mL}$ screw cap equipped reaction vial, acetic acid (20 mol \%, $6 \mathrm{mg}$ ), water (1 mmol, $18 \mathrm{mg})$, diphenylacetylene (1a, $0.5 \mathrm{mmol}, 89.1 \mathrm{mg}), \mathrm{B}_{2} \mathrm{Pin}_{2}(0.5 \mathrm{mmol}, 127 \mathrm{mg})$, 4acetylphenylboronic acid (2w, $0.5 \mathrm{mmol}, 82 \mathrm{mg})$ and $\mathrm{Pd}\left(\mathrm{PCy}_{3}\right)_{2}(1 \mathrm{~mol} \%, 3.3 \mathrm{mg})$ were added, dissolved in dry THF $(2 \mathrm{~mL})$ and the reaction mixture was heated in a pre-heated metal block for 
4h with continuous stirring. After the completion of the reaction, the reaction mixture was filtered using a short column using diethyl ether. The filtrate was distilled under reduced pressure and the crude mixture was dissolved in sufficient amount of $\mathrm{CDCl}_{3}$. To this, $0.125 \mathrm{mmol}$ terephthalaldehyde as internal standard was added, dissolved and submitted for NMR analysis. The crude mixture was then purified by column chromatography to afford the compound 3aw in $62 \%$ isolated yield.

The same procedure was followed for the following control wherein $2 \mathrm{~mol} \%$ of $\mathrm{AcOH}$ was used instead of $20 \mathrm{~mol} \%$.

Note: $2 \mathrm{~mol} \% \mathrm{AcOH}$ was added by preparing a stock solution of $6 \mathrm{mg}$ of $\mathrm{AcOH}$ in $3 \mathrm{~mL}$ of THF (0.6 $\mathrm{mg}$ in $0.5 \mathrm{~mL}$ of THF).

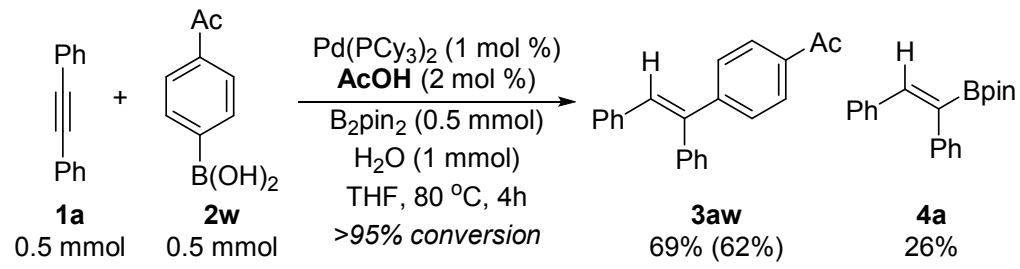

An additional control was performed using the same procedure wherein 2 mol \% of AcOH was used but with $\mathrm{B}_{2} \mathrm{pin}_{2}$ omitted from the reaction.

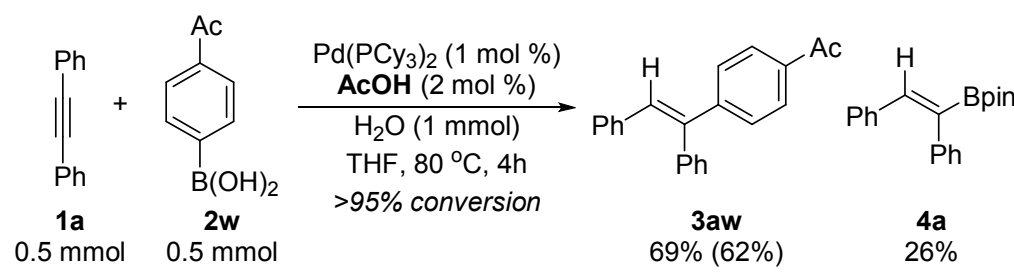

\section{C) Probing Palladium's C-B Oxidative Addition Capability}
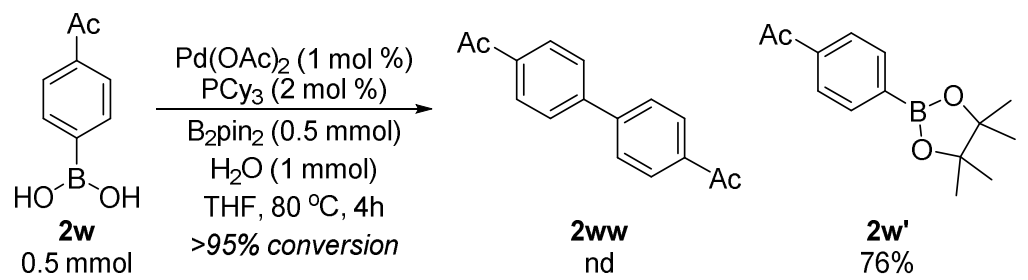

To a pre-dried $10 \mathrm{~mL}$ screw cap equipped reaction vial, water $(1 \mathrm{mmol}, 18 \mathrm{mg}), \mathrm{B}_{2} \operatorname{Pin}_{2}(0.5$ mmol, $127 \mathrm{mg})$, 4-acetylphenylboronic acid (2w, $0.5 \mathrm{mmol}, 82 \mathrm{mg}), \mathrm{PCy}_{3}(2 \mathrm{~mol} \%, 2.8 \mathrm{mg}$ ) and $\mathrm{Pd}(\mathrm{OAc})_{2}(1 \mathrm{~mol} \%, 1.1 \mathrm{mg})$ were added, dissolved in dry THF $(2 \mathrm{~mL})$ and the reaction mixture was heated in a pre-heated metal block for $4 \mathrm{~h}$ with continuous stirring. After the completion of the reaction, the reaction mixture was filtered using a short column using diethyl ether. The 
Santhosh, Nibin and Prabhu/Organic Chemistry/IISc_Org Chem

filtrate was distilled under reduced pressure and the crude mixture was dissolved in sufficient amount of $\mathrm{CDCl}_{3}$. To this, $0.125 \mathrm{mmol}$ terephthalaldehyde as internal standard was added, dissolved and submitted for NMR analysis. 


\section{References}

(1) Gottlieb, H. E.; Kotlyar, V.; Nudelman, A. NMR Chemical Shifts of Common Laboratory Solvents as Trace Impurities. J. Org. Chem.1997, 62, 7512-7515.

(2) Fulmer, G. R.; Miller, A. J. M.; Sherden, N. H.; Gottlieb, H. E.; Nudelman, A.; Stoltz, B. M.; Bercaw, J. E.; Goldberg, K. I. NMR Chemical Shifts of Trace Impurities: Common Laboratory Solvents, Organics, and Gases in Deuterated Solvents Relevant to the Organometallic Chemist. Organometallics2010, 29, 2176-2179.

(3) Rao, S.; Prabhu, K. R. Stereodivergent Alkyne Reduction by using Water as the Hydrogen Source. Chem. Eur. J.2018, 24, 13954-13962. 


\section{NMR spectral data}

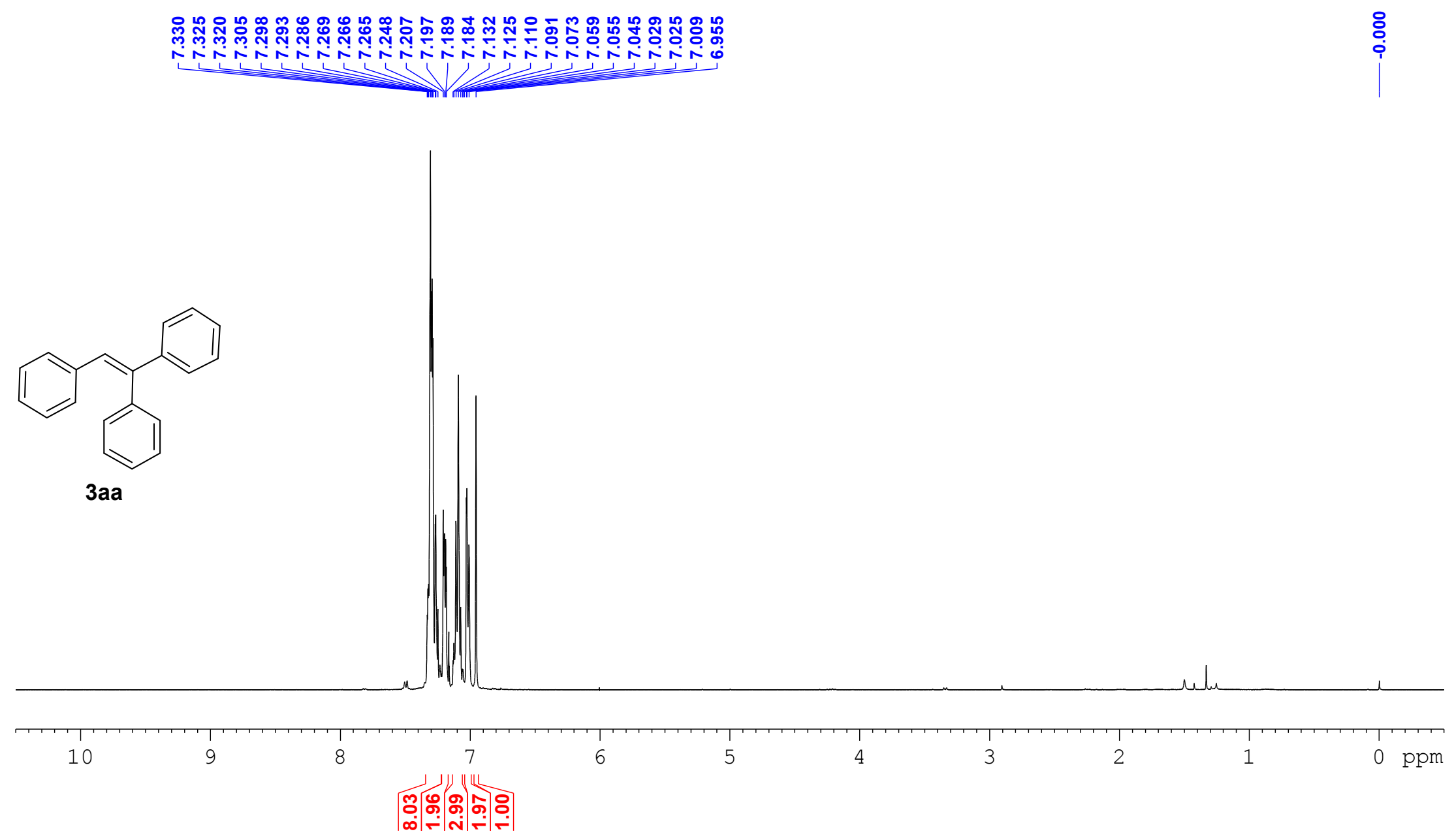




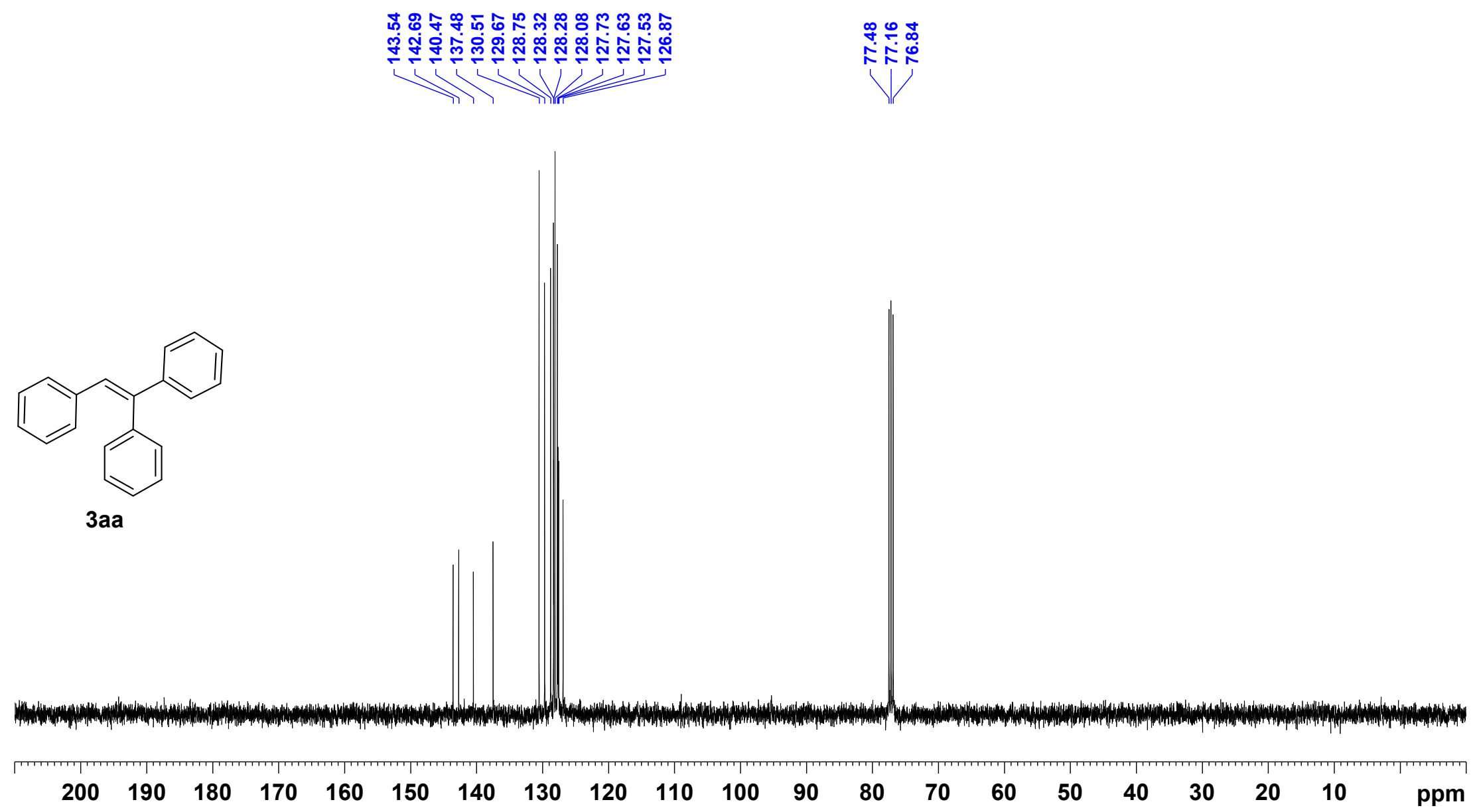




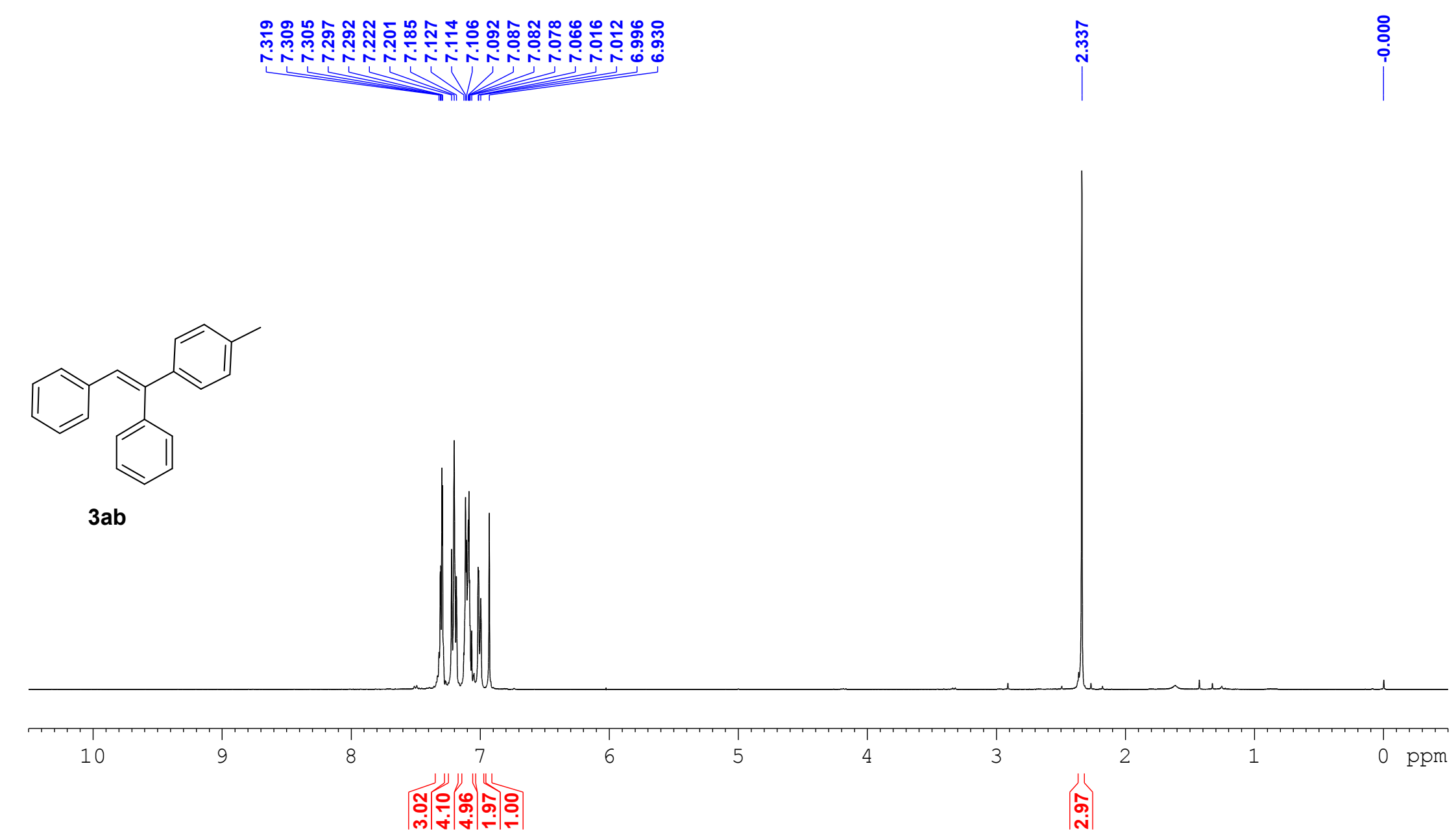



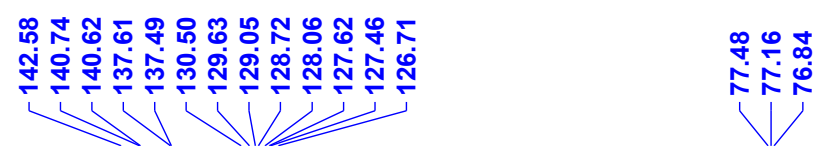

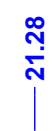

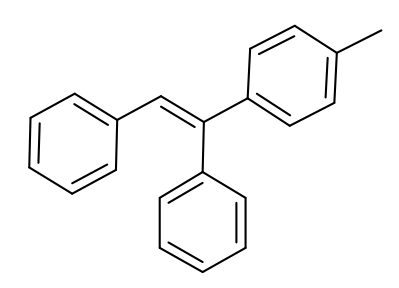

$3 a b$

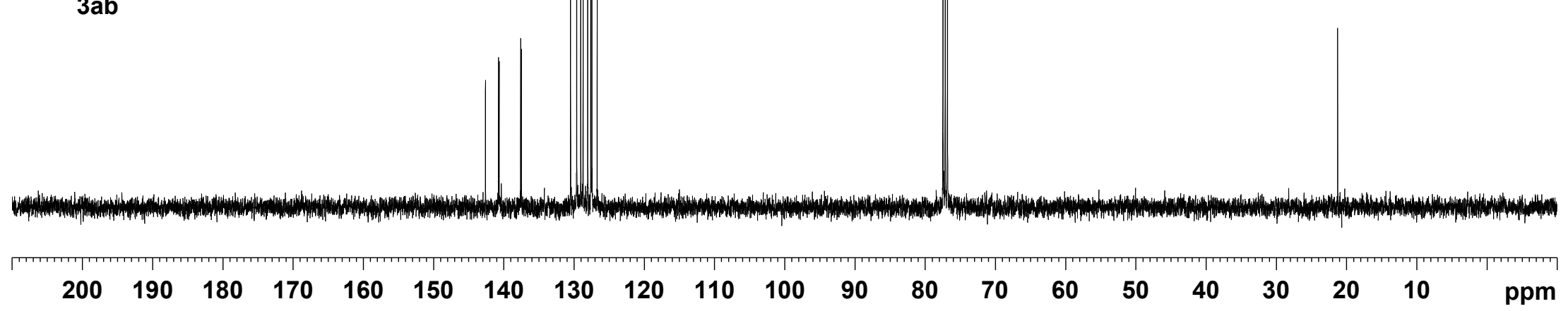




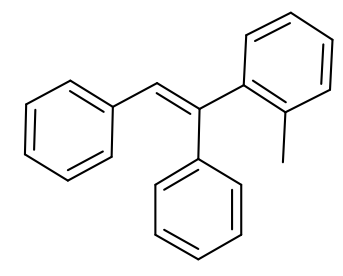

3ac

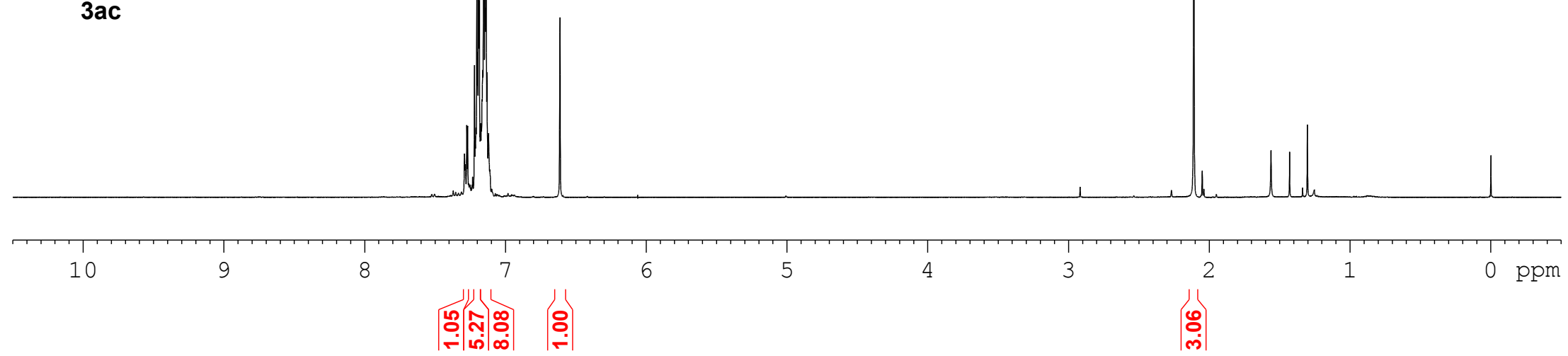




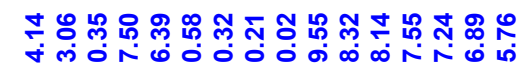

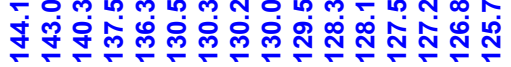
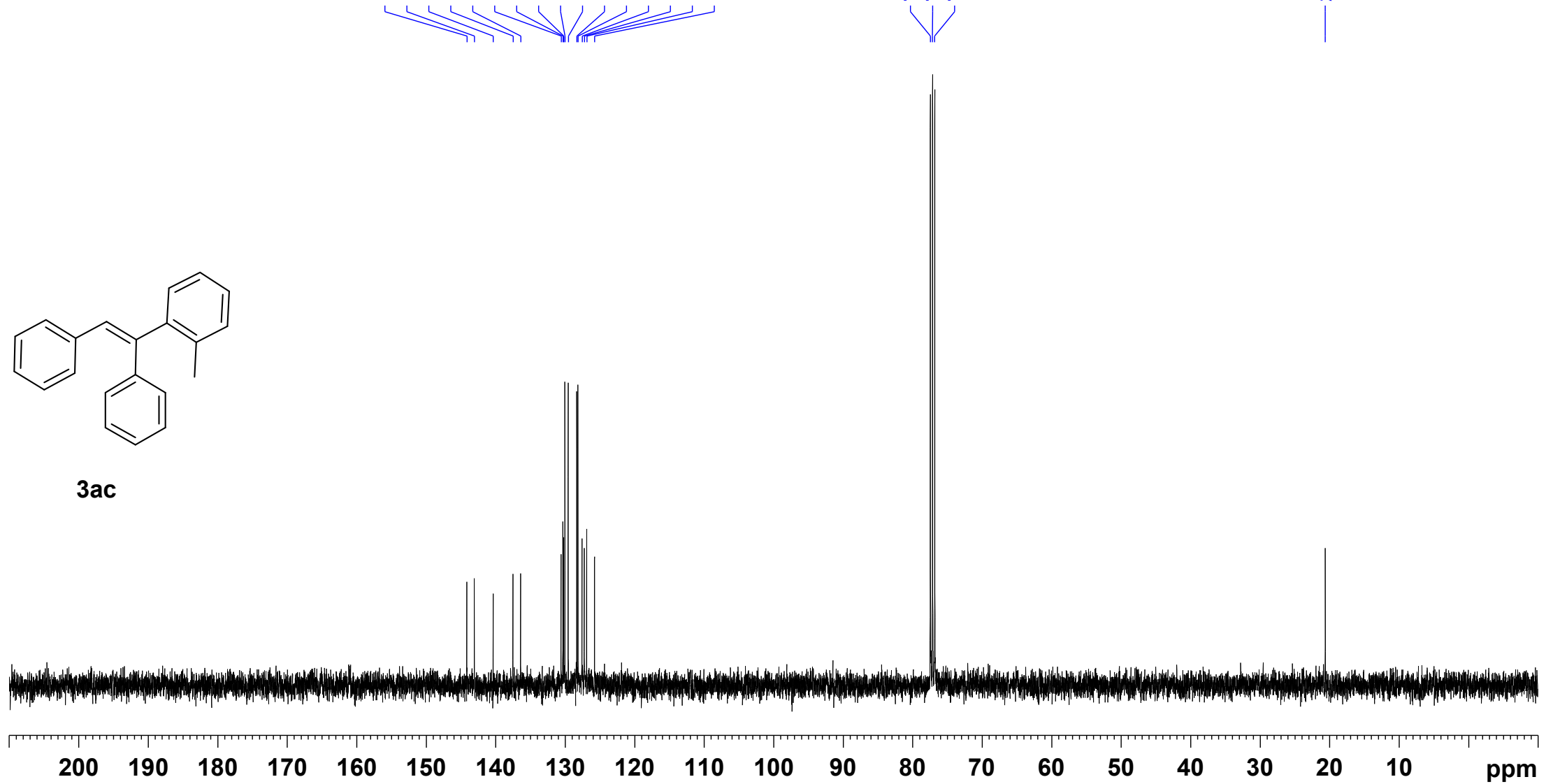

$3 a c$
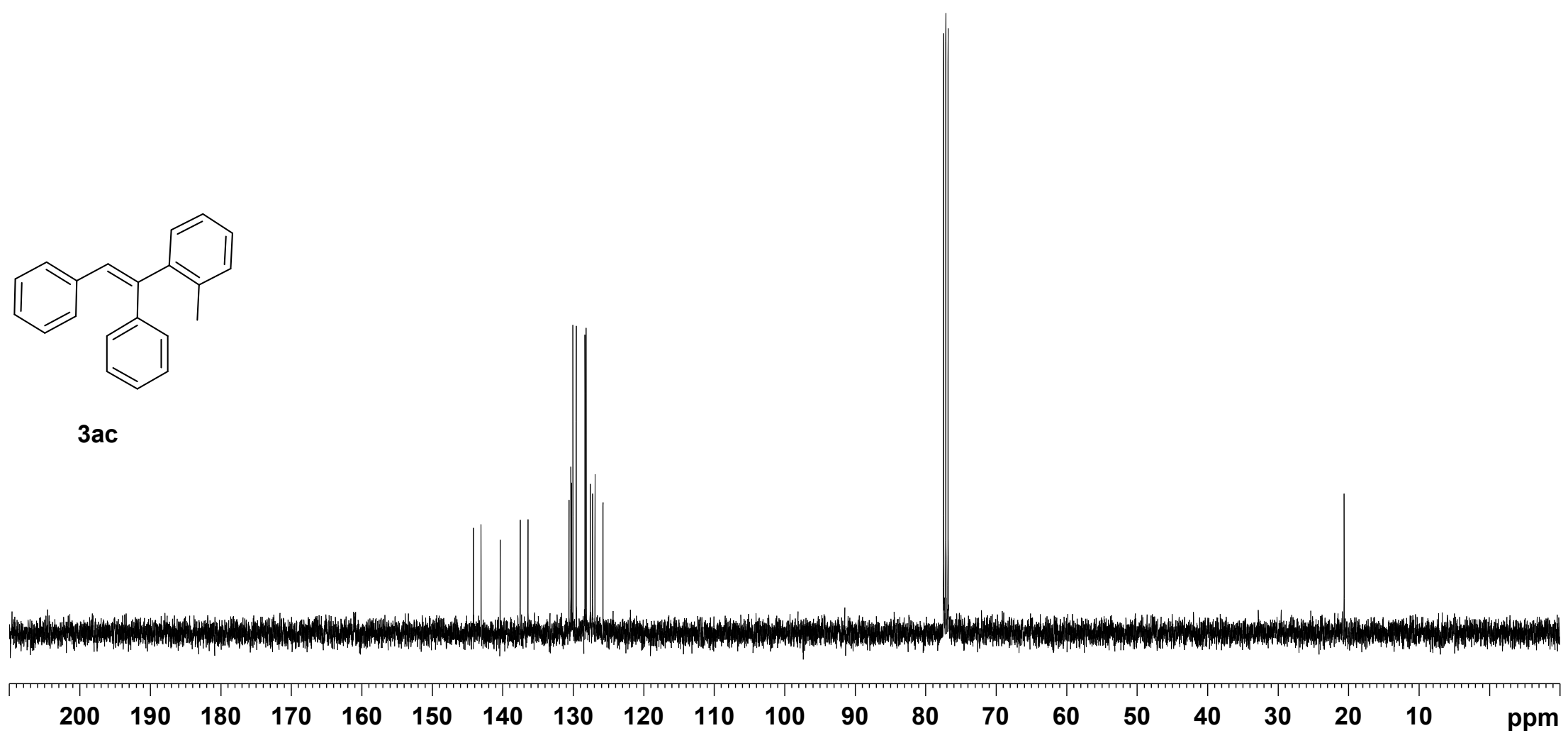

$\begin{array}{llllllll}200 & 190 & 180 & 170 & 160 & 150 & 140 & 130\end{array}$
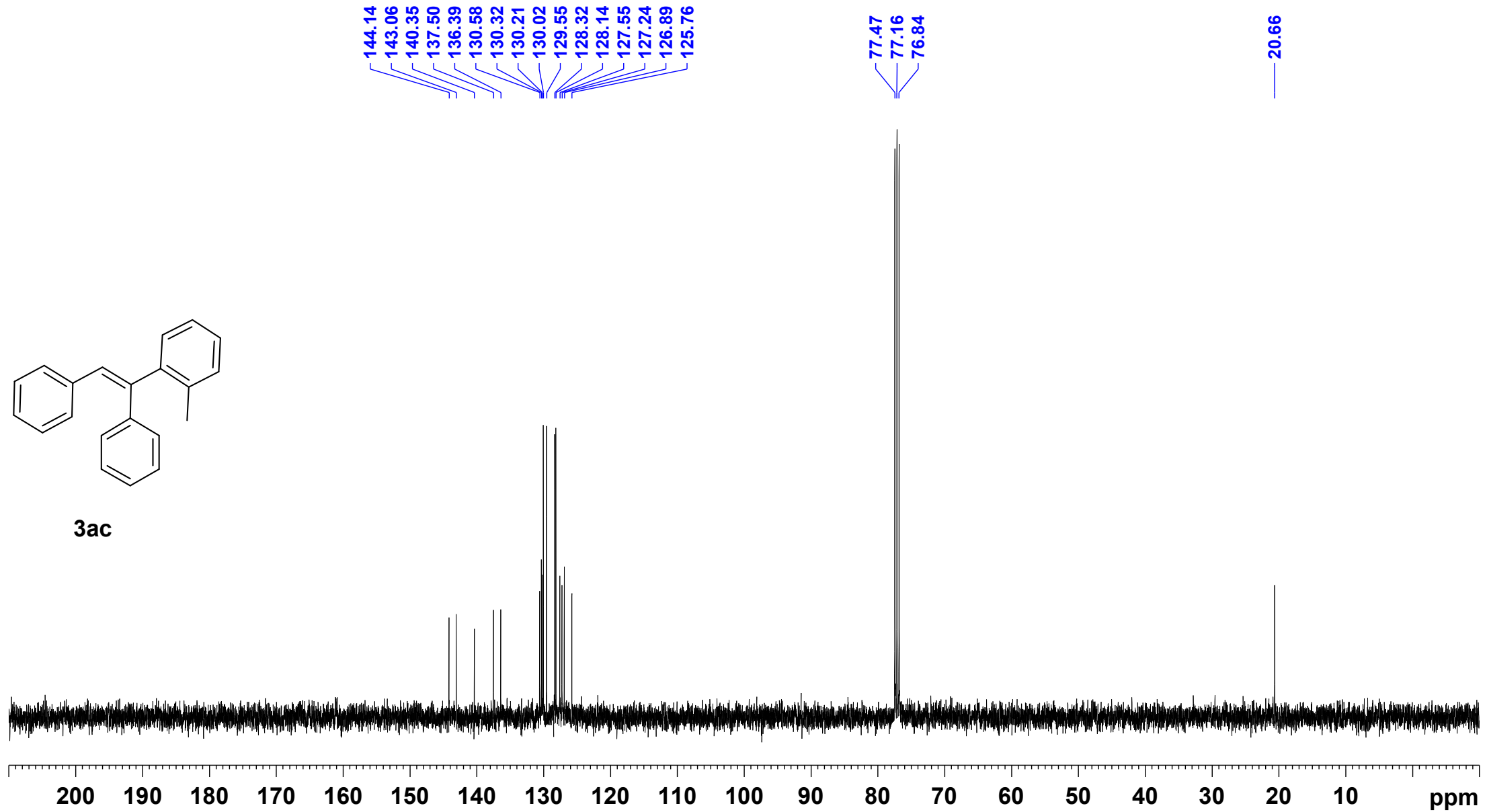

$\stackrel{8}{\stackrel{8}{1}}$ 


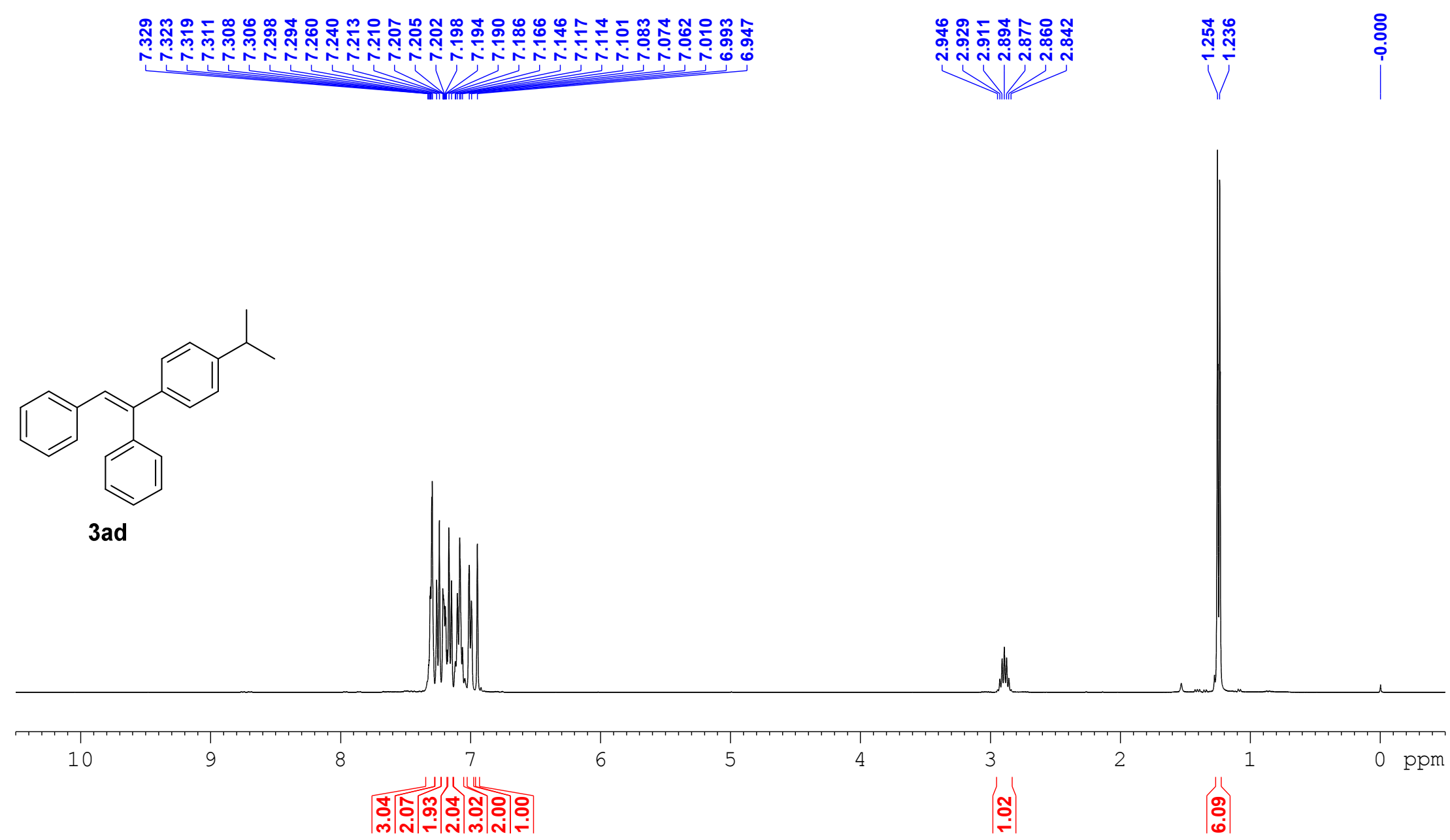




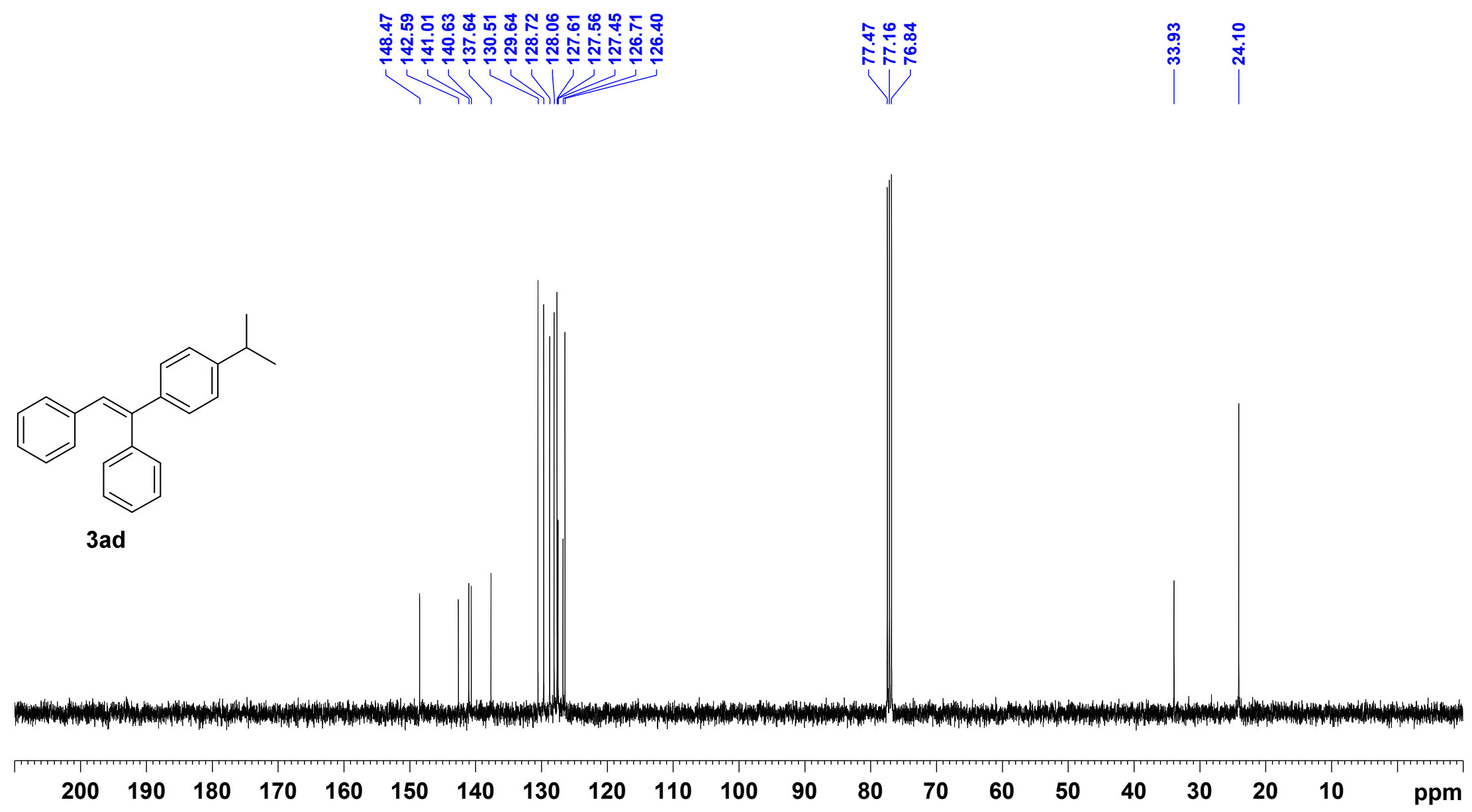




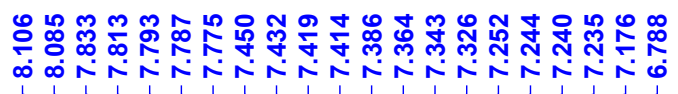

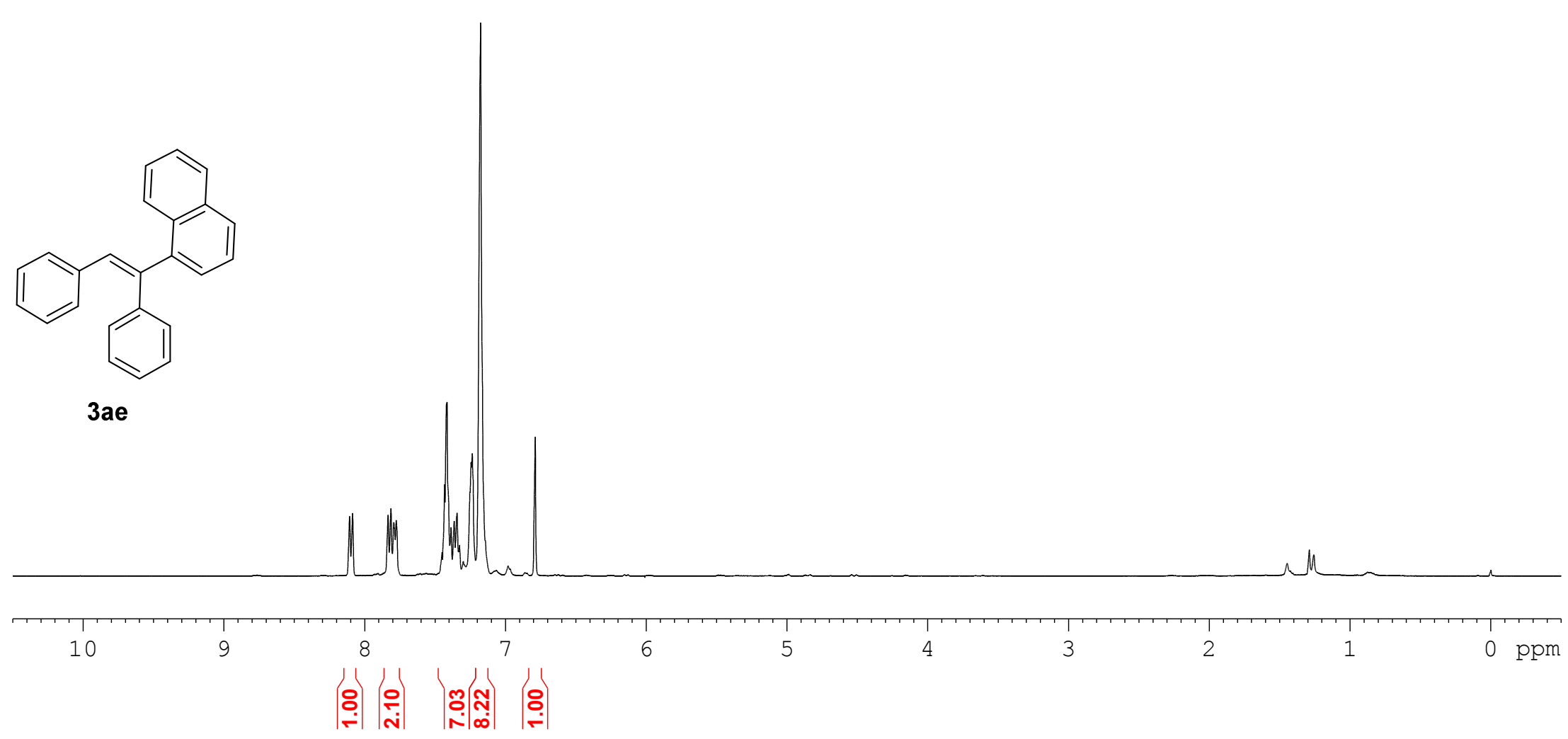




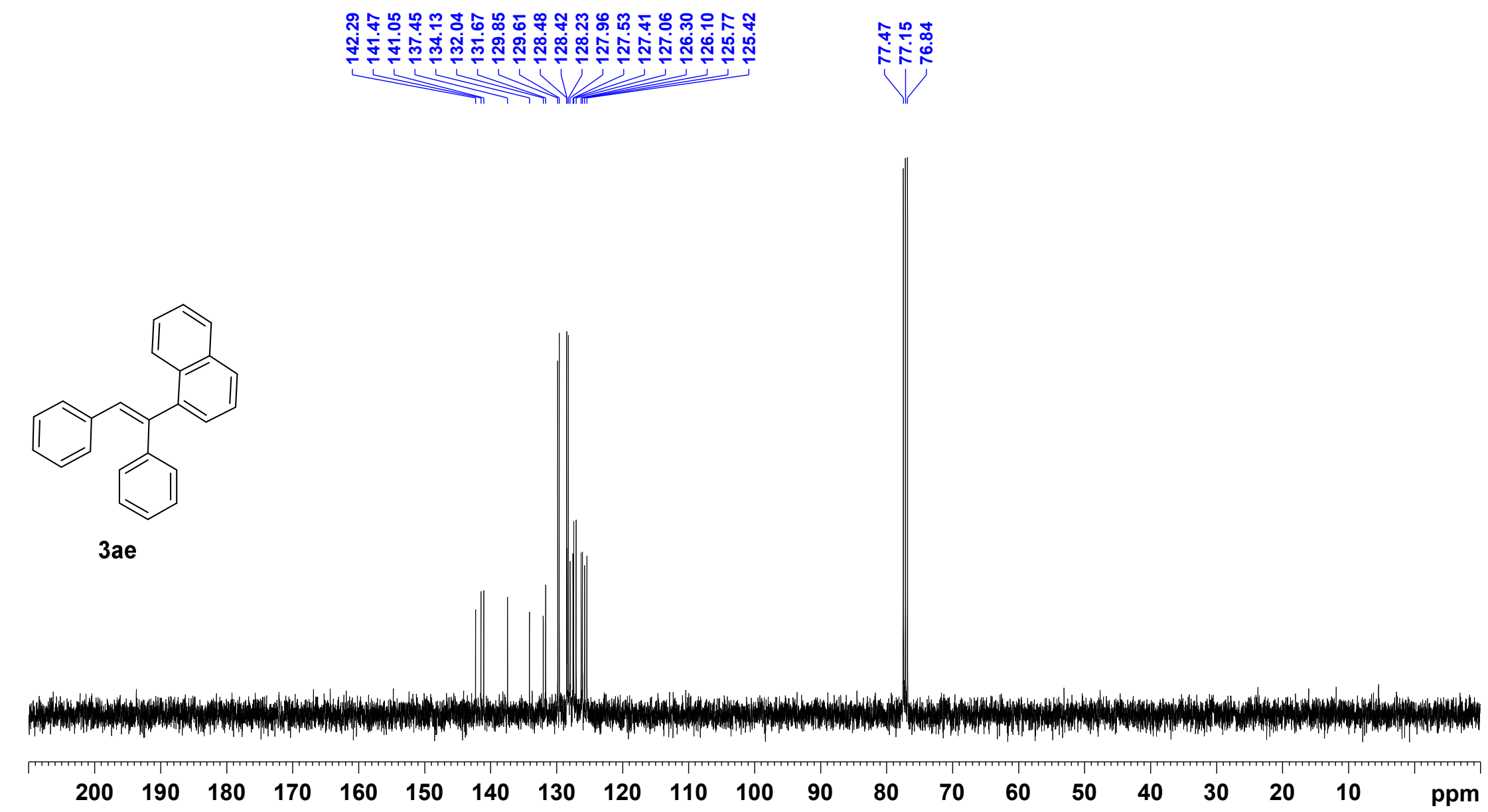




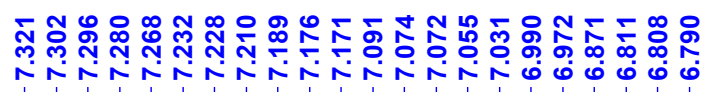

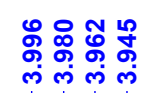

an

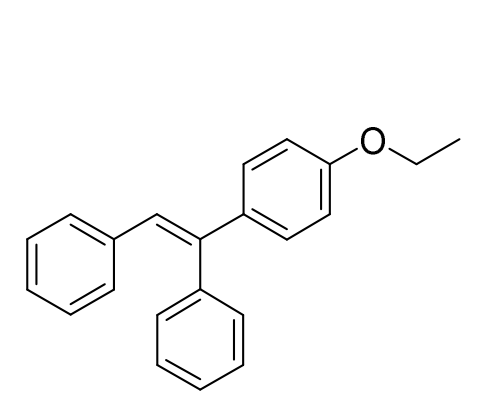

3af
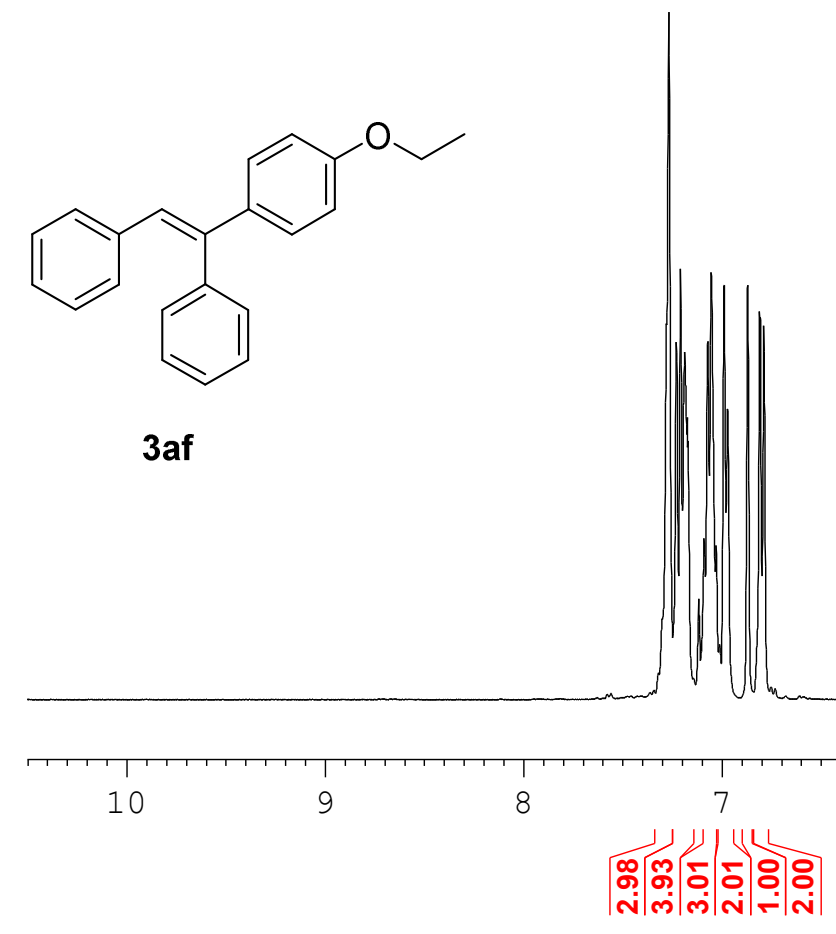

6

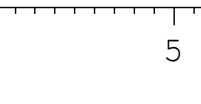

5

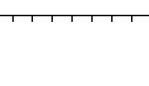

\begin{tabular}{l}
4 \\
욤 \\
\hdashline
\end{tabular}

2 


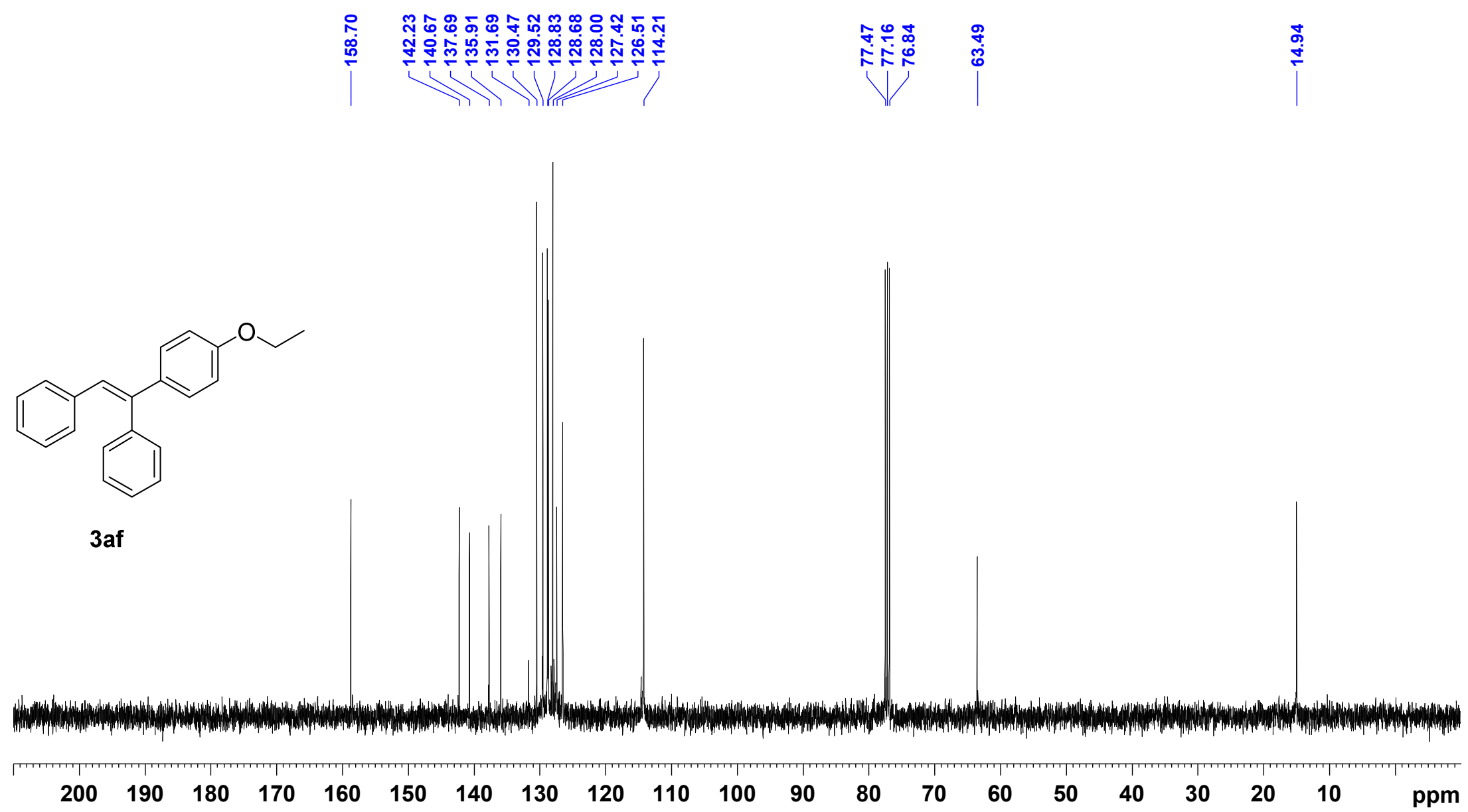




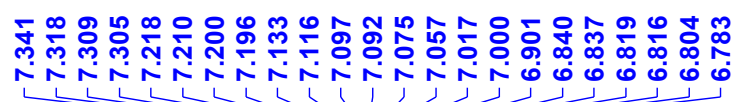

$\overbrace{\substack{\infty \\ \infty}}^{\infty}$

$\stackrel{\circ}{\circ}$

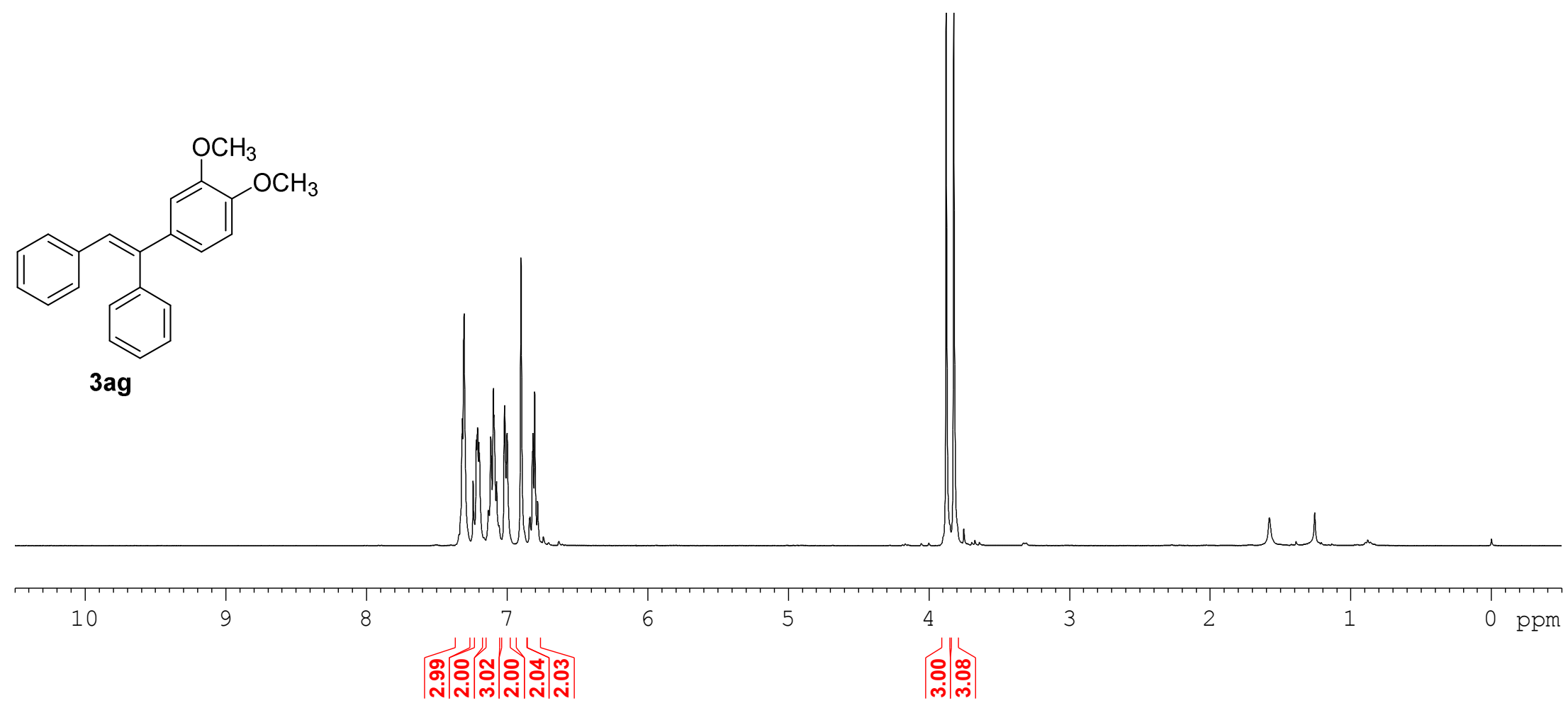

mirim 


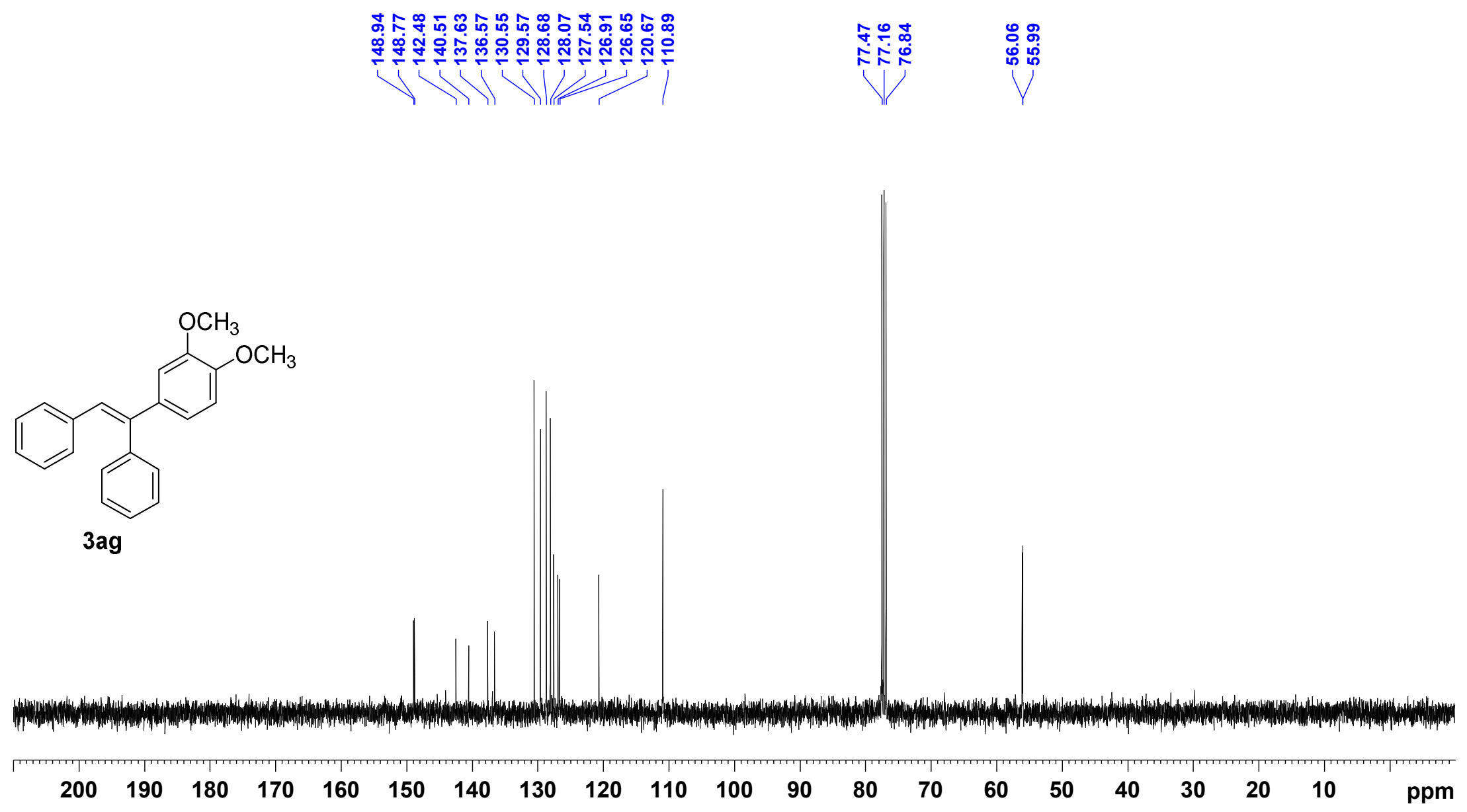




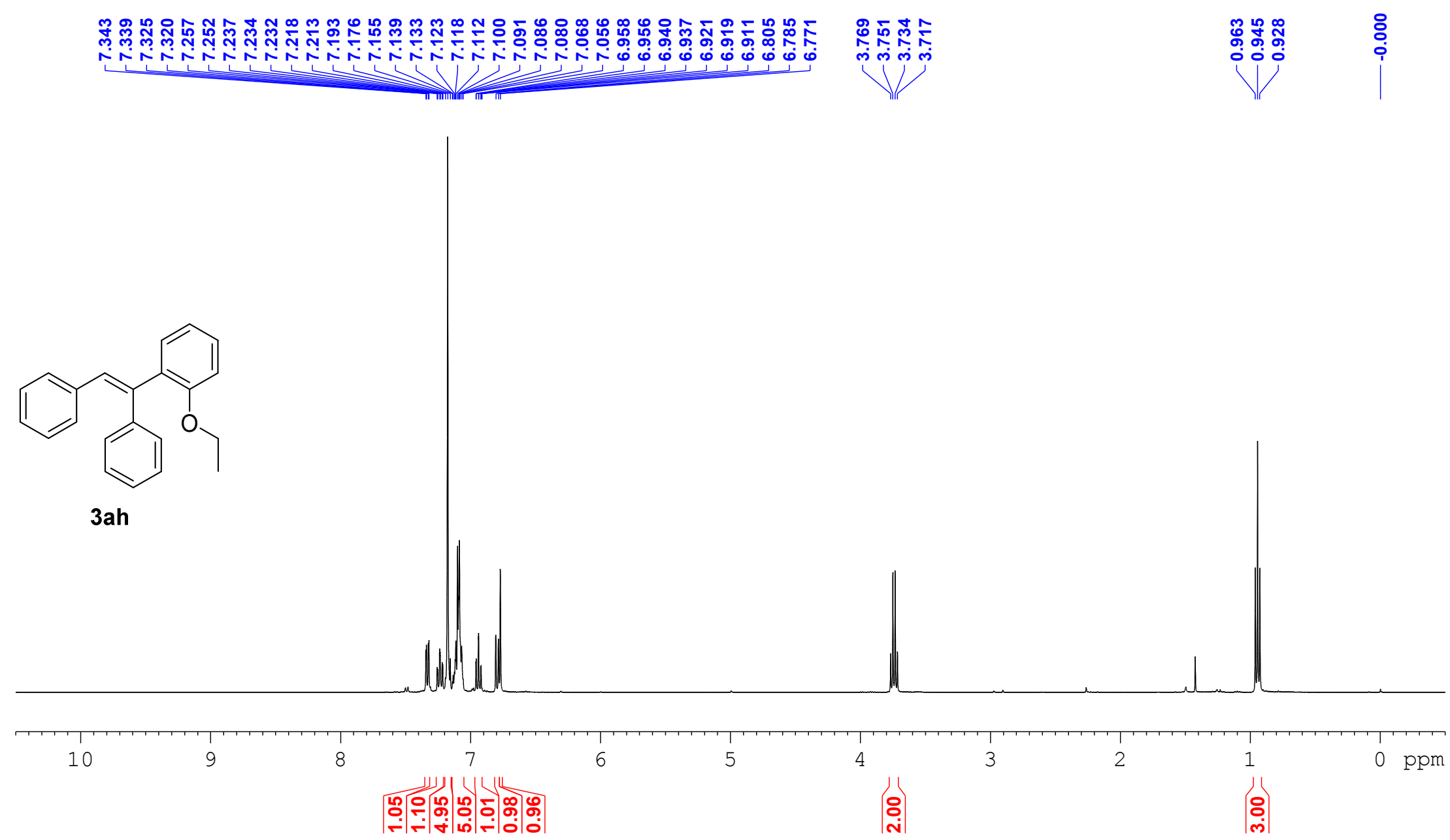




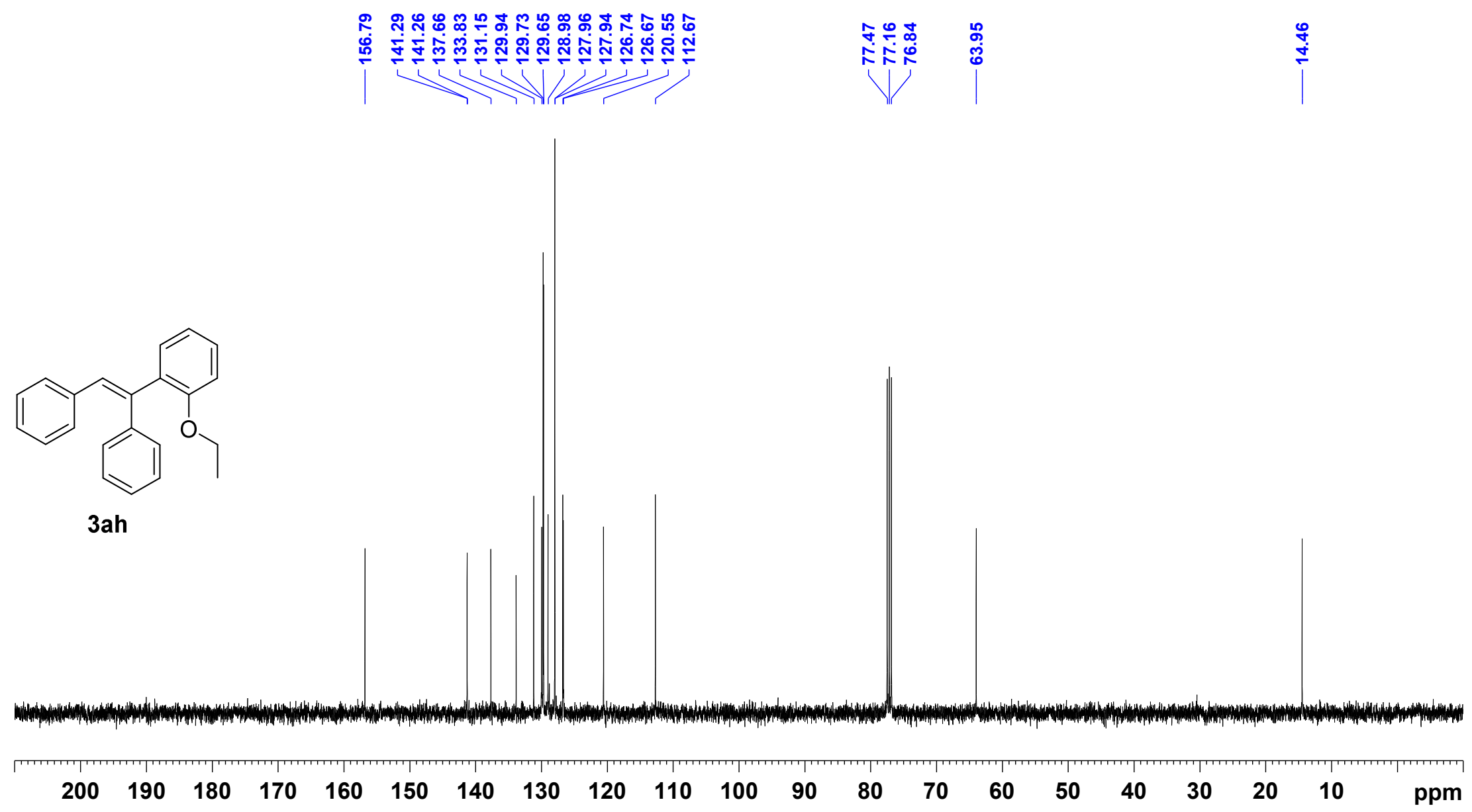




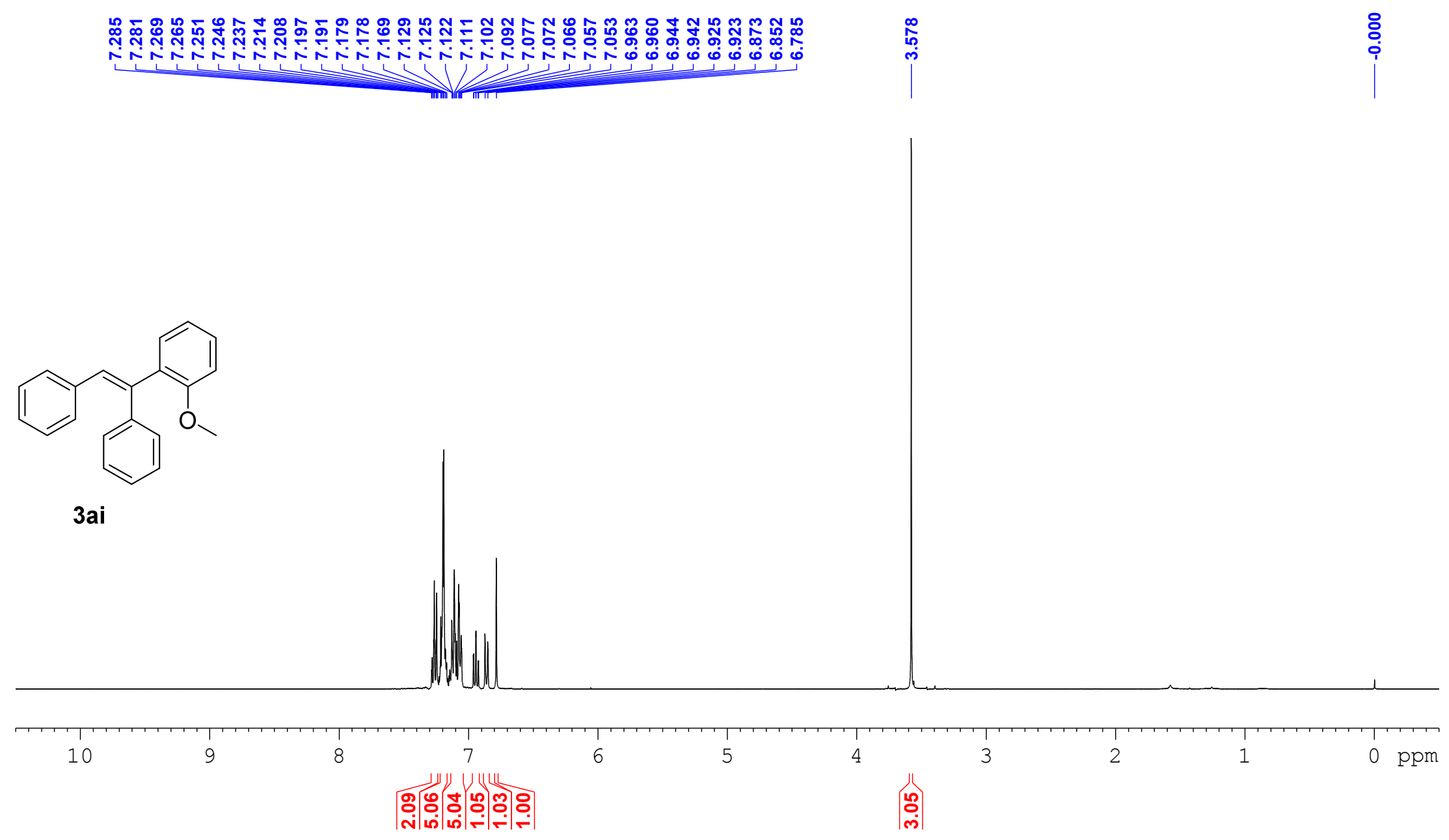




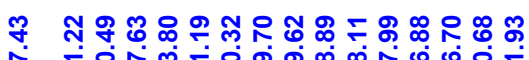

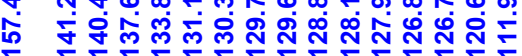

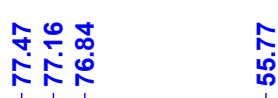

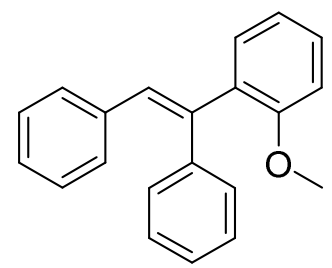

3ai

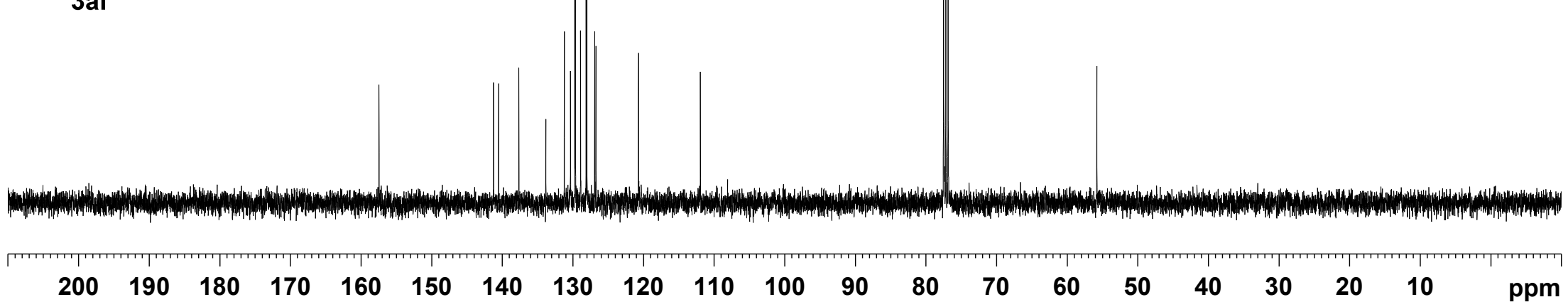




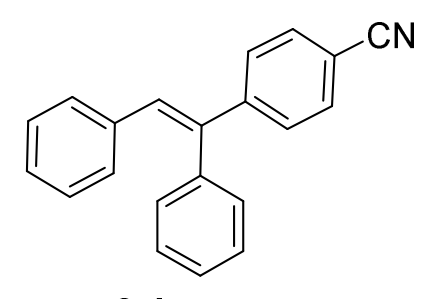

3aj

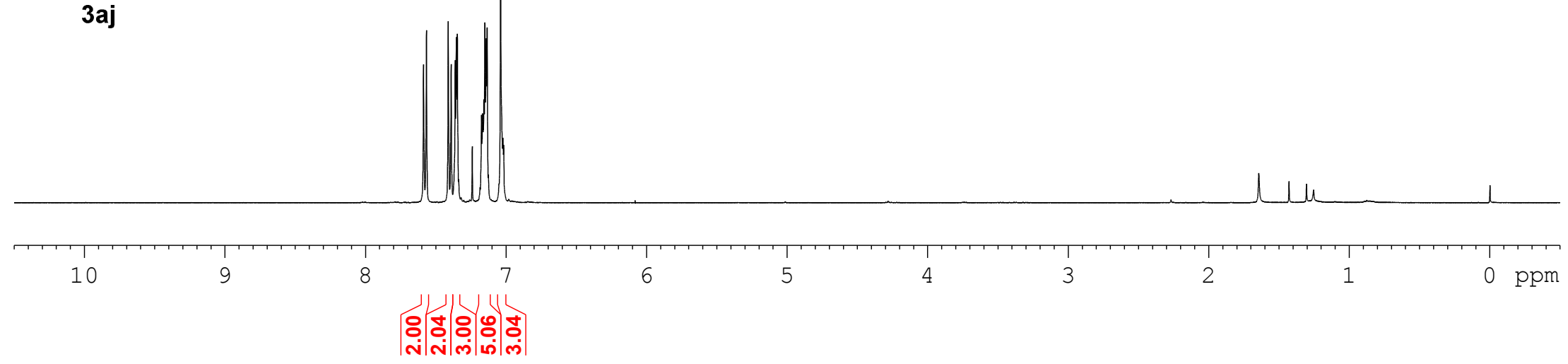




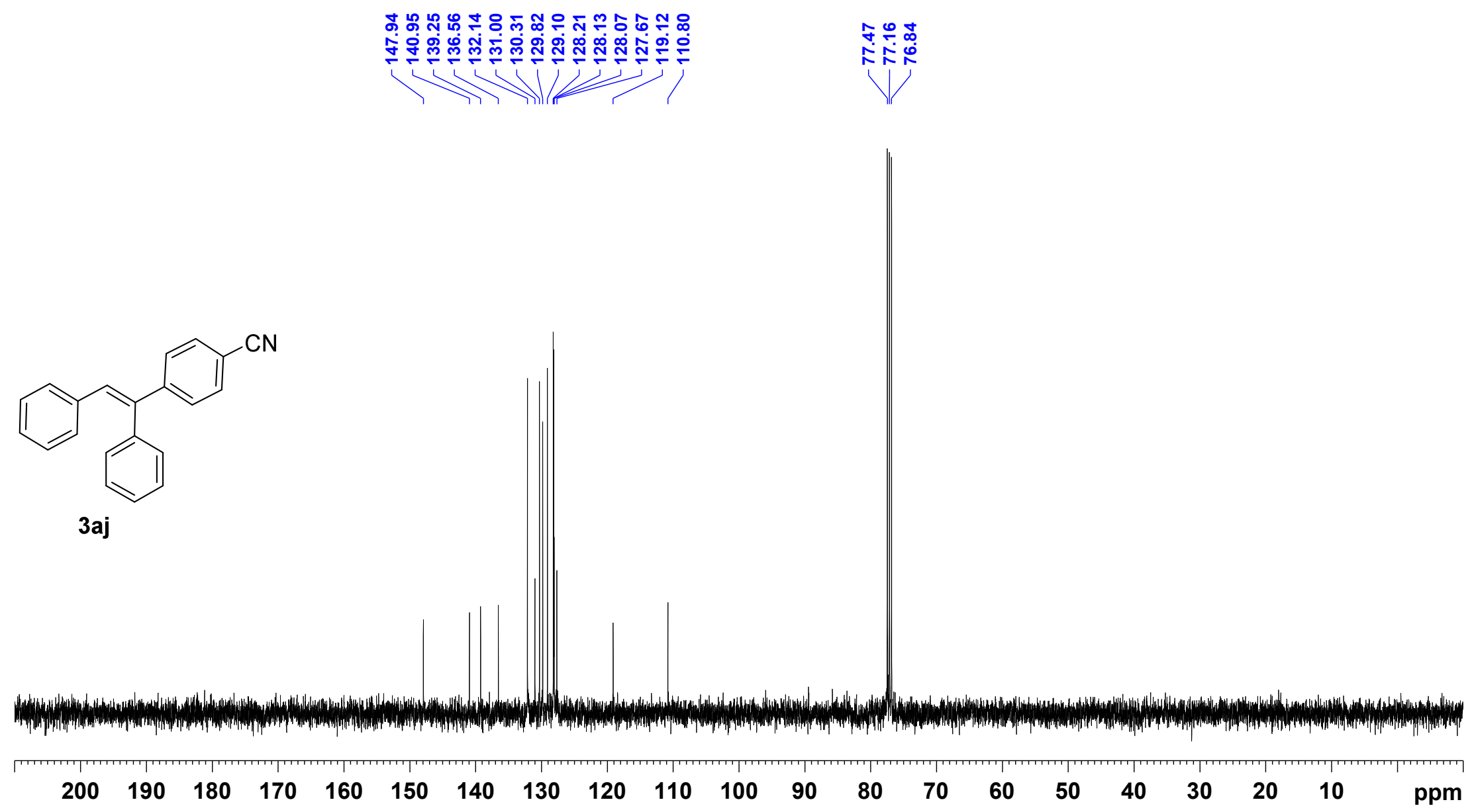




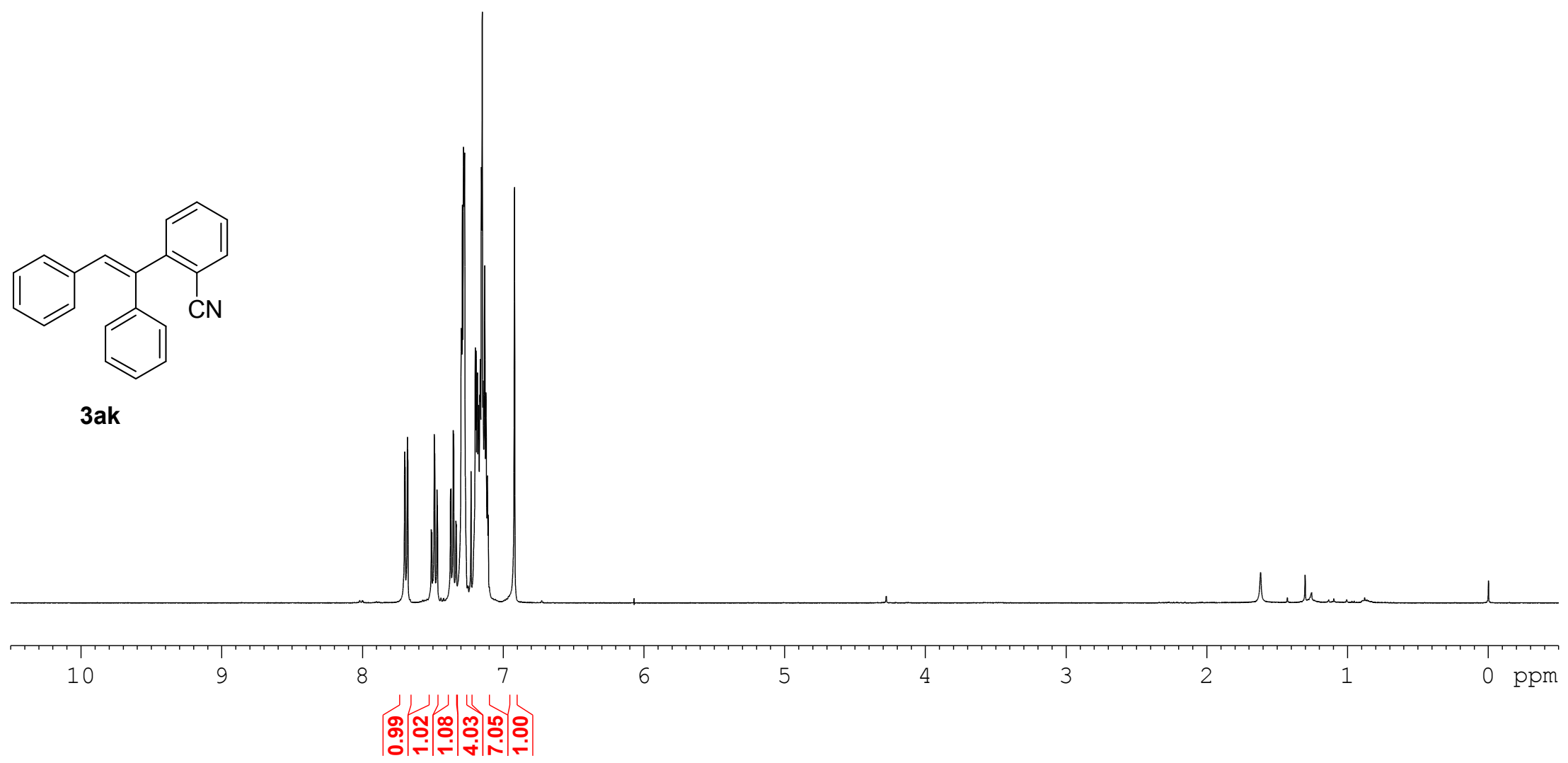




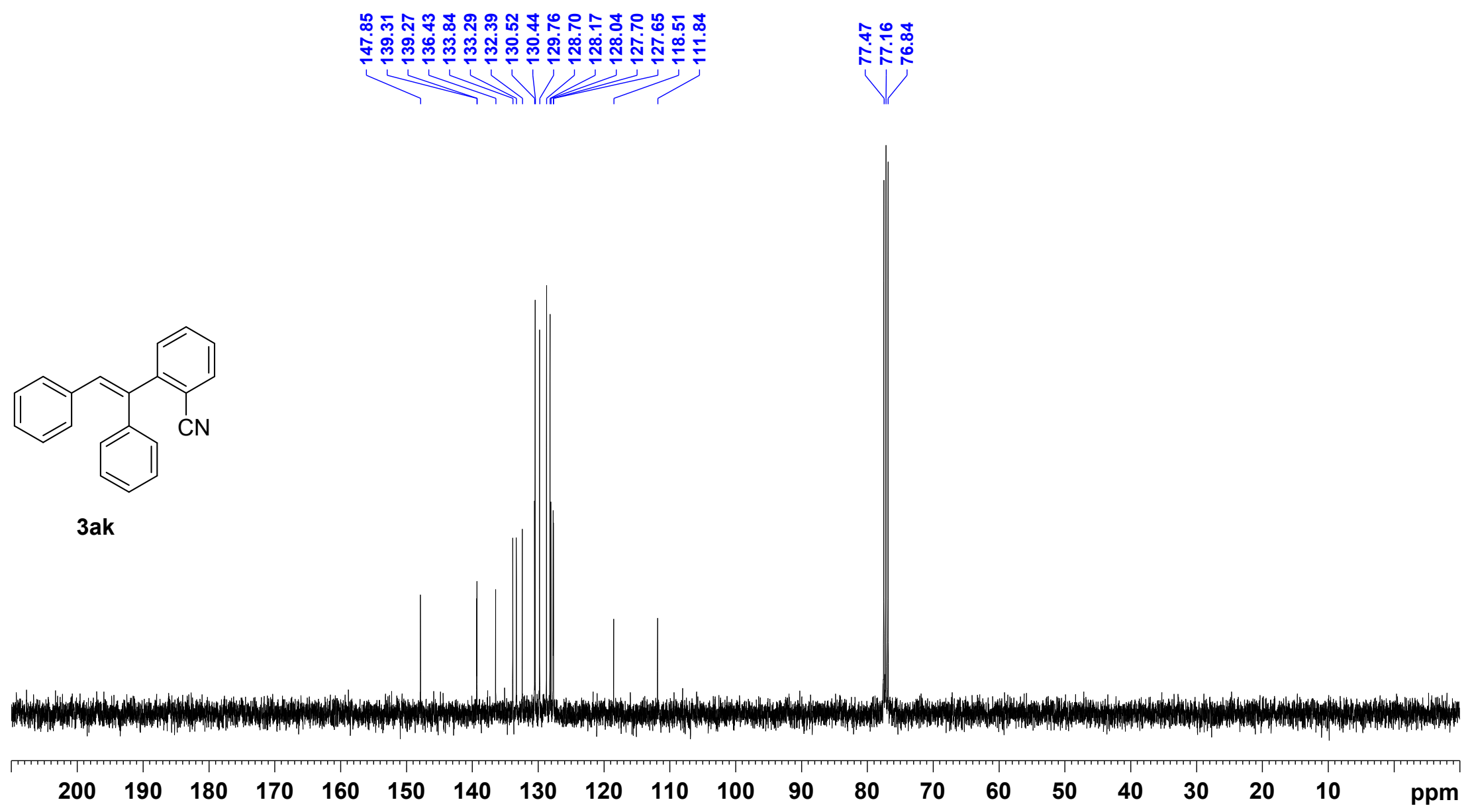




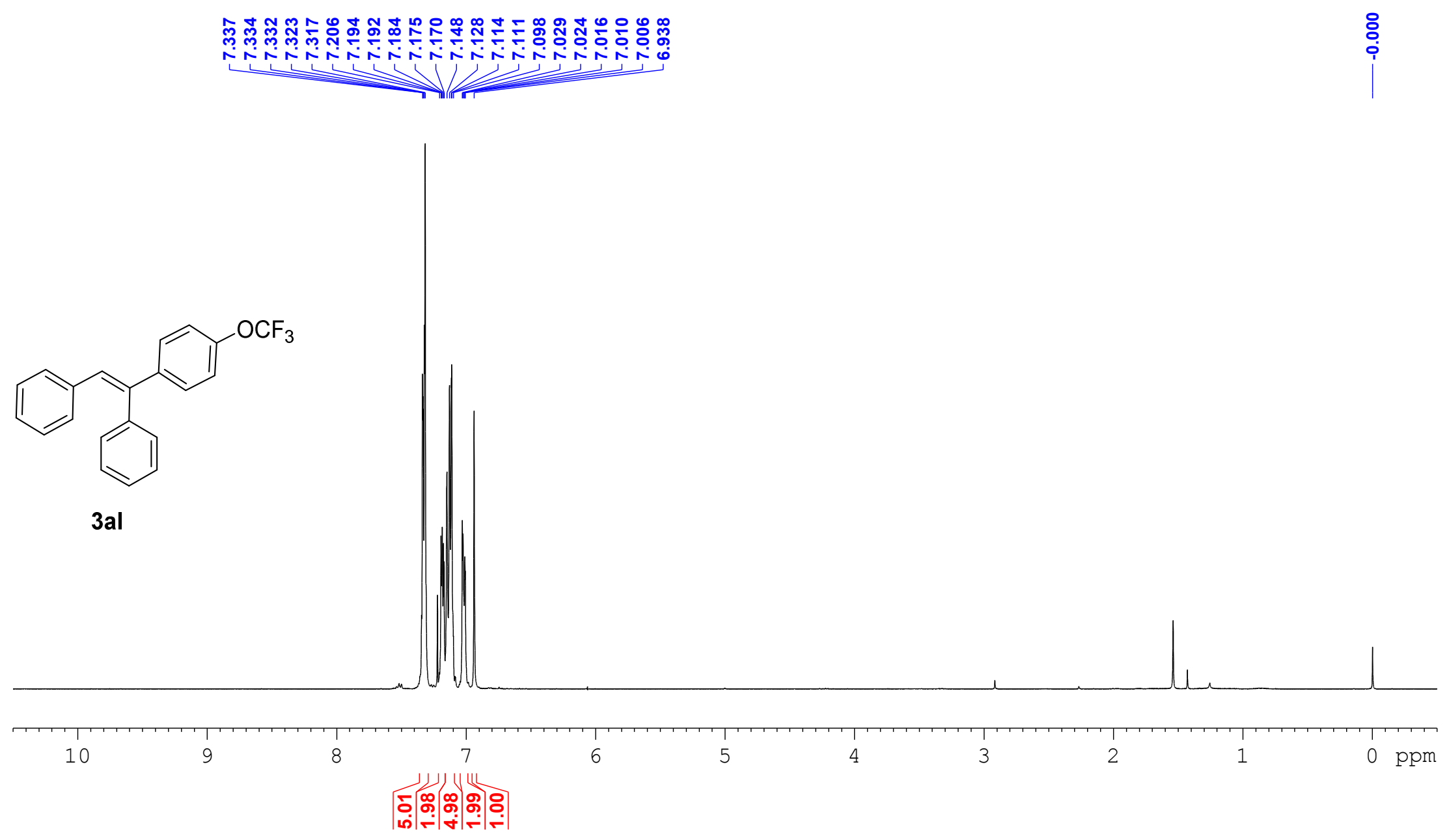




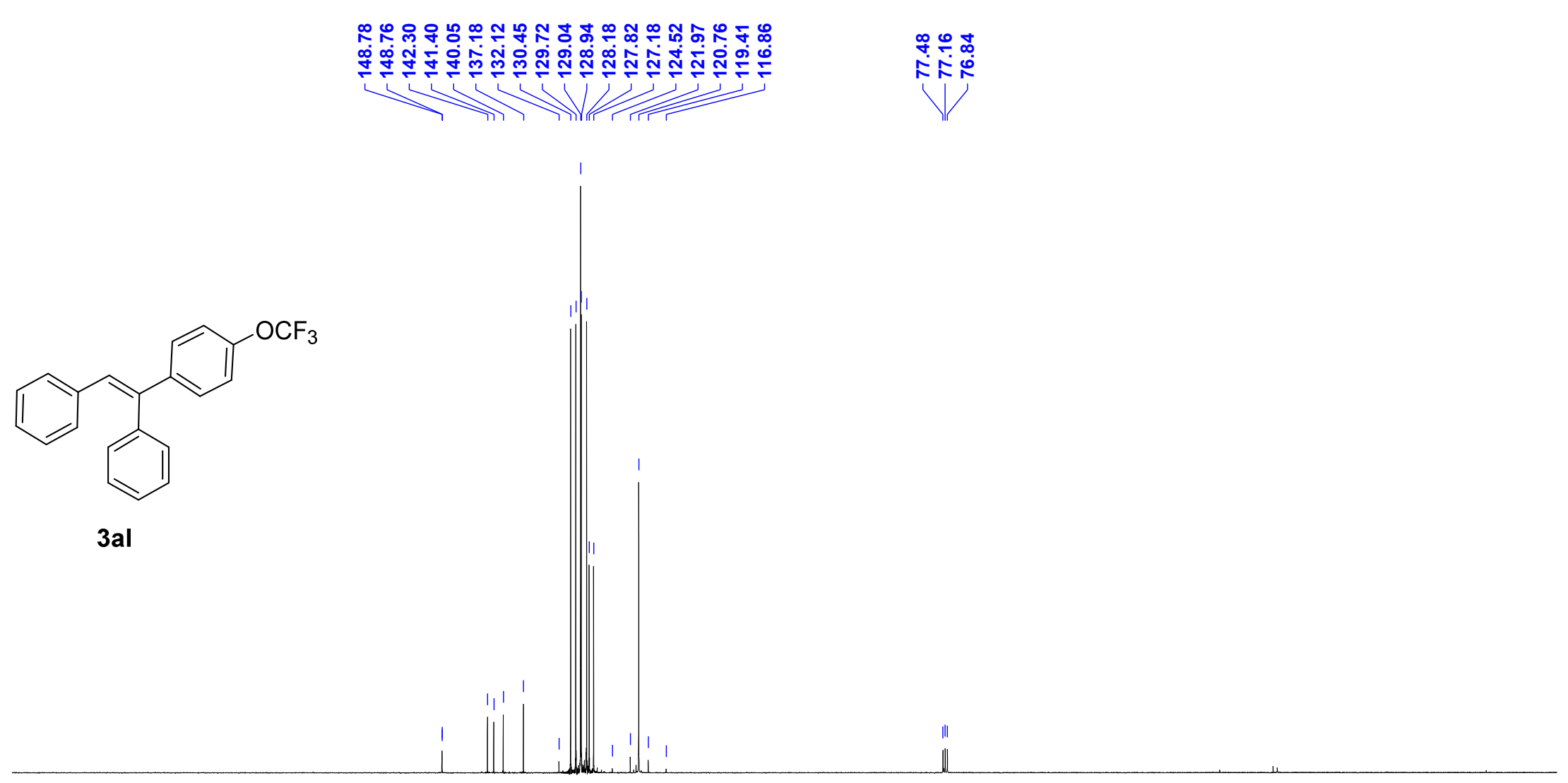

100

807

60

5040

$40 \quad 30$

$20 \quad 10$

ppm 


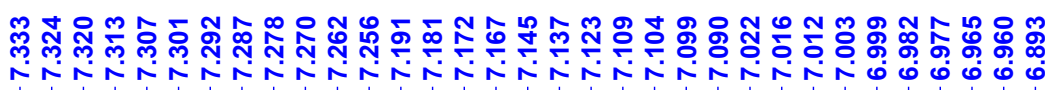

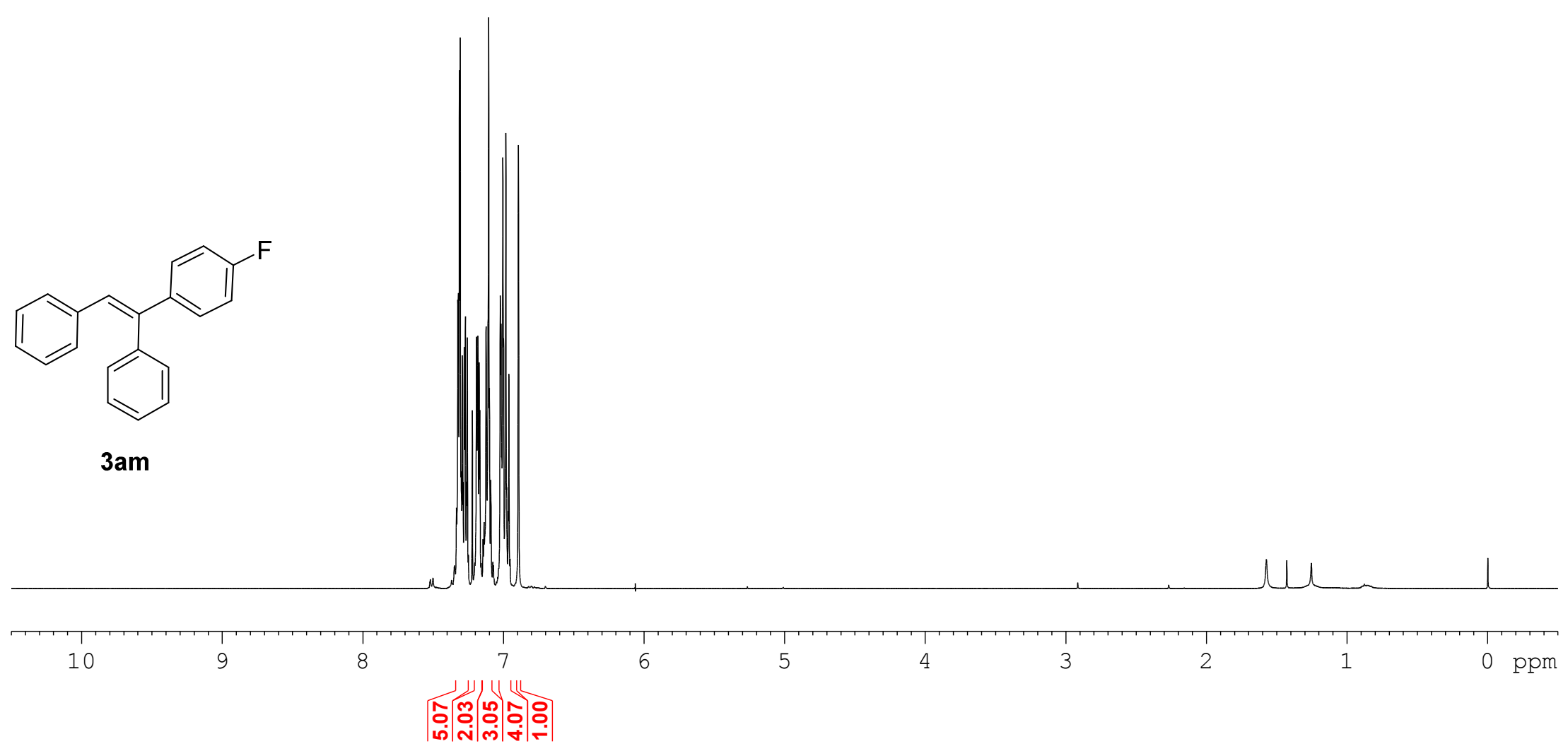




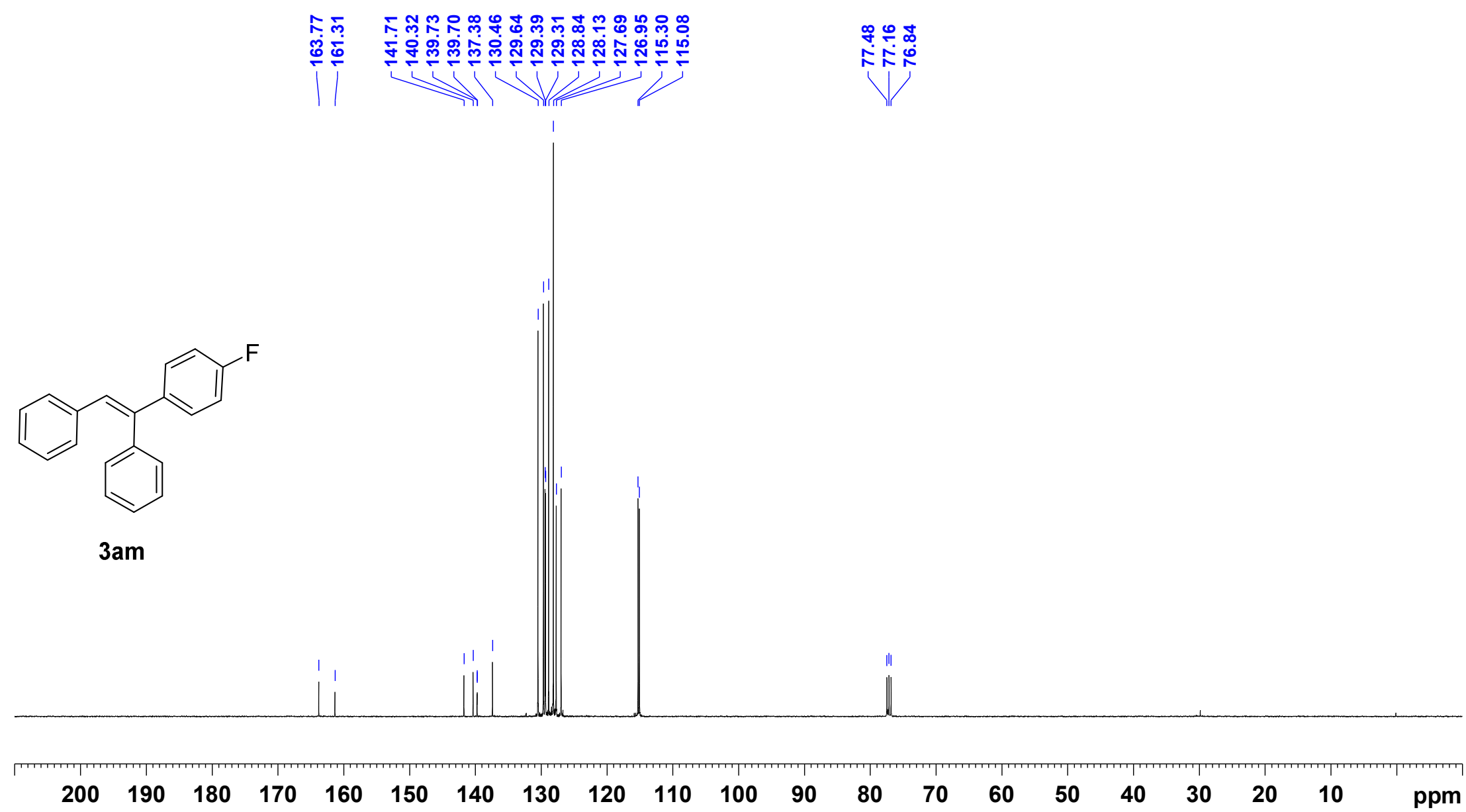




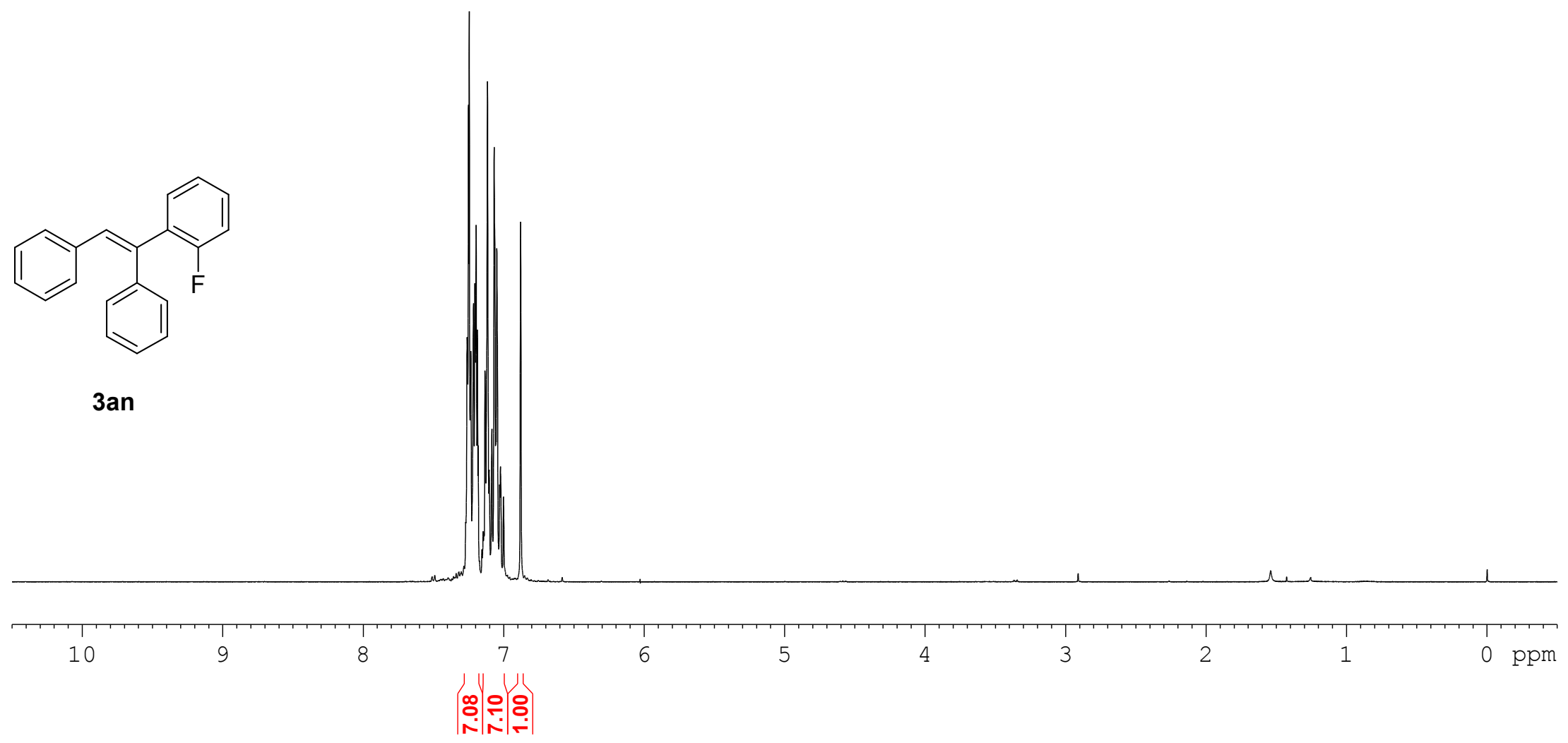




\section{定究}

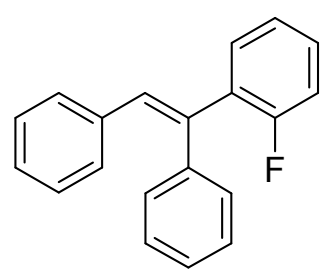

3an

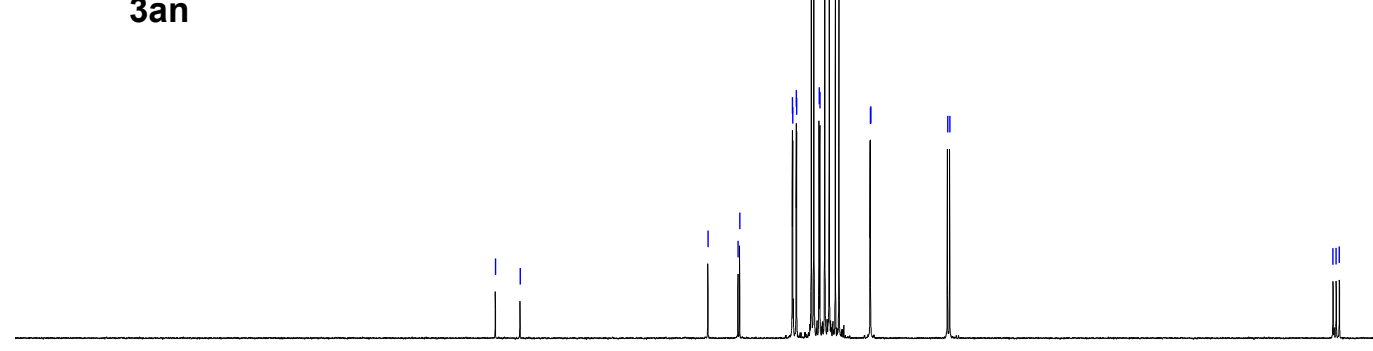

$\begin{array}{llllllll}200 & 190 & 180 & 170 & 160 & 150 & 140 & 130\end{array}$

120110

90

80

60

50

4030

2010

ppm 


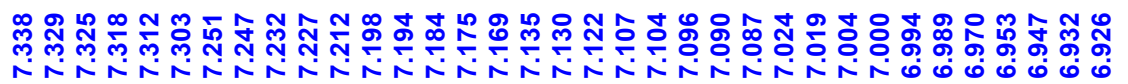

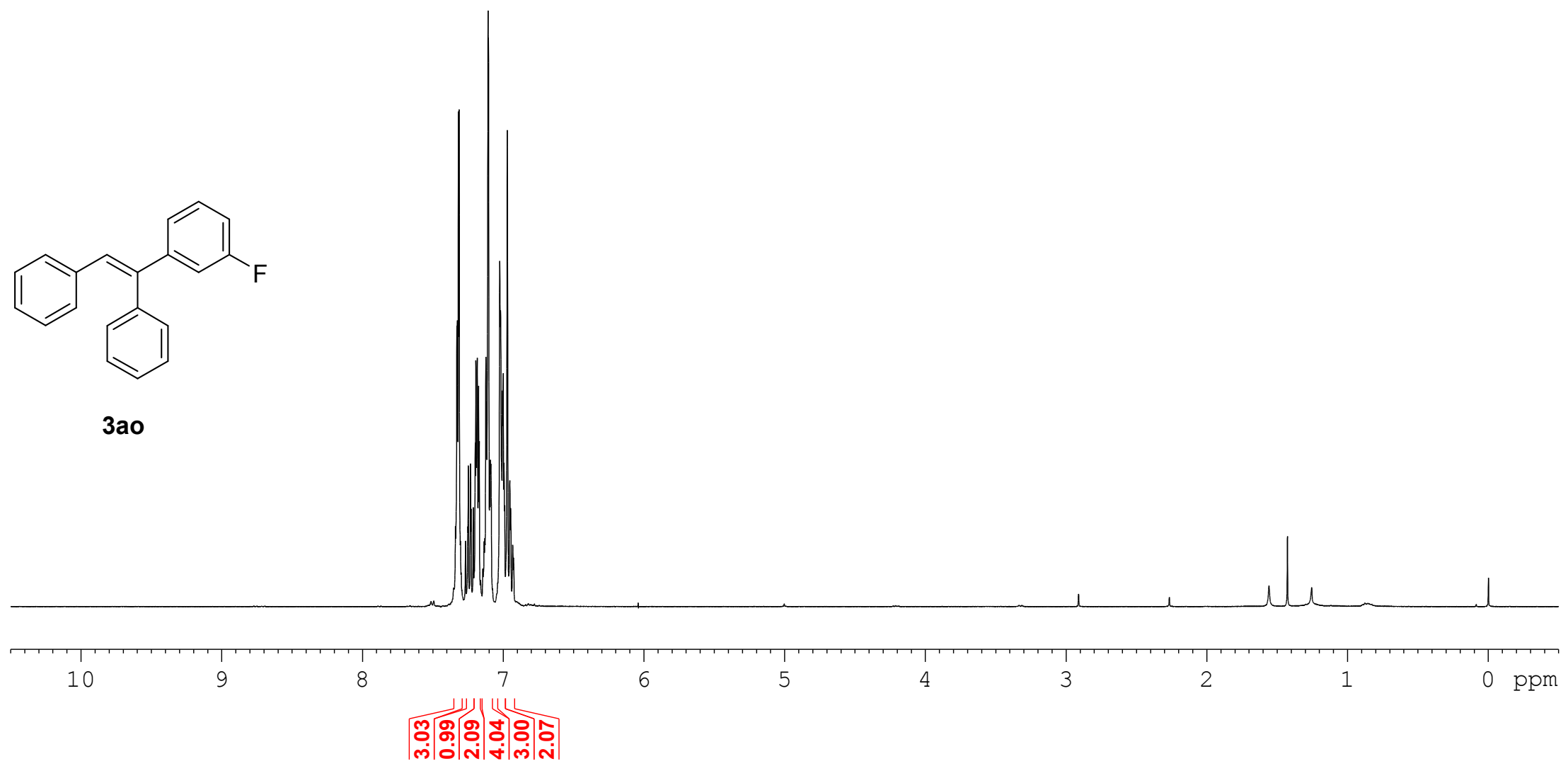




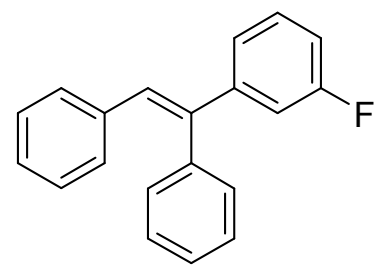

$3 a o$

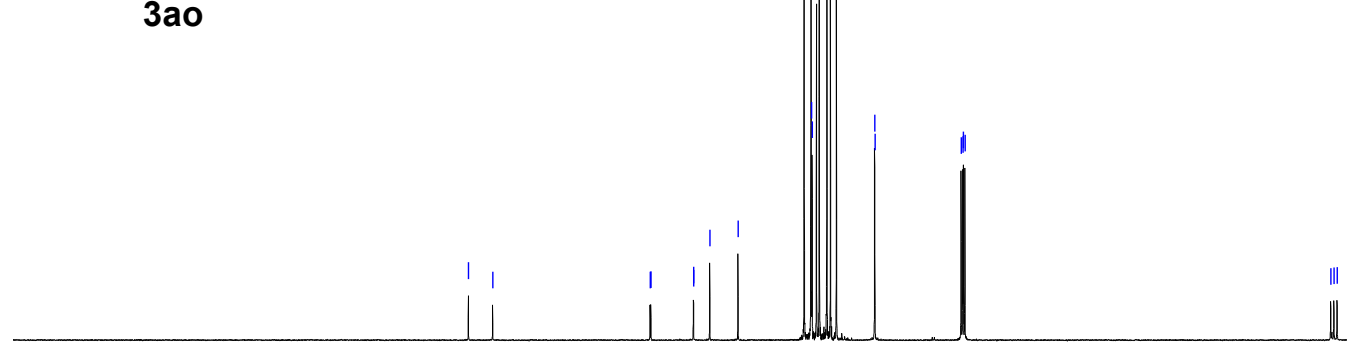

ppm 


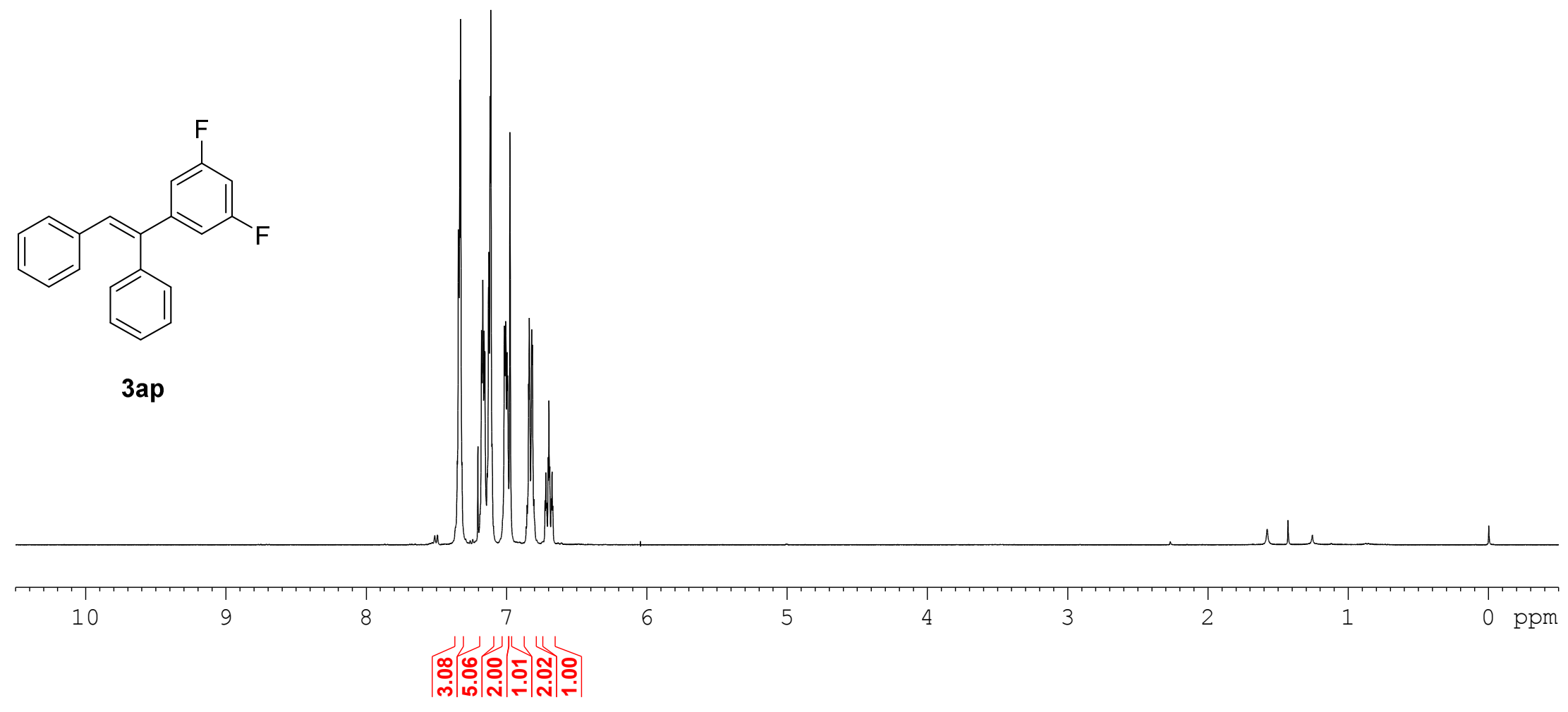




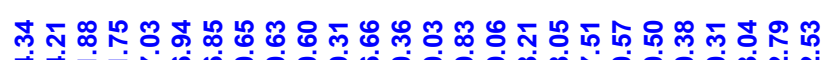

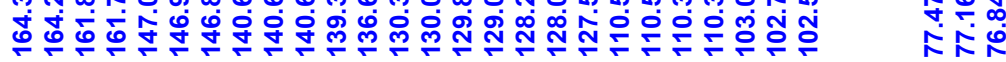

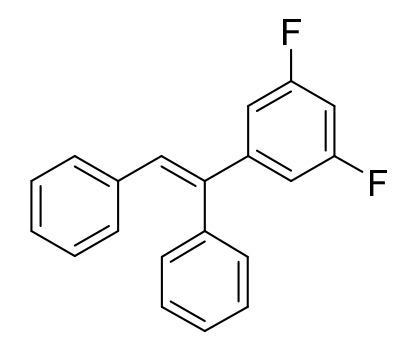

3ap

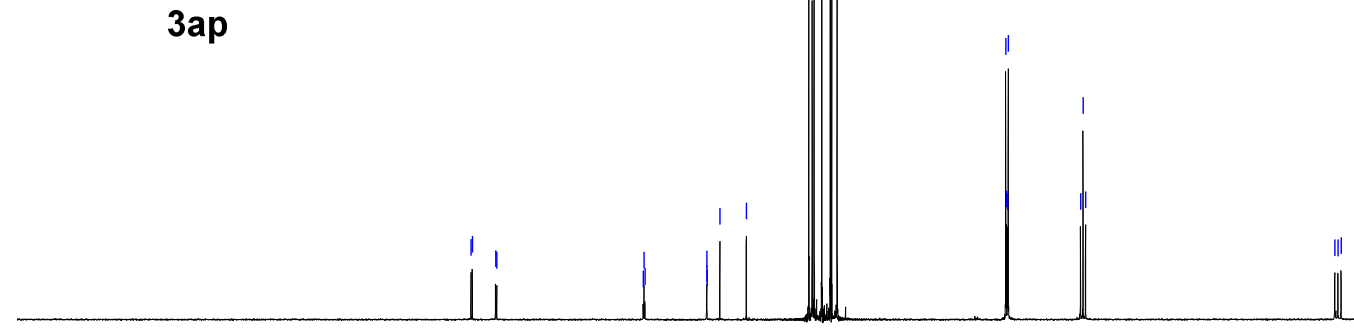

200

ppm 


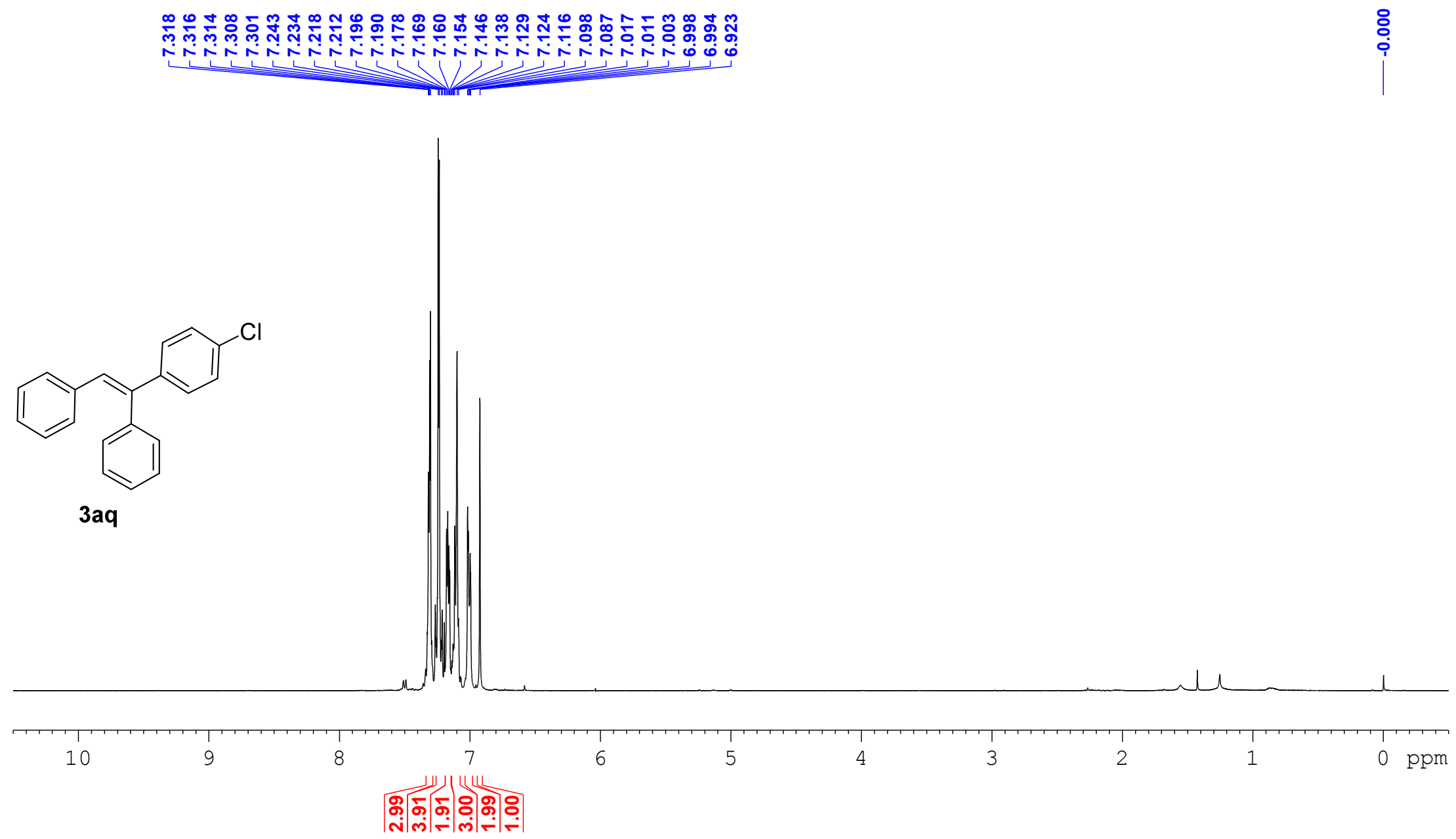




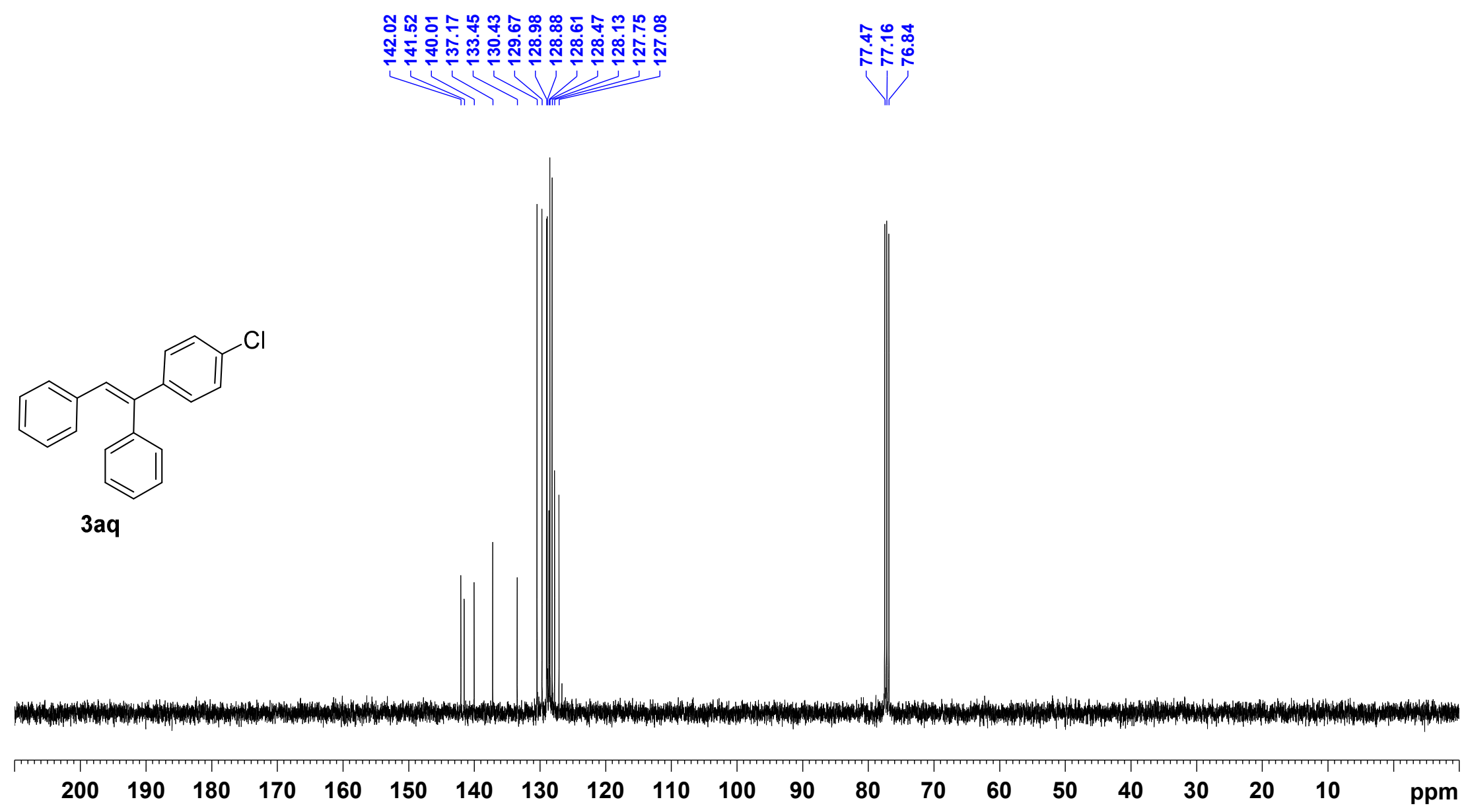




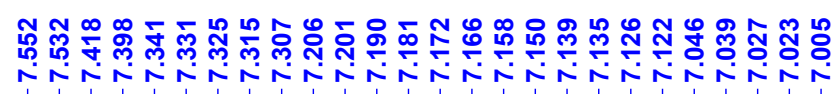

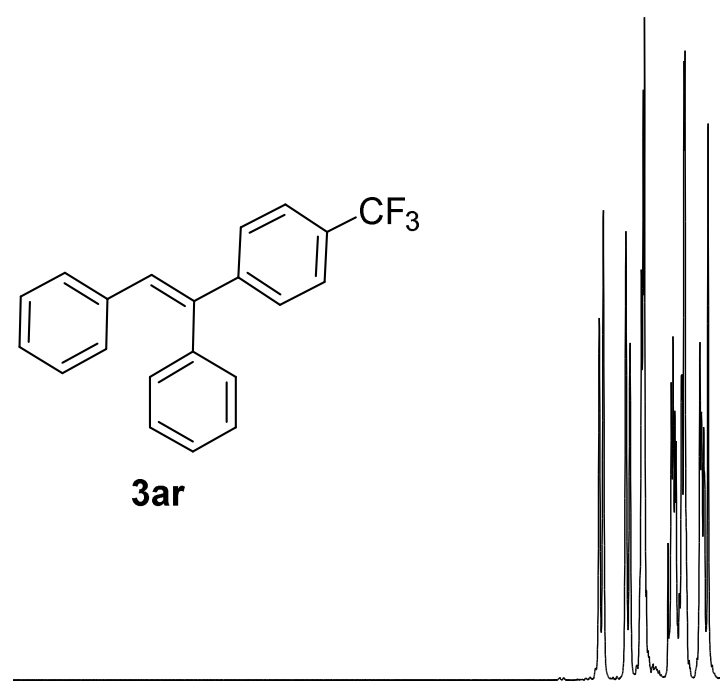



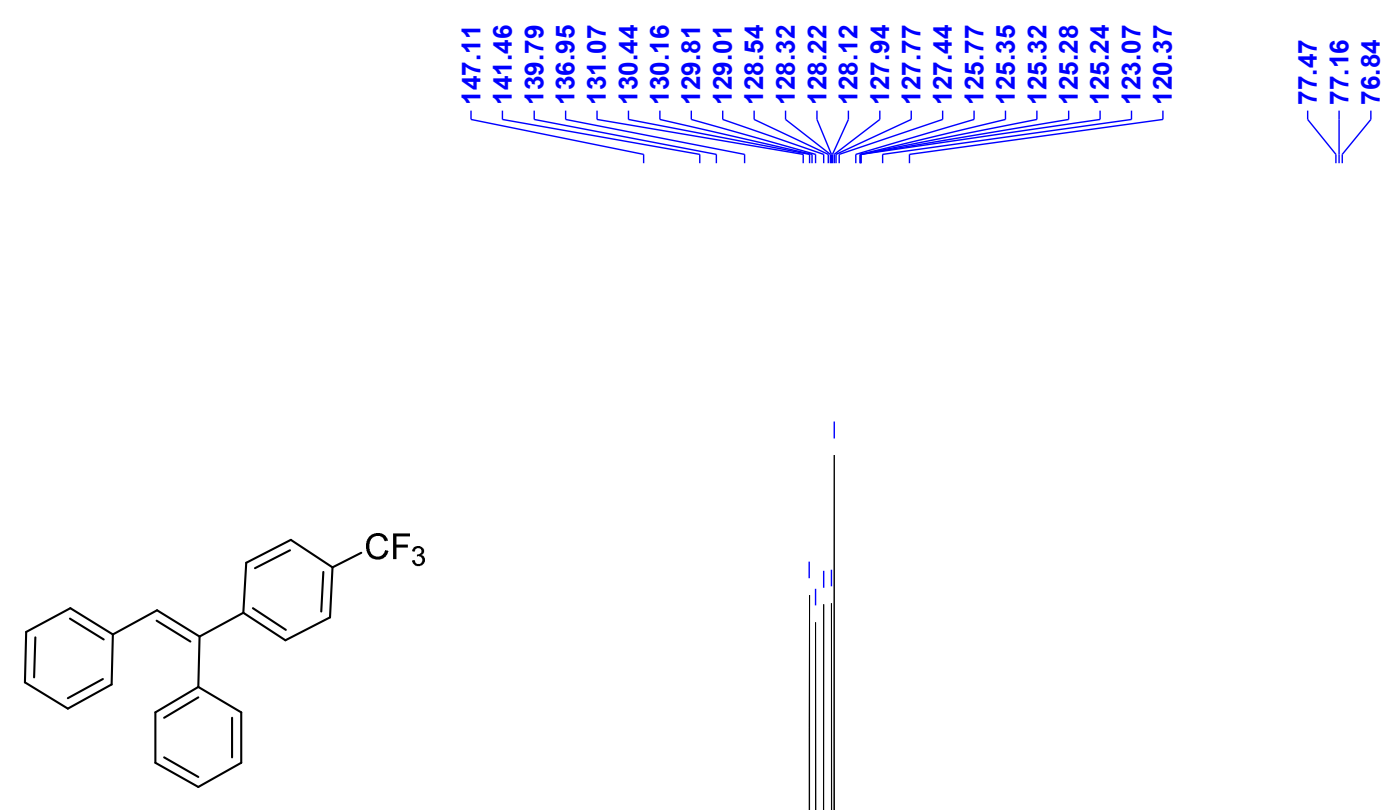

3ar

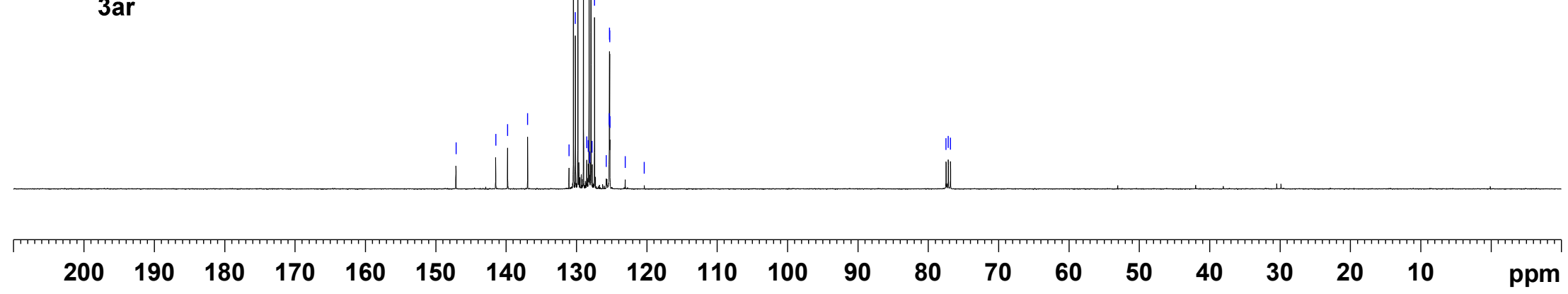




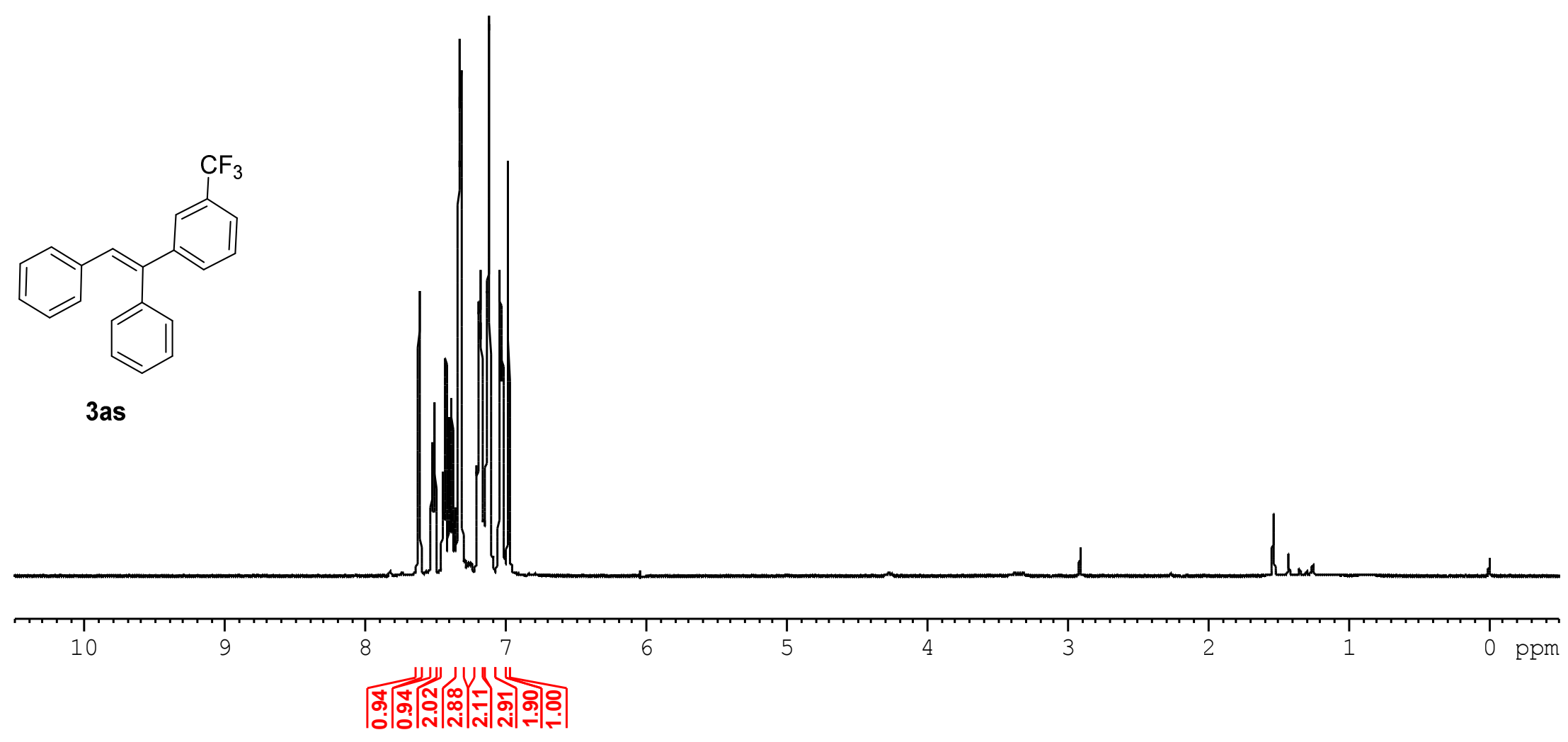




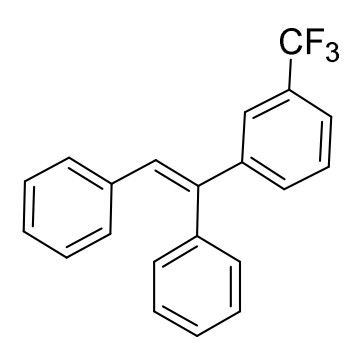

3as

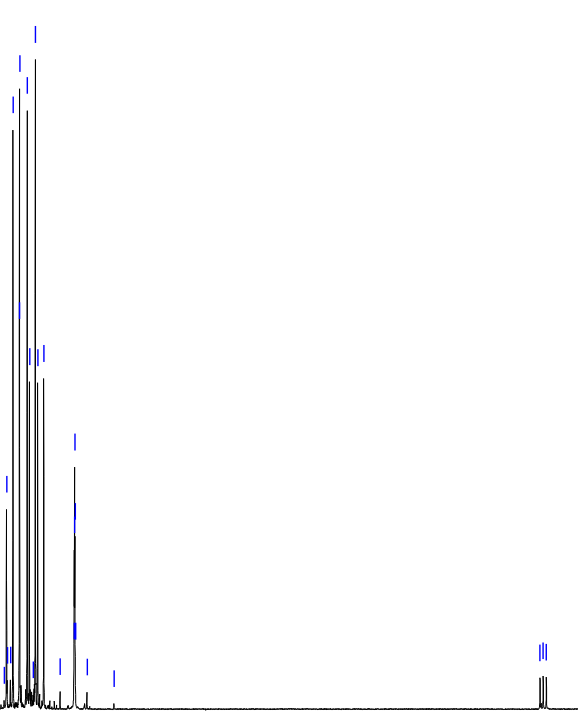




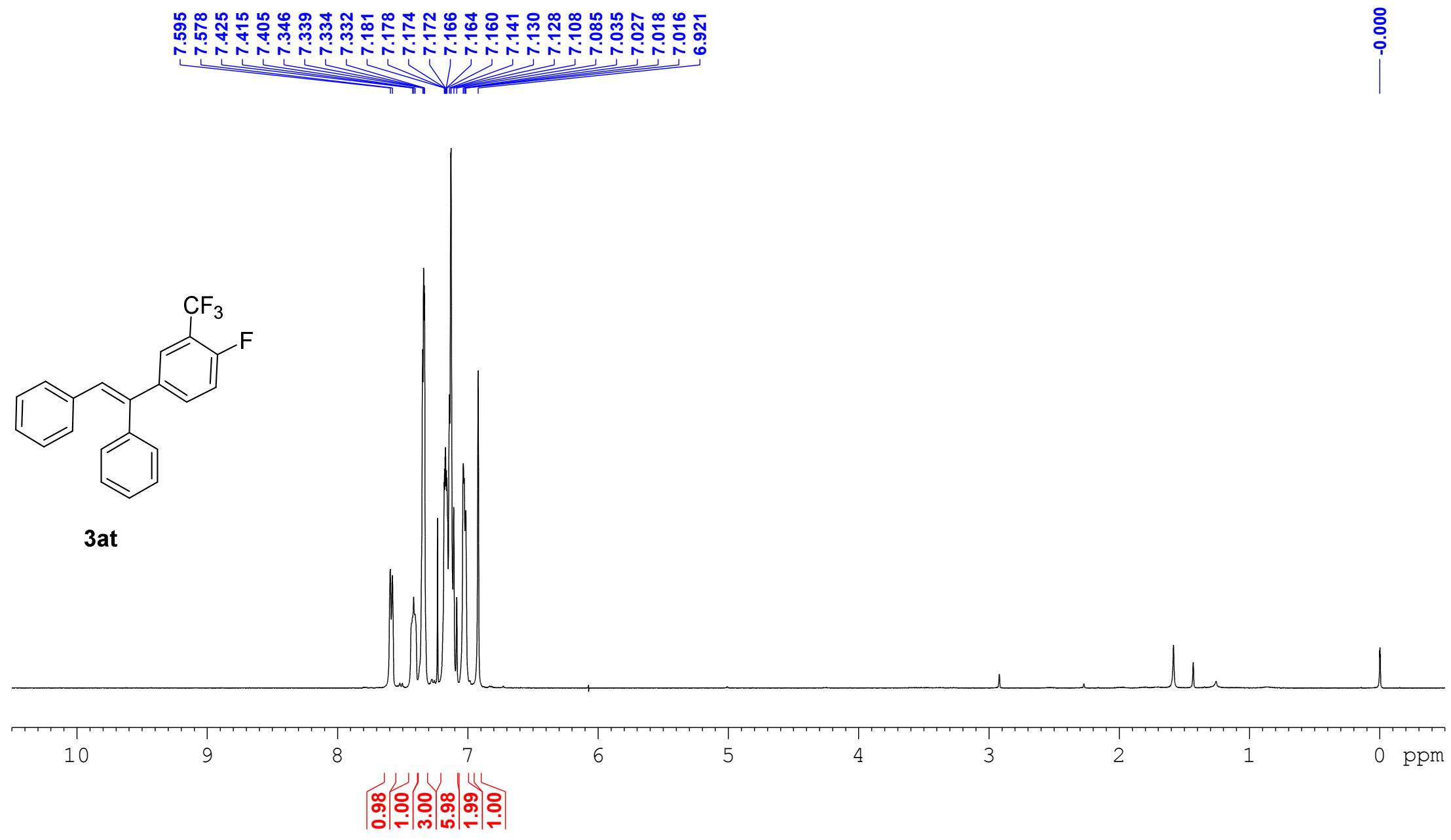



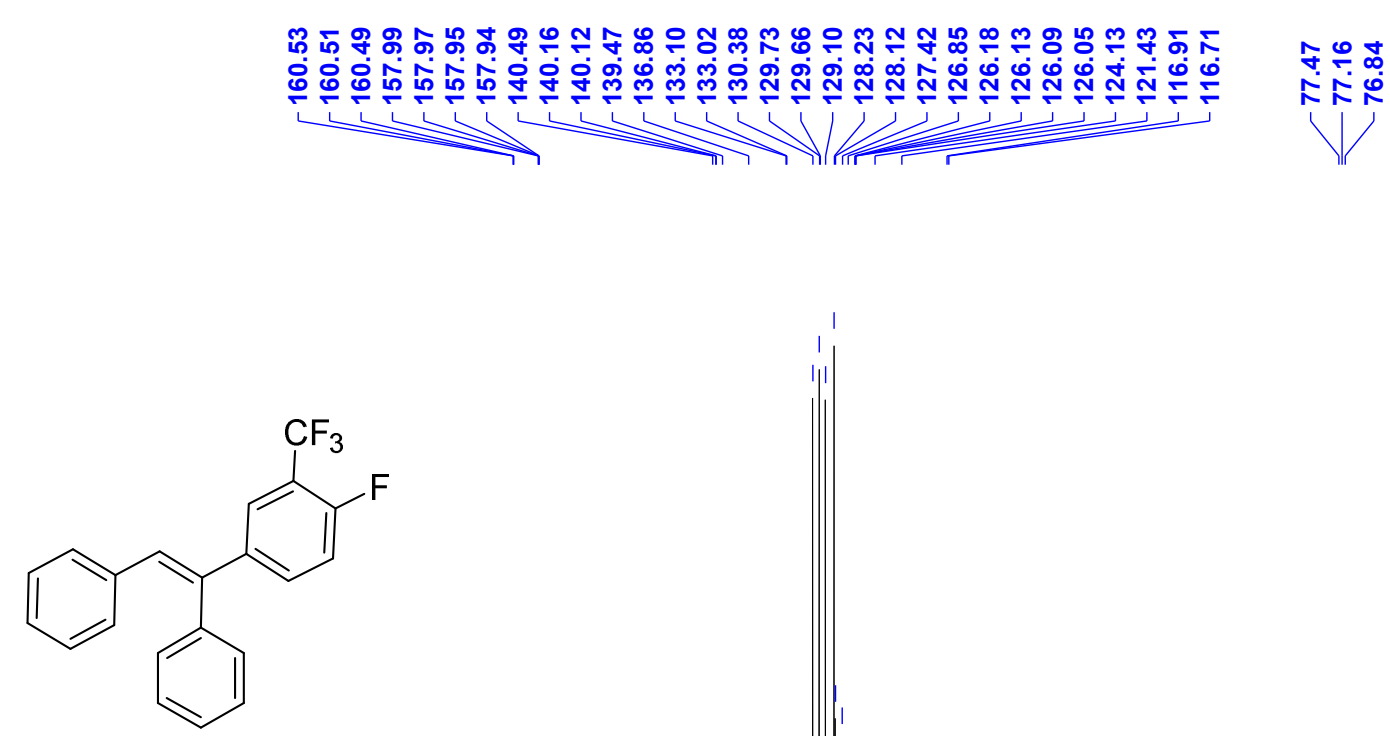

3at

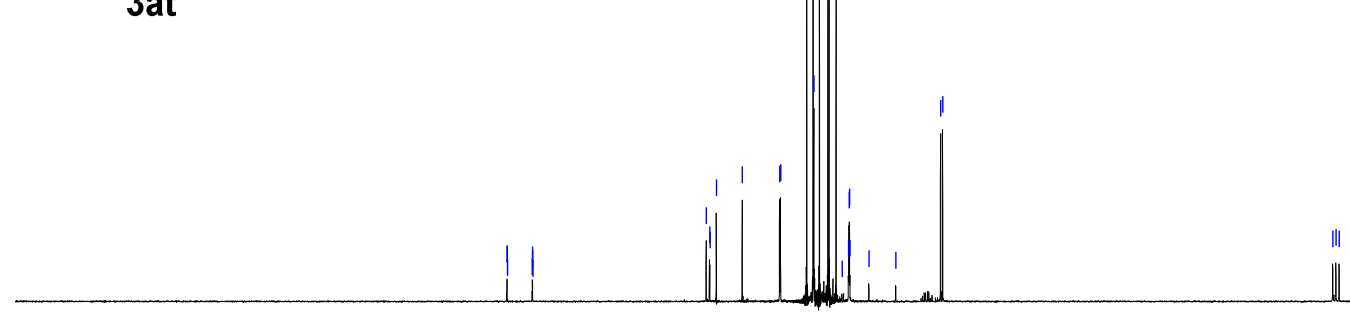

$\begin{array}{lllllll}200 & 190 & 180 & 170 & 160 & 150 & 140\end{array}$

$120110 \quad 100$

90

8070

60

50

$40 \quad 30$

$20 \quad 10$

ppm 


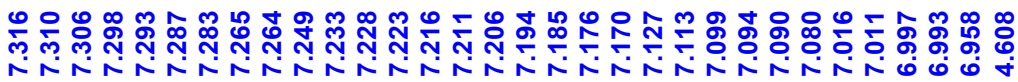

(I)

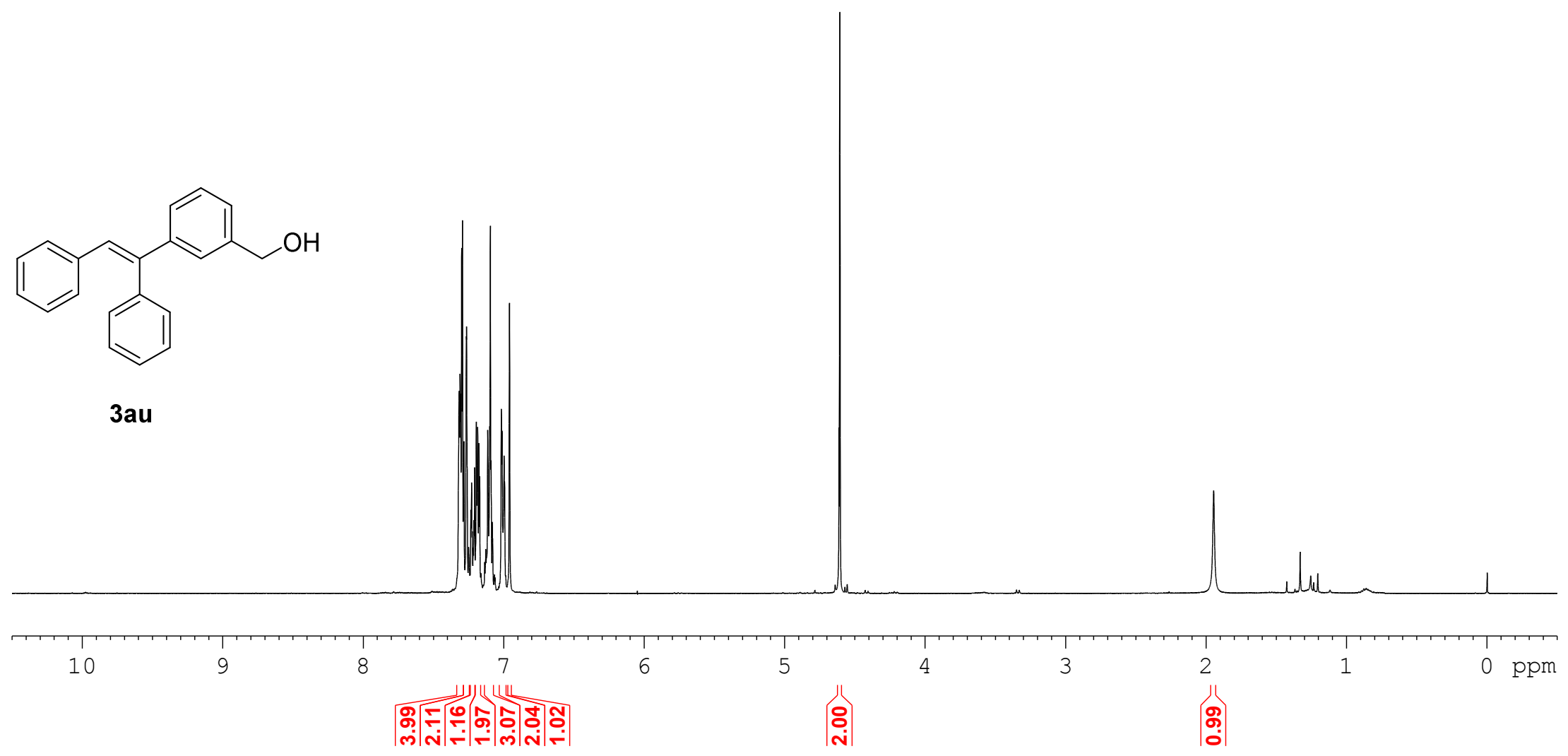




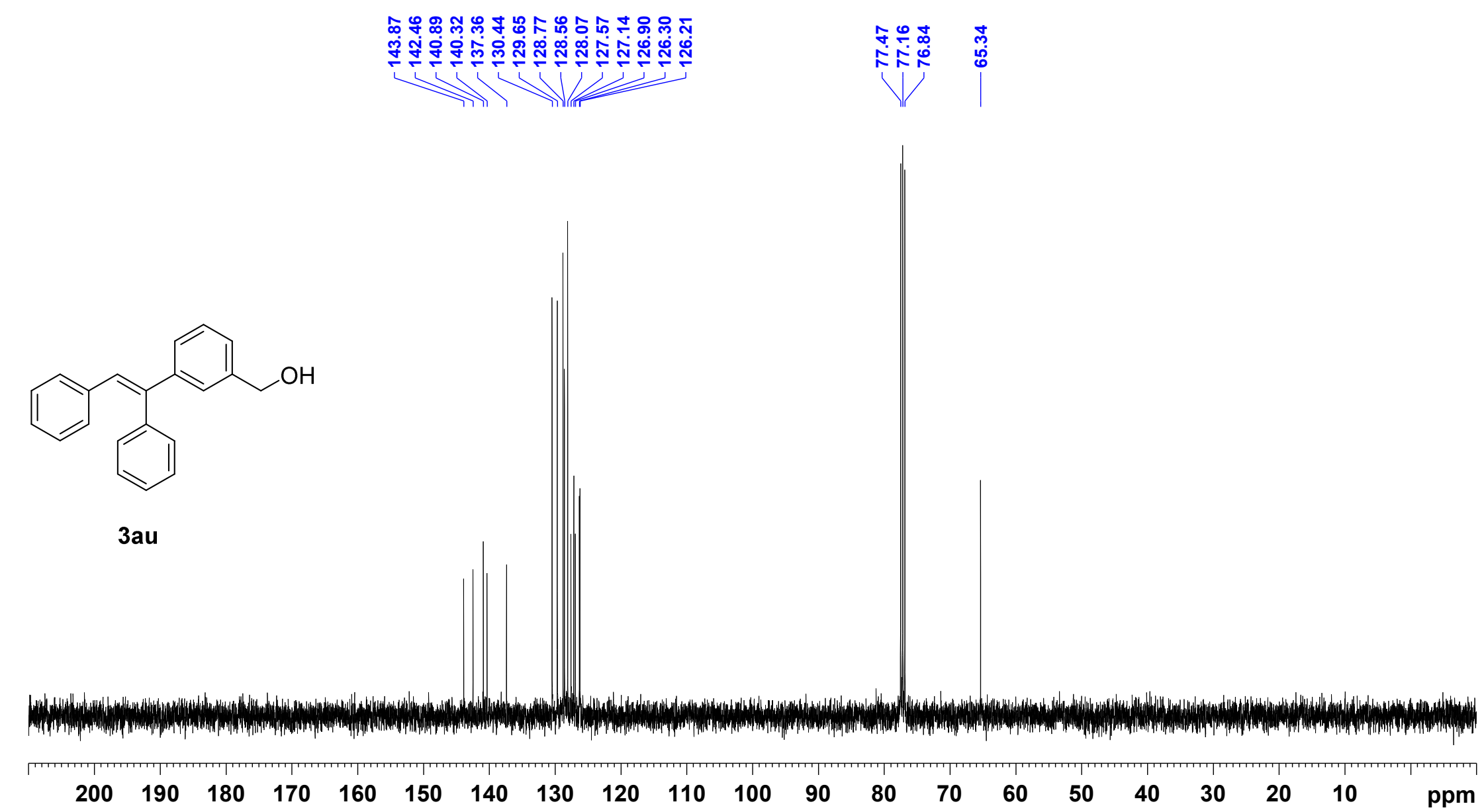




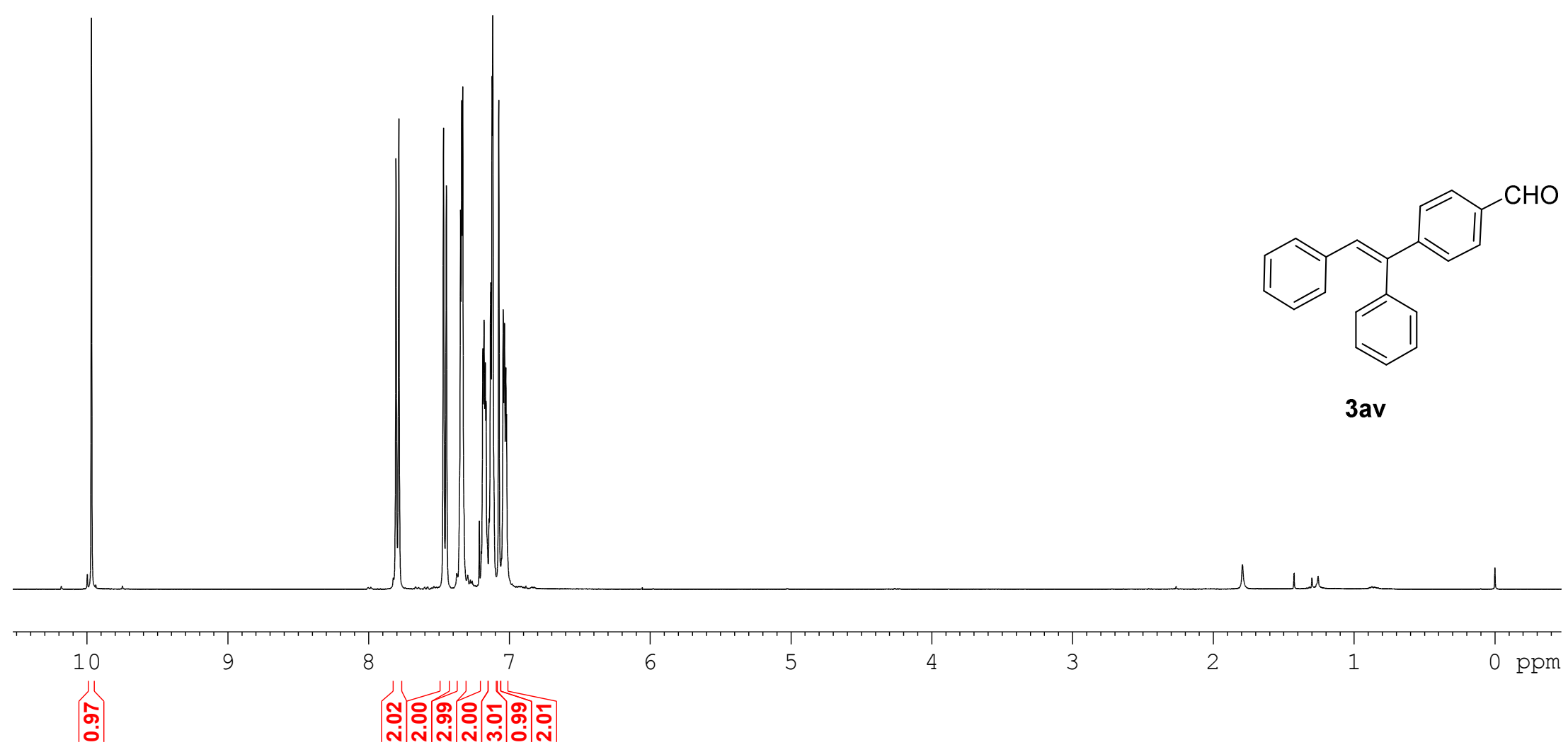




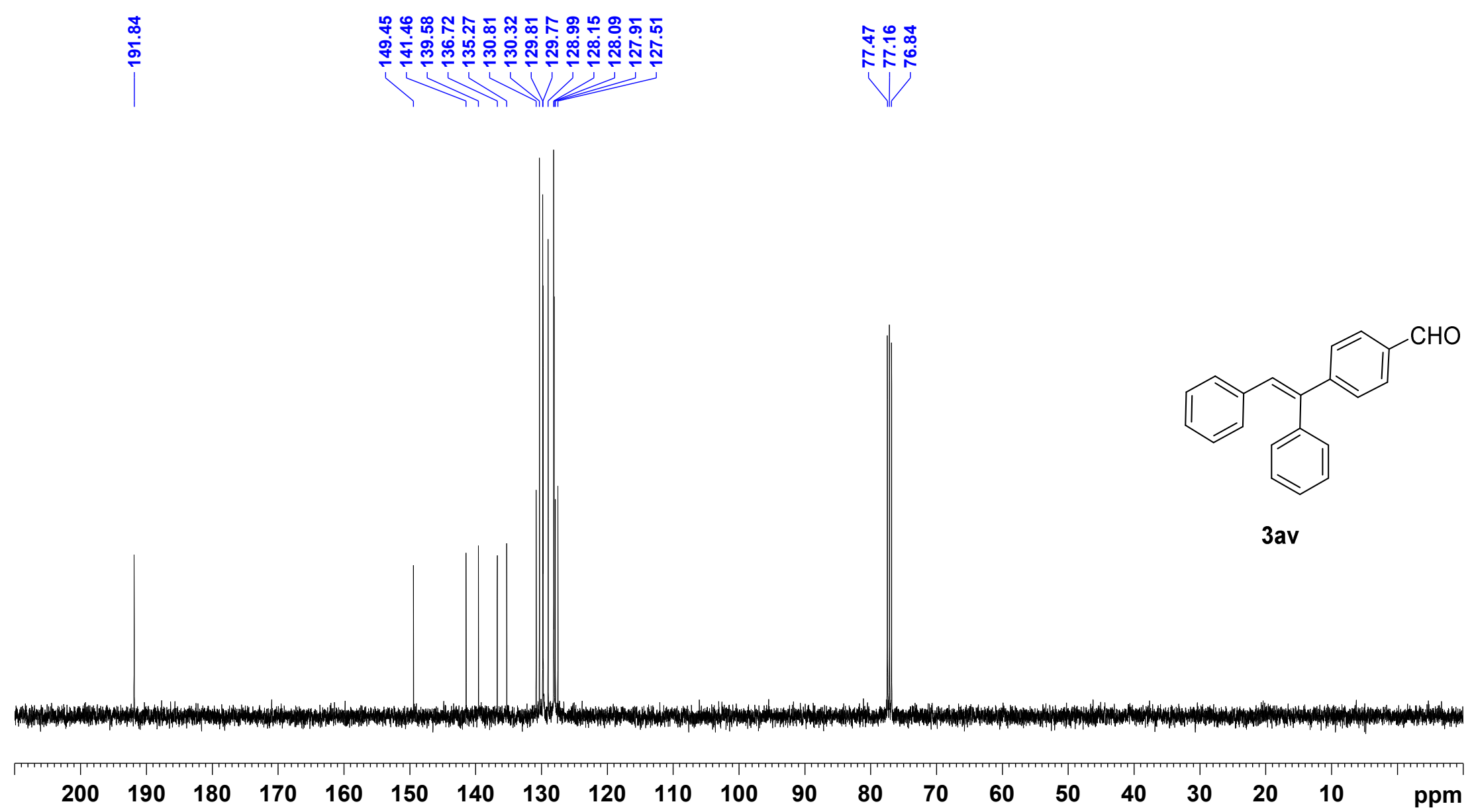




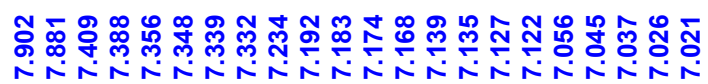

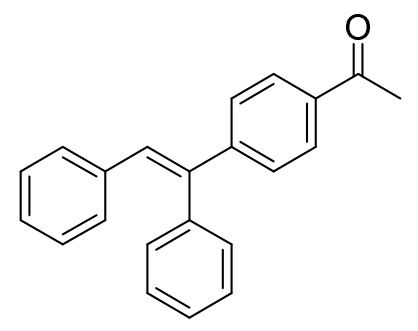

3aw

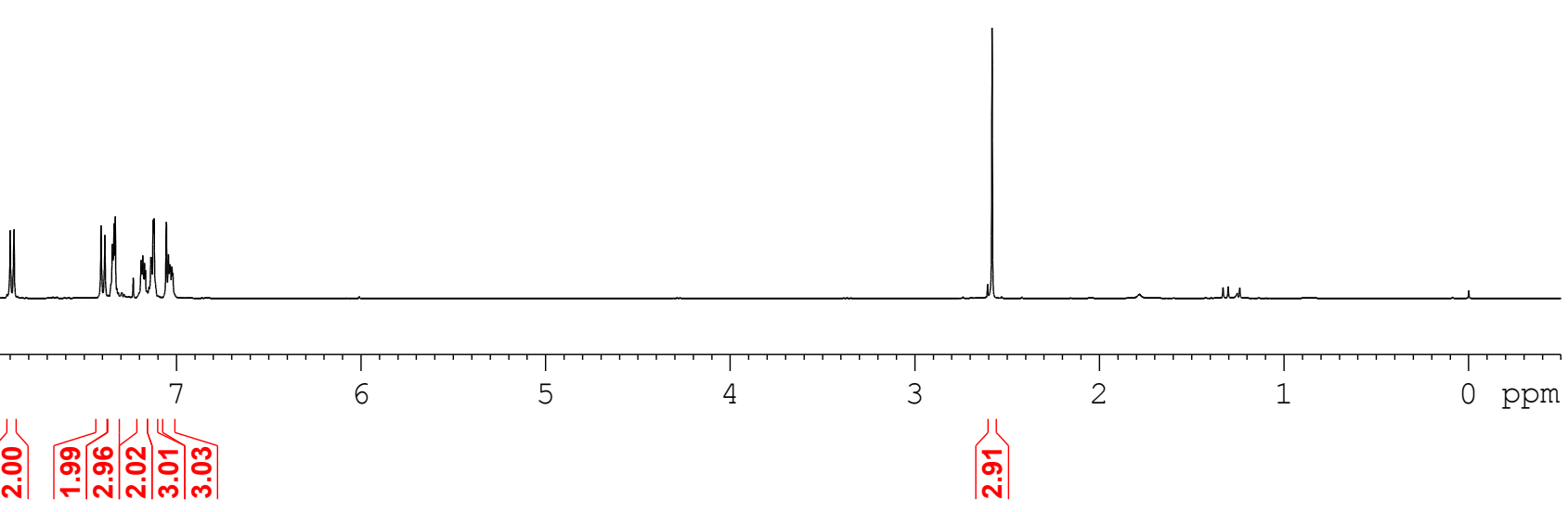




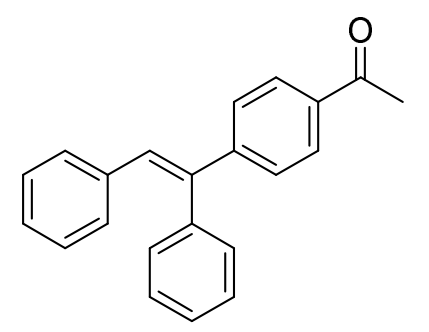

3aw

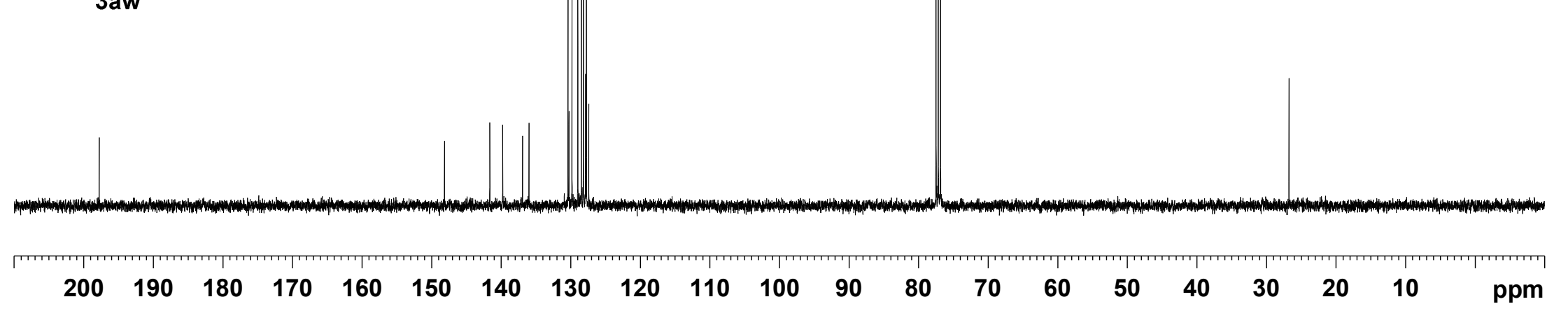




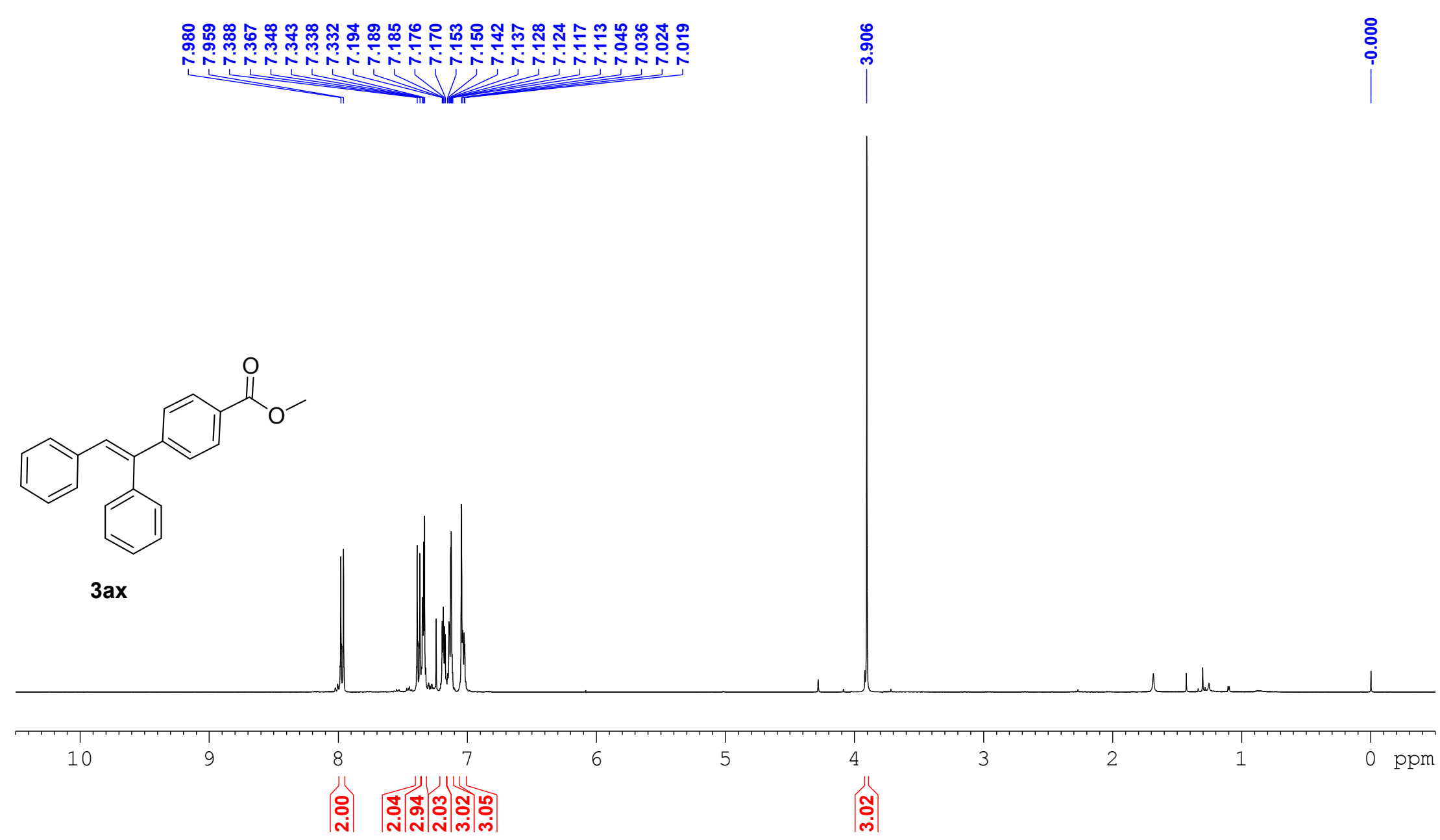




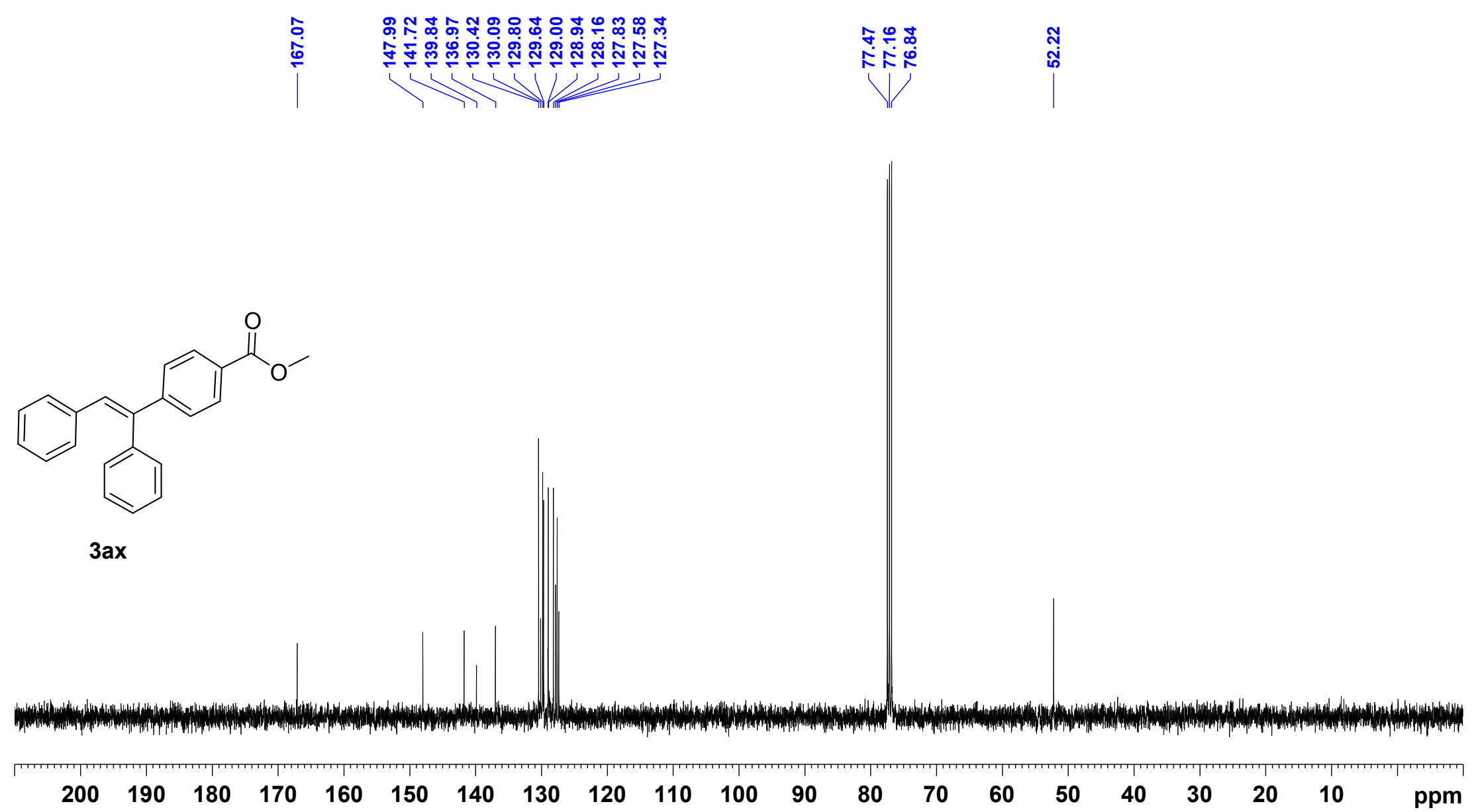




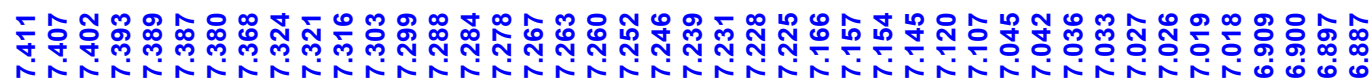

TIIIII

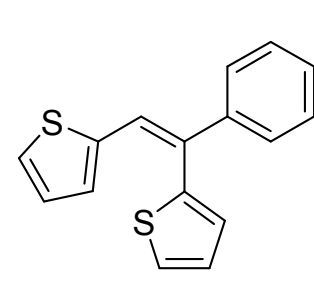

$3 \mathrm{ba}$

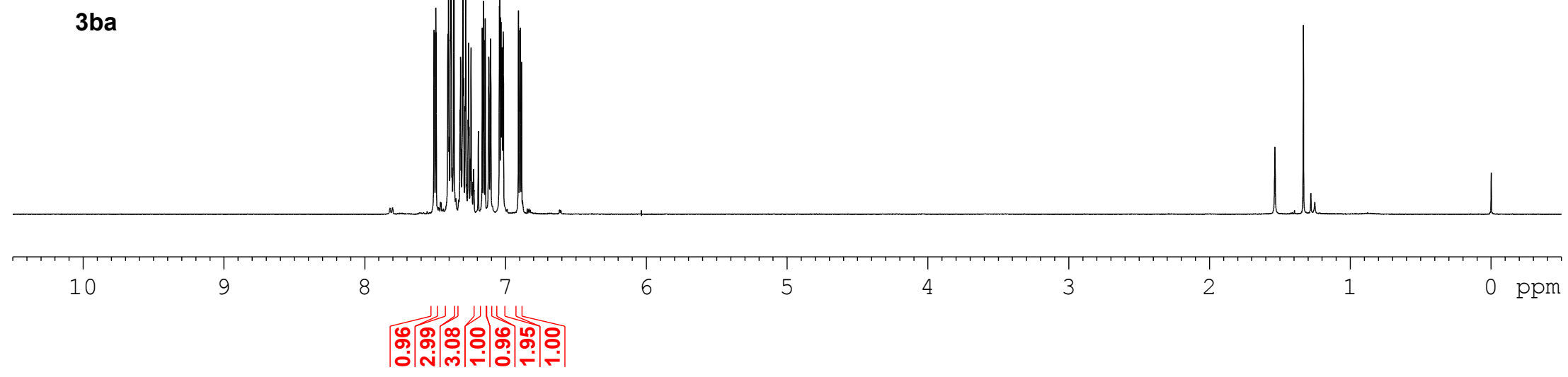




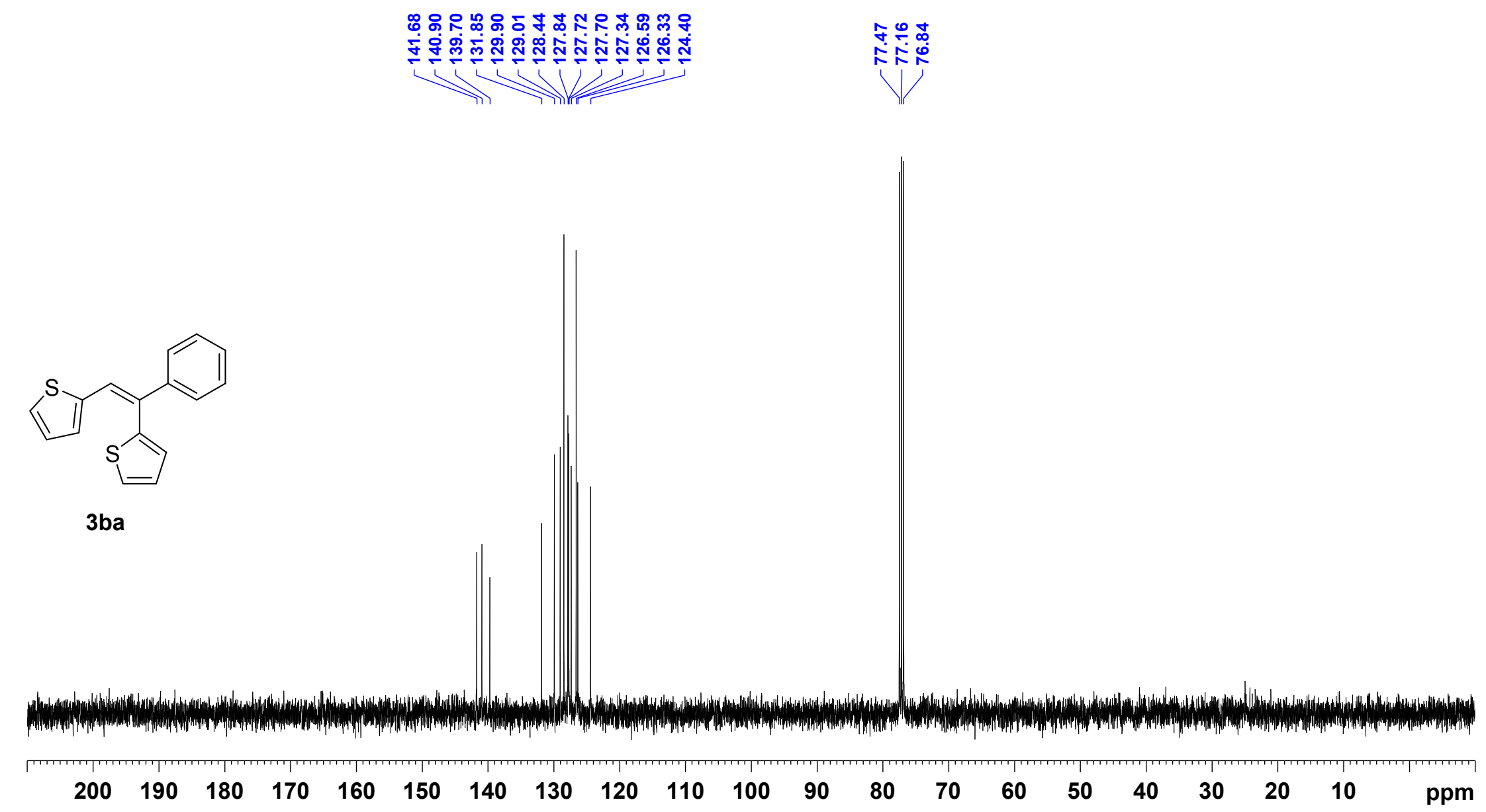




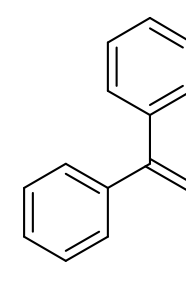

$3 c a$ 

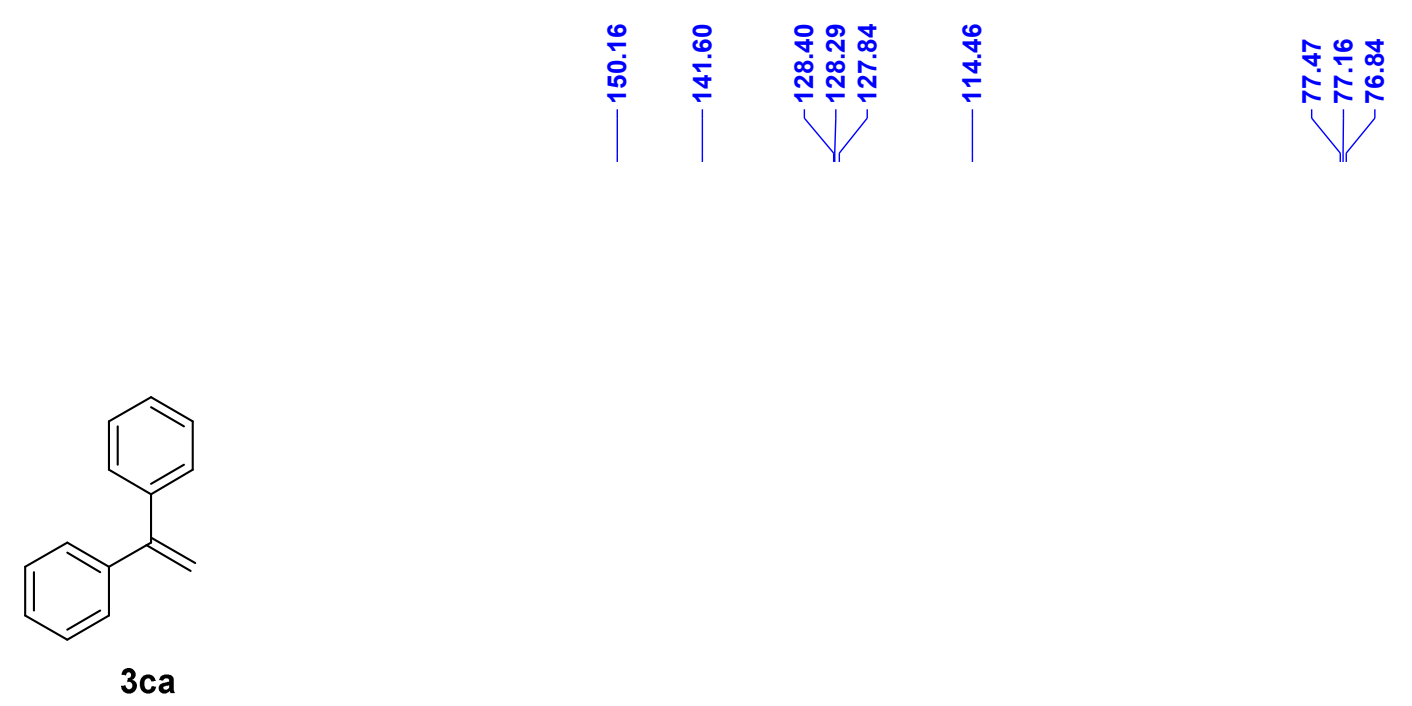

$3 c a$

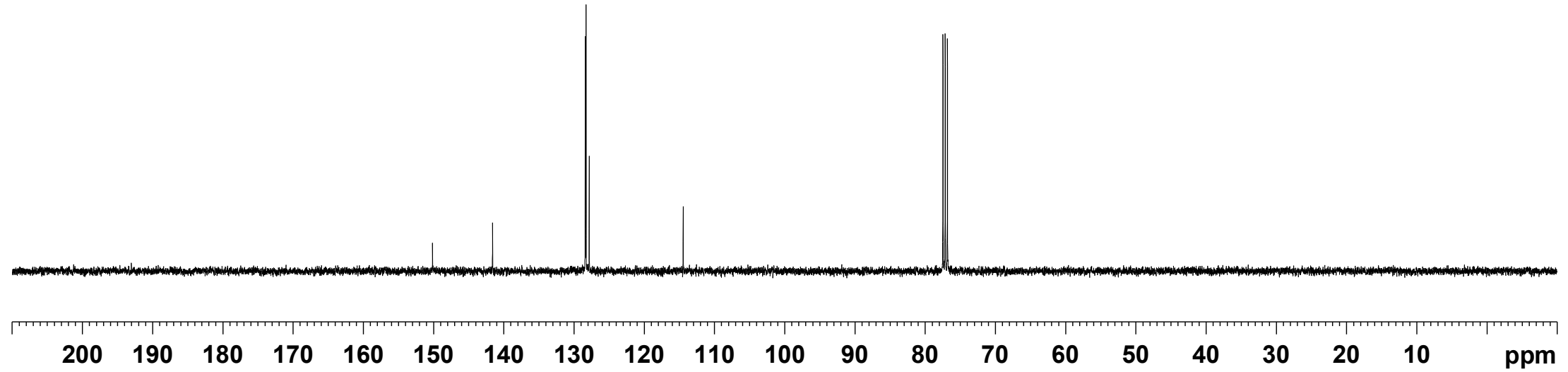




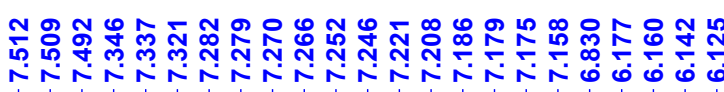

(1)
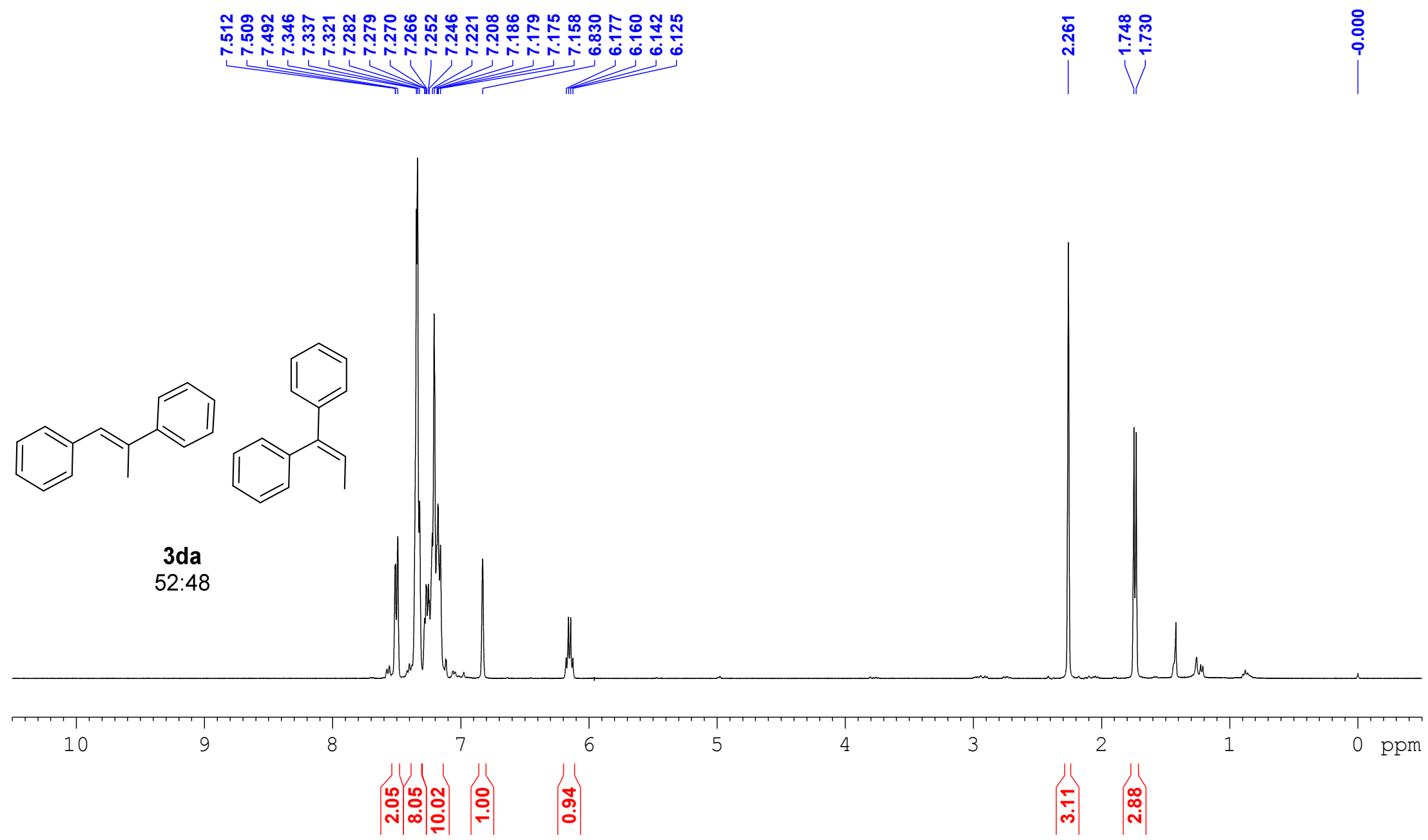


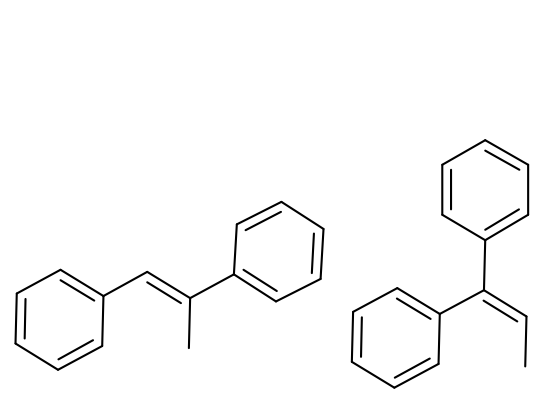

3 da

$52: 48$

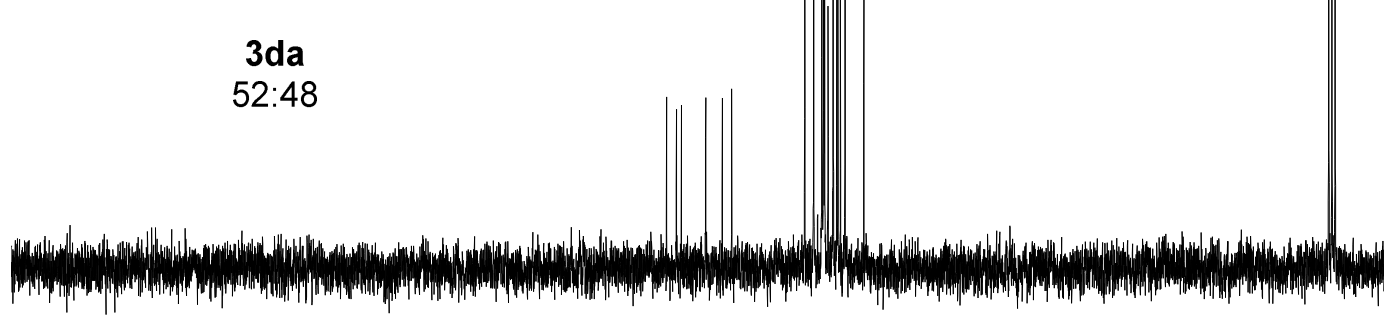

200190 


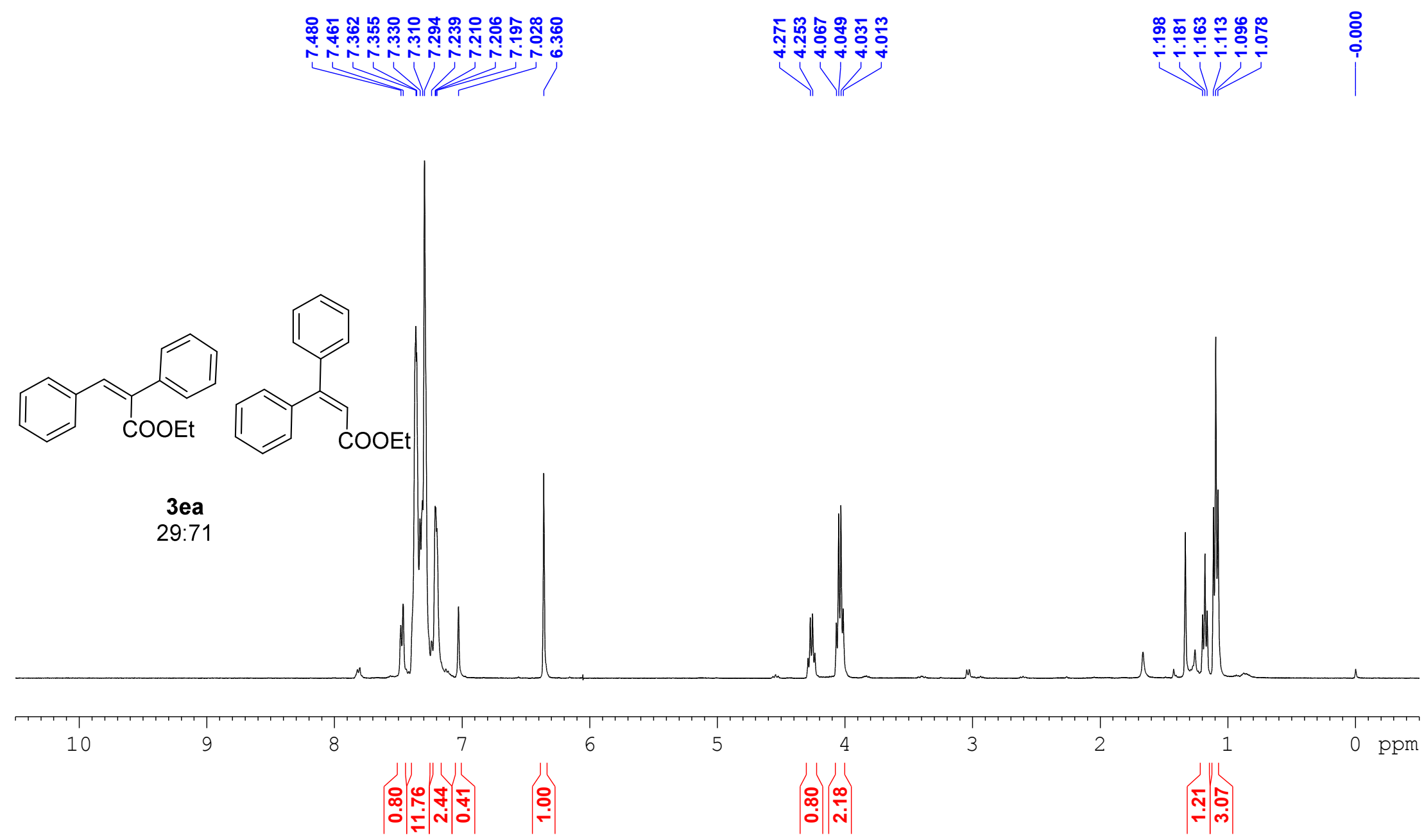



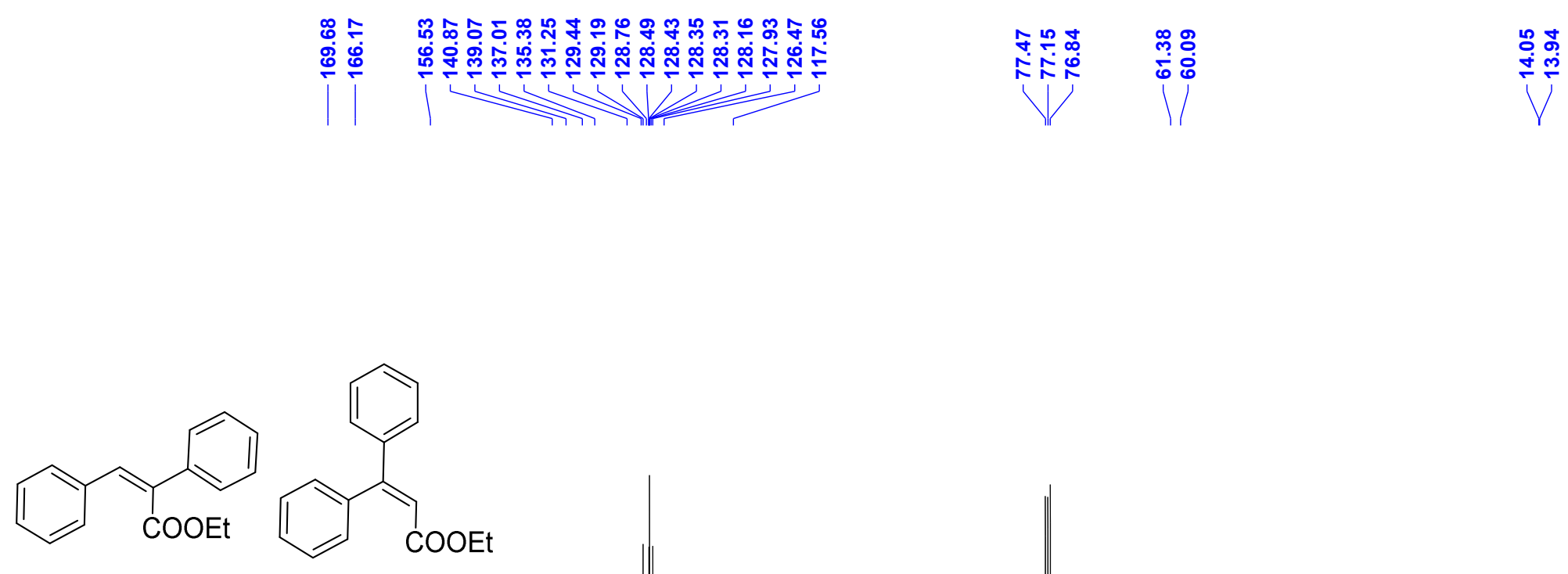

3ea

29:71

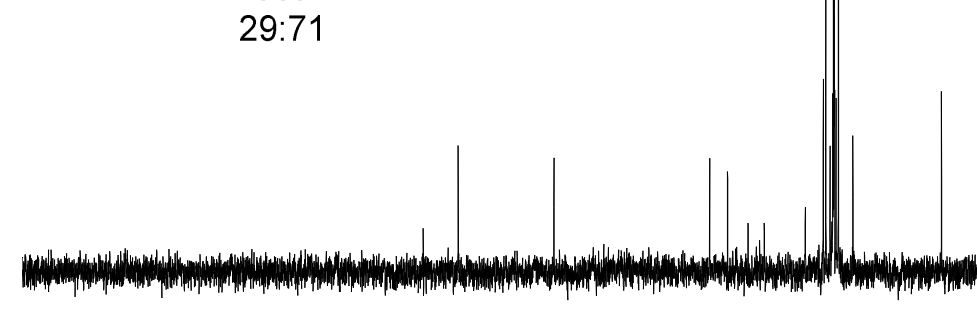

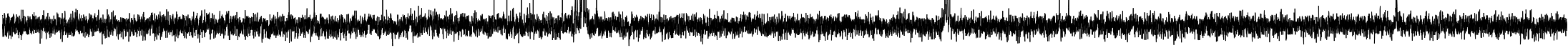

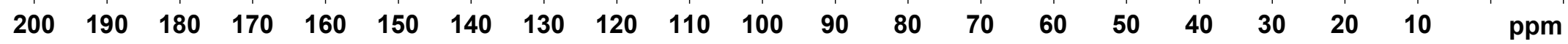




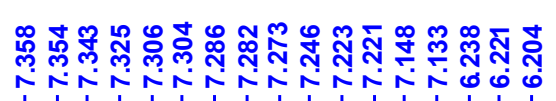

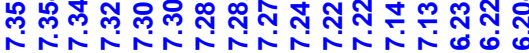

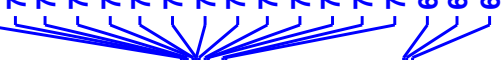

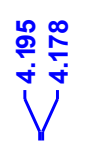

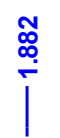

i̊ํํ

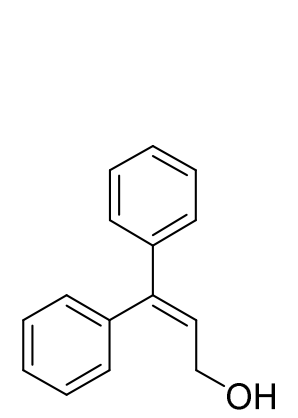

$3 \mathrm{fa}$
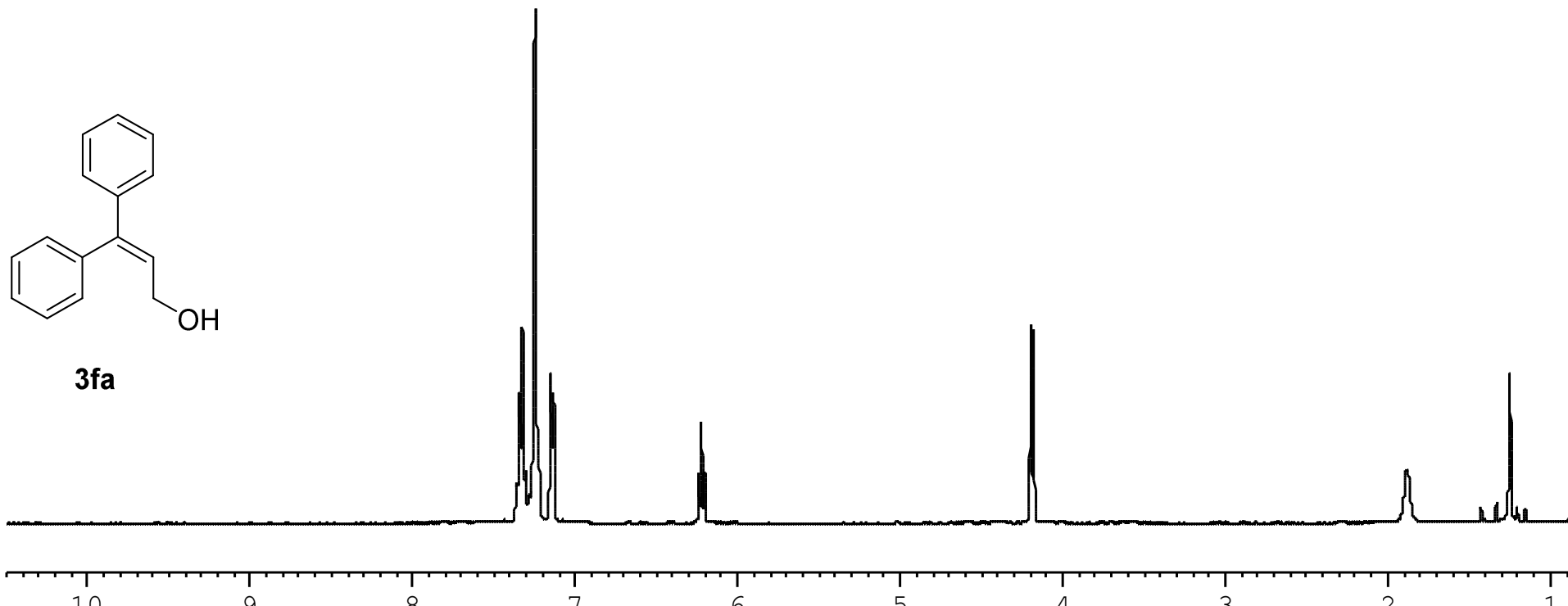

9
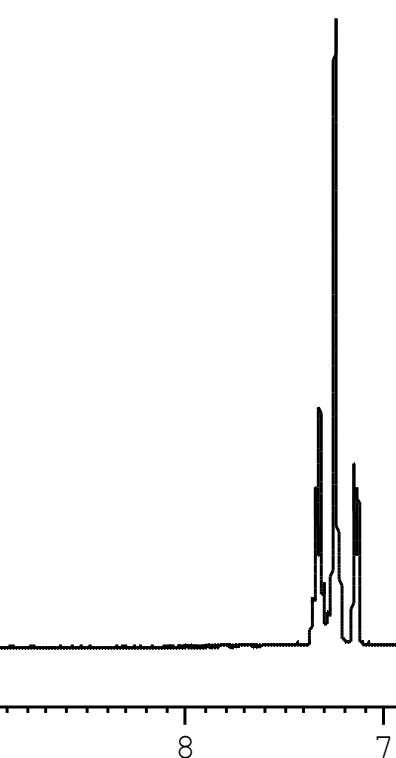

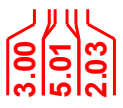

|잉|
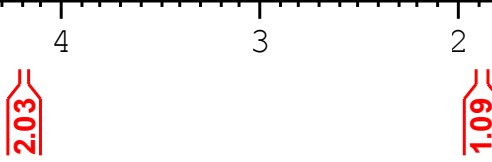

|r. 


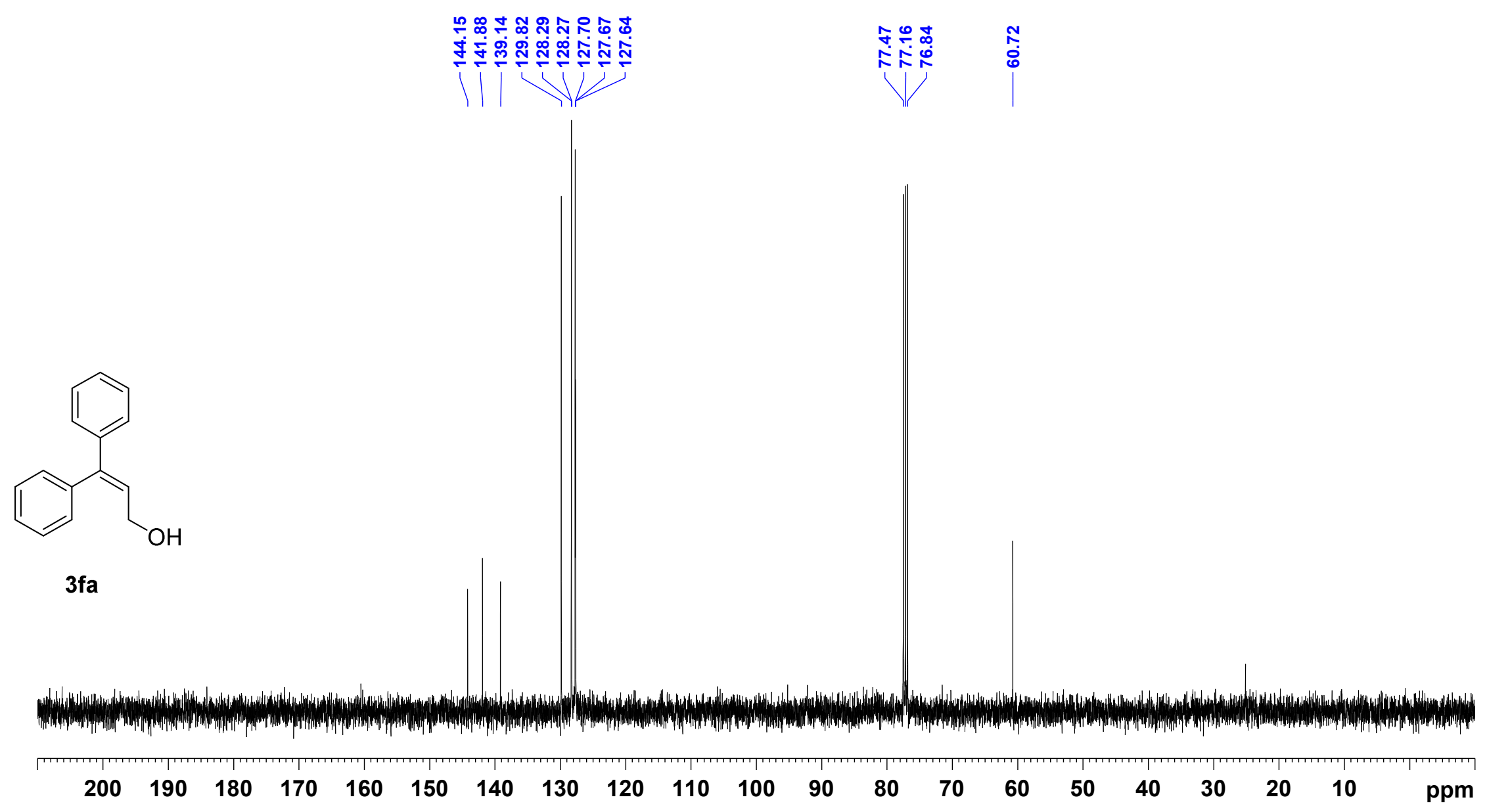




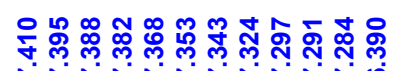

NixiñNiñ

(1)

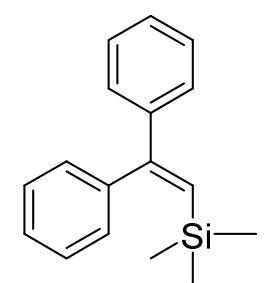

3ga

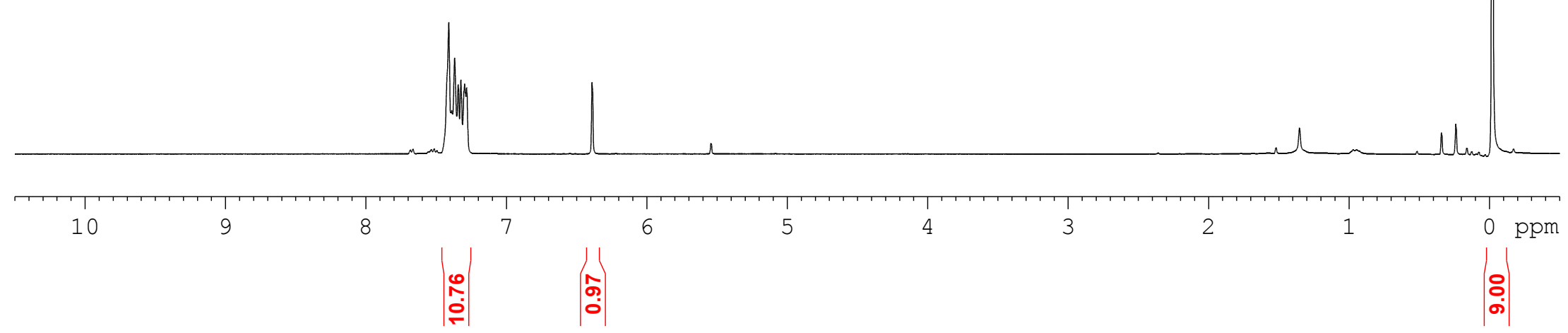




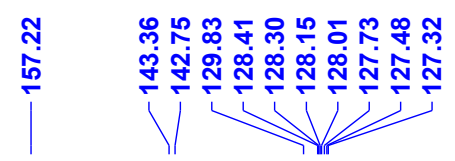

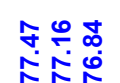

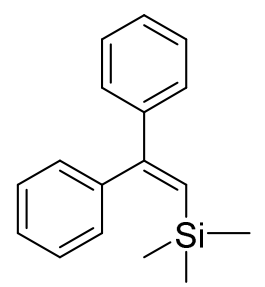

3ga

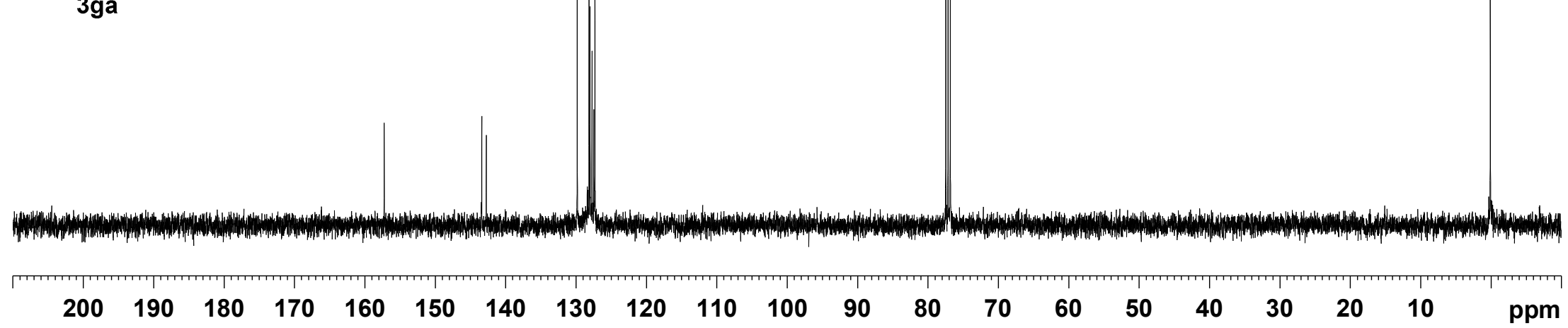




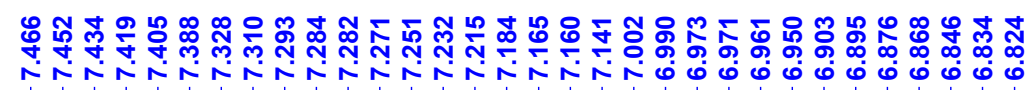

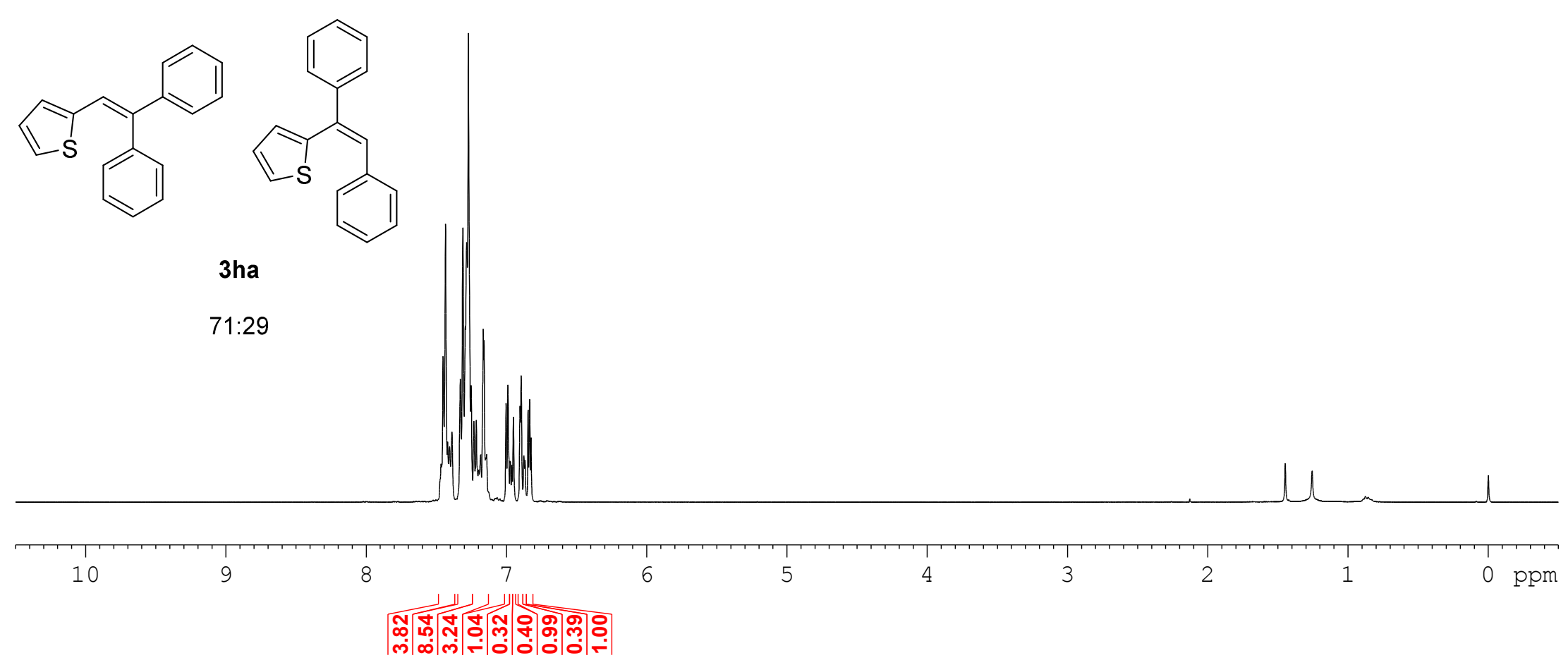



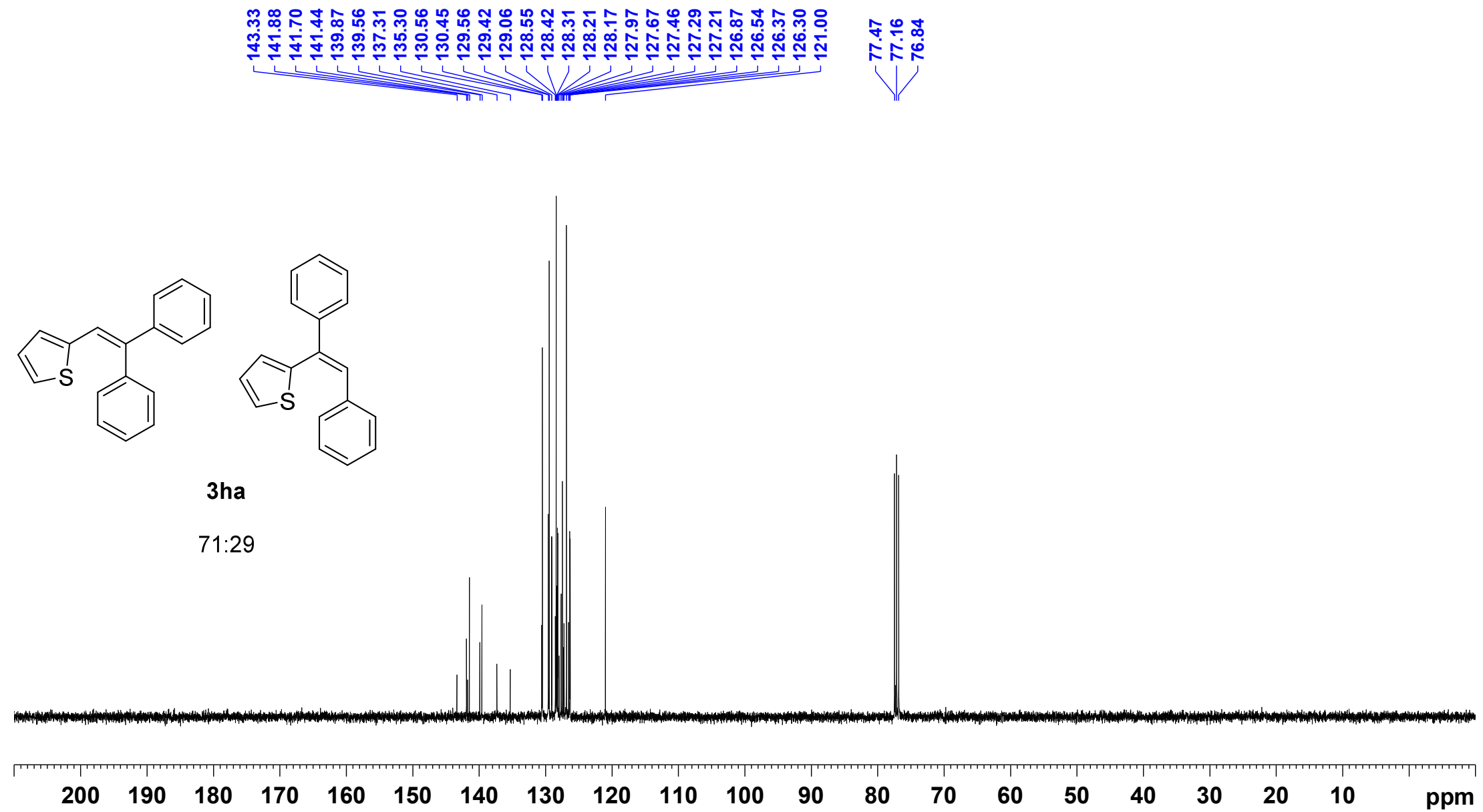


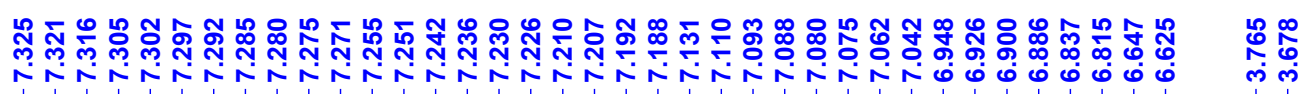

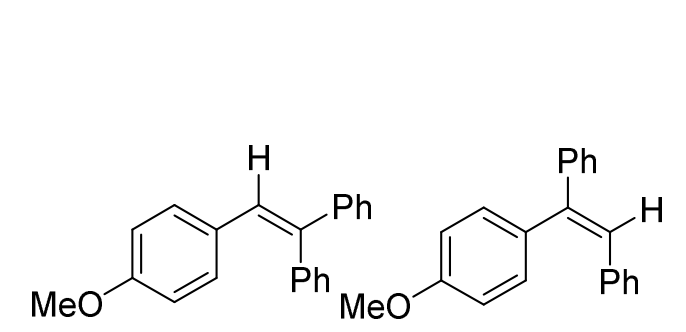

3ja

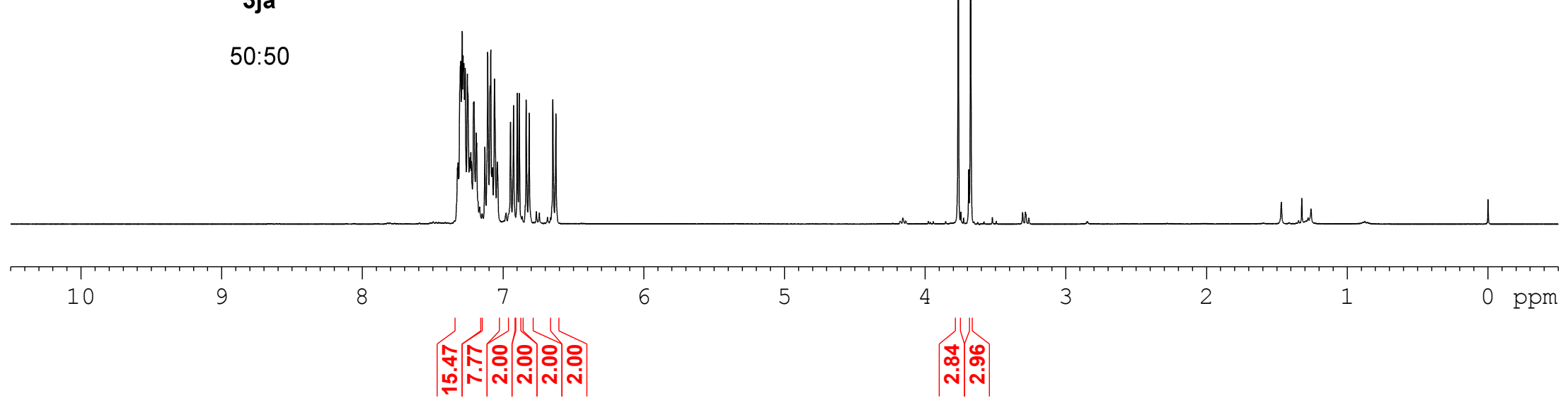



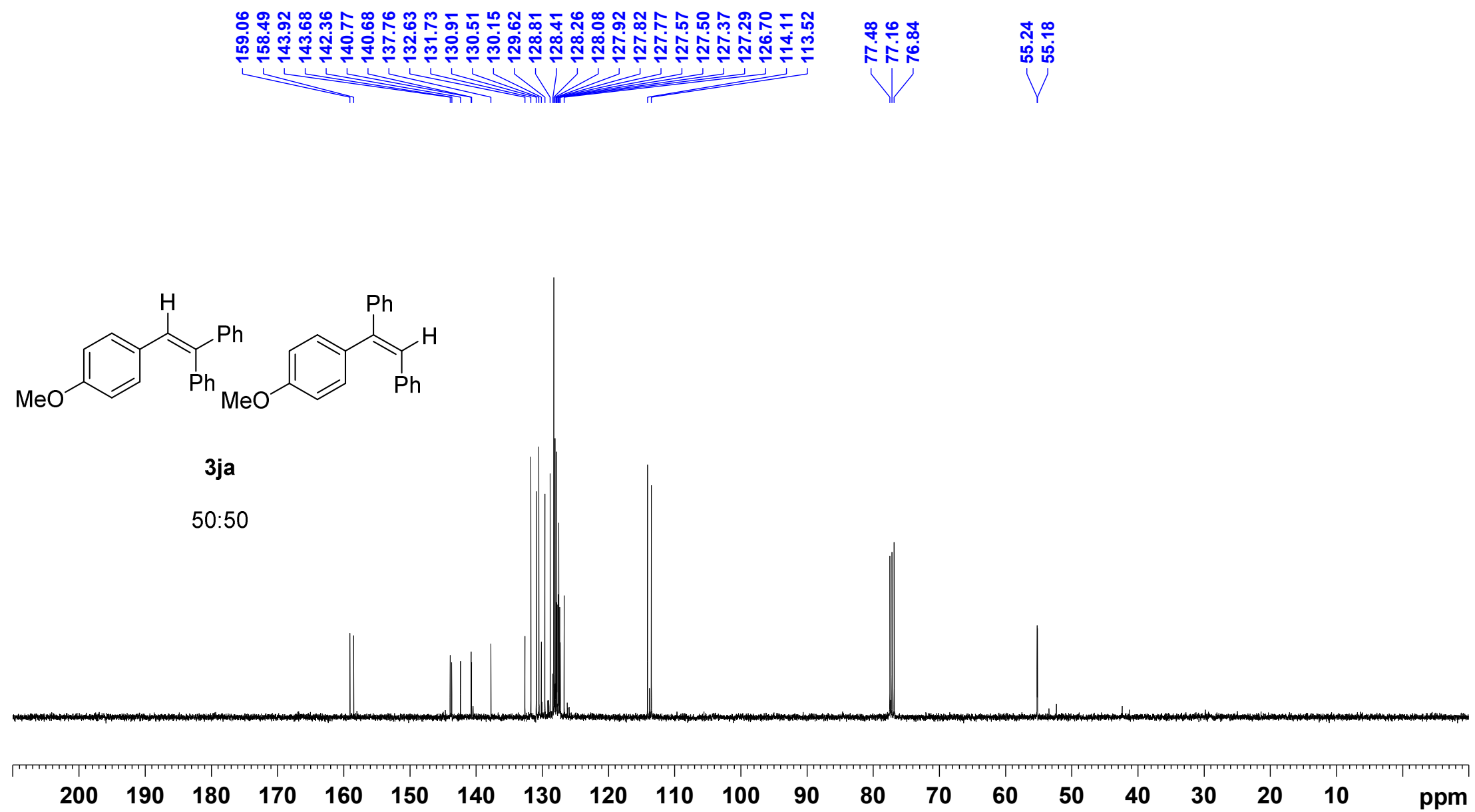


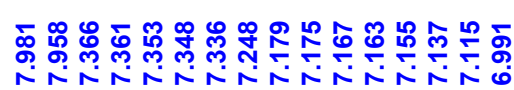

W

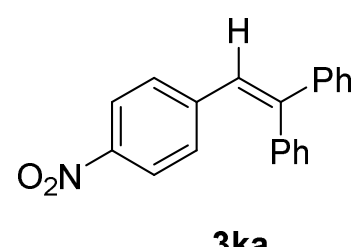

3ka

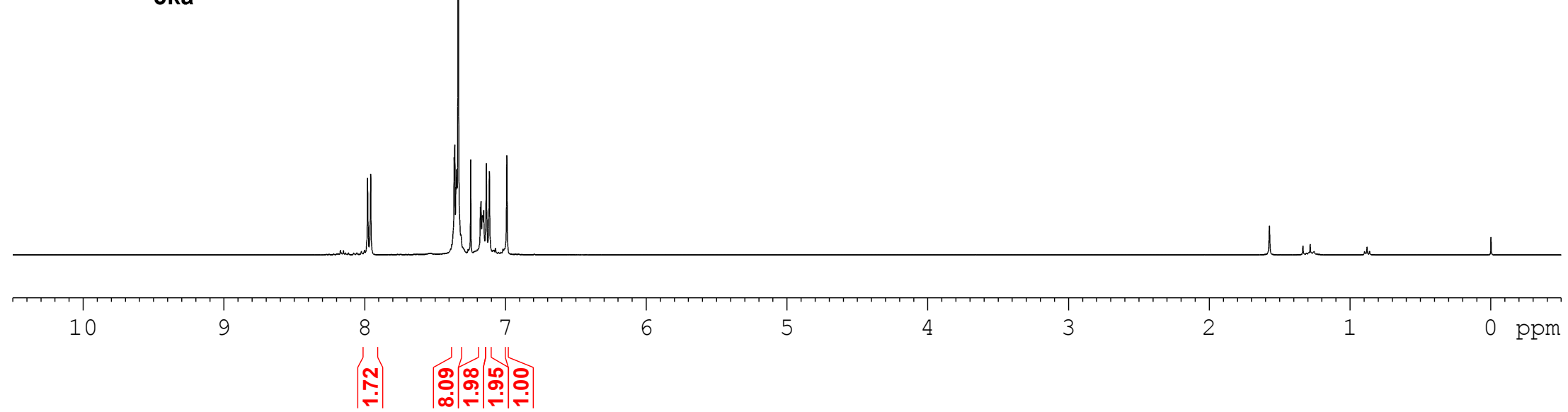




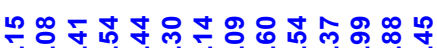

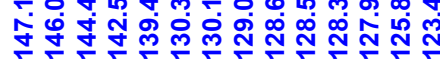

fㅇำ

ilive

Kag

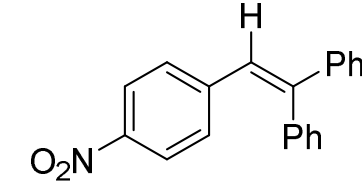

3ka

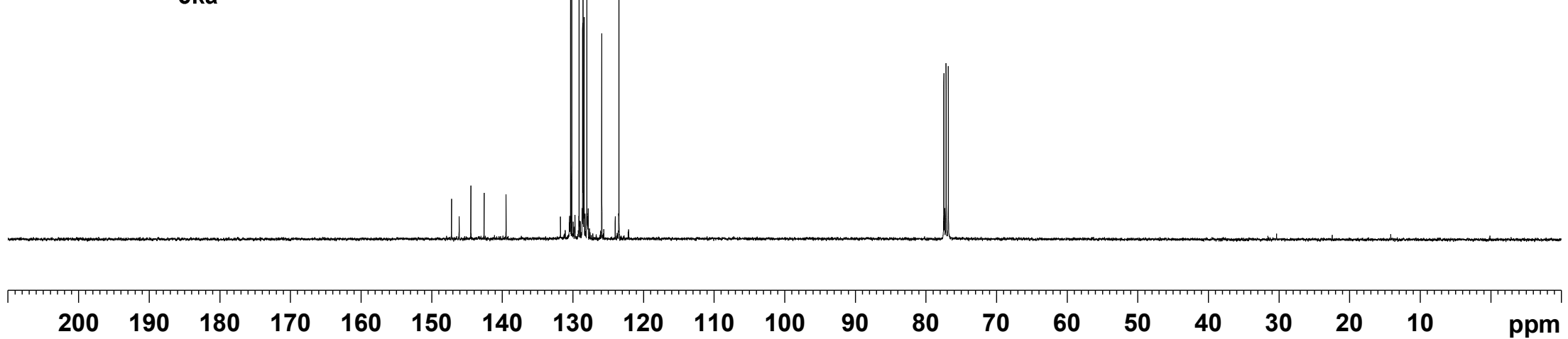

